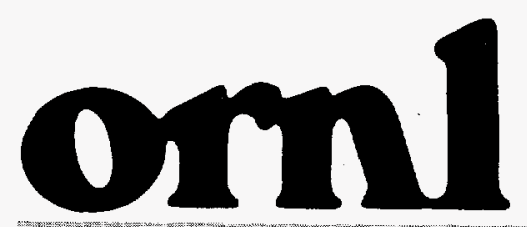

OAK RIDGE NATIONAL LABORATORY
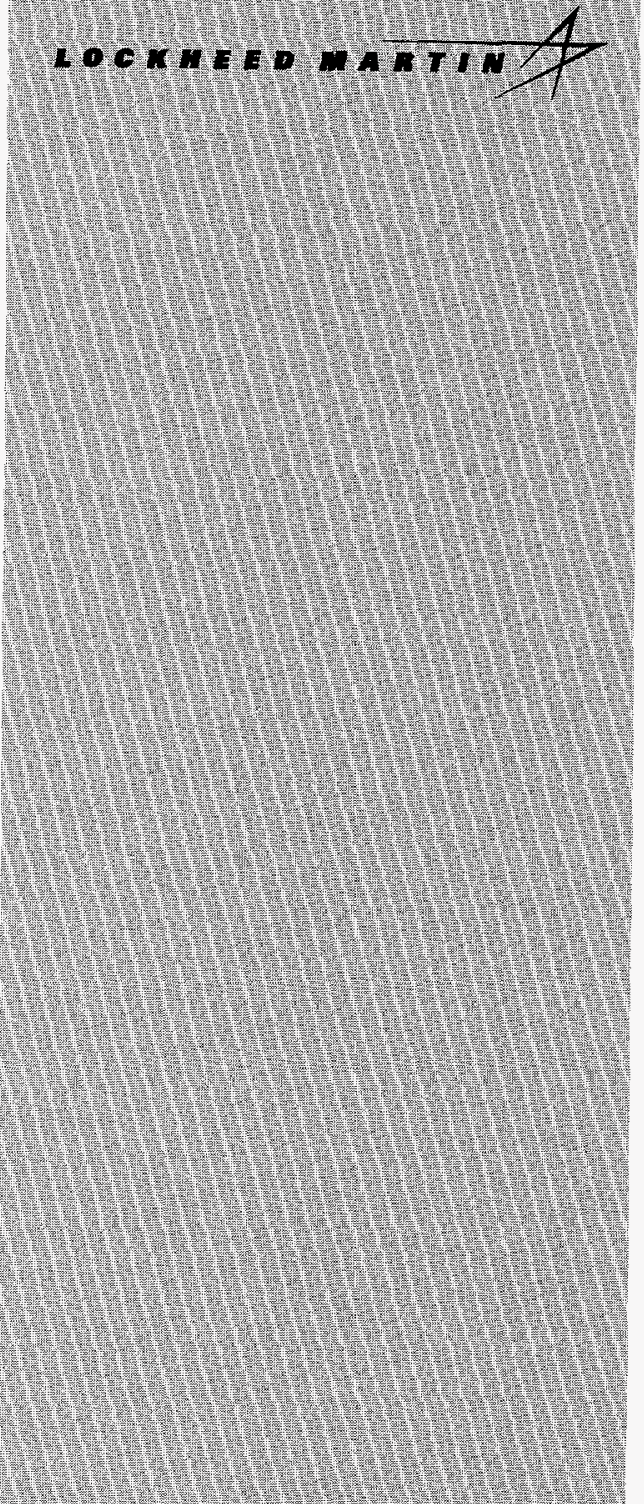

MANAGED MYD OPERATED BY LOCKHEED WARTI EHERCY RESEARCH CORPORATION FOR THE UMTED STATES DEPARTHETT OF ENERGY
ORNL/NCEDR-1

$$
\text { ORNL/M- } 6220
$$

Energy Division

\section{ENVIRONMENTAL CITIZENSHIP: PROBLEMS AND PROSPECTS}

\author{
Bruce Tonn \\ Oak Ridge National Laboratory \\ Carl Petrich \\ The Ernst and Young
}




\title{
ASSESSING POTENTIAL FUTURE ENVIRONMENTAL LEGAL EVENTS
}

\author{
Bruce Tonn \\ Oak Ridge National Laboratory \\ P.O. Box 2008 \\ Oak Ridge, TN 37831-6207 \\ E-mail: bet@ornl.gov \\ Carl Petrich \\ The Ernst and Young \\ Center for Business Innovation \\ One Cambridge Center \\ Cambridge, MA 02142 \\ E-mail: carl.petrich@ey.com
}

National Center for Environmental Decision-making Research

October 28, 1997

This submitted manuscript has been authored by a contractor of the US Government under contract No. DE-AC $05960 R 22464$ Accordíngly, the U.S. Government retains a nonexclusive, royalty free license to publish or reproduce the published form of this contribution, or allow others to 00 so, for $U .5$ government purposes?

Prepared by the

OAK RIDGE NATIONAL LABORATORY

MASTER

Oak Ridge, Tennessee 37831

managed by

LOCKHEED MARTIN ENERGY RESEARCH CORPORATION

for the

U.S. DEPARTMENT OF ENERGY

under contract DE-AC05-96OR22464

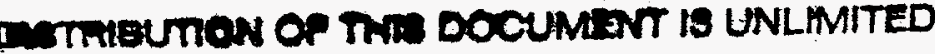

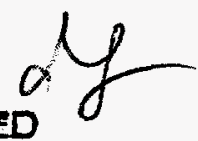




\section{DISCLAIMER}

Portions of this document may be illegible electronic image products. Images are produced from the best available original document. 


\section{TABLE OF CONTENTS}

\section{EXECUTIVE SUMMARY}

1. INTRODUCTION

2. A MODEL OF ENVIRONMENTAL CITIZENSHIP $\ldots \ldots \ldots \ldots \ldots \ldots \ldots \ldots \ldots \ldots 7$

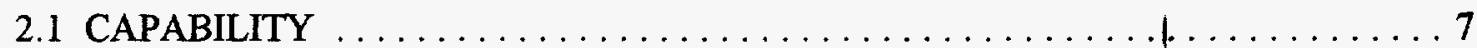

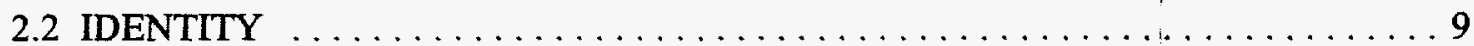

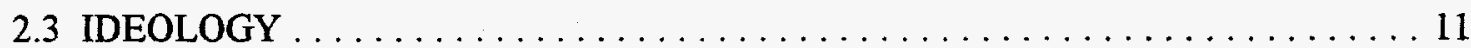

2.4 MENTAL MODELS OF GOVERNANCE $\ldots \ldots \ldots \ldots \ldots \ldots \ldots \ldots \ldots \ldots \ldots$

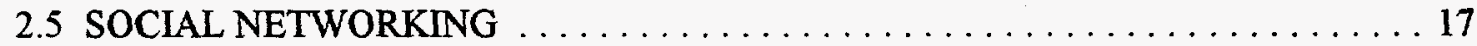

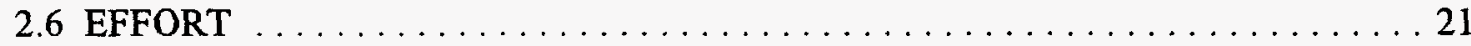

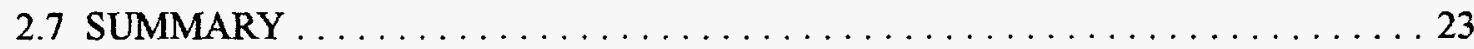

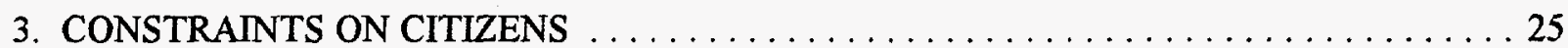

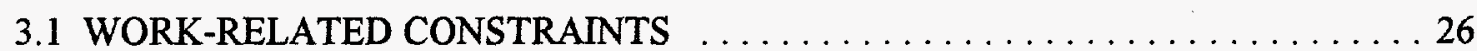

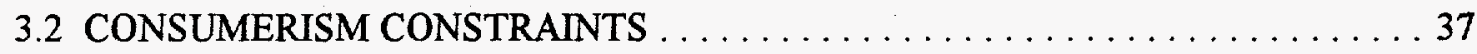

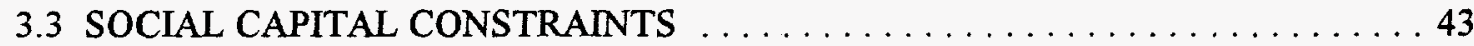

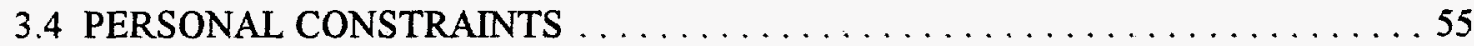

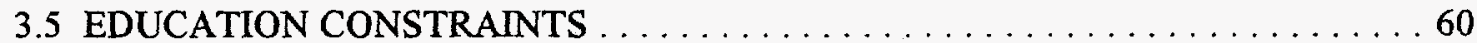

3.6 BUILT-ENVIRONMENT CONSTRAINTS $\ldots \ldots \ldots \ldots \ldots \ldots \ldots \ldots \ldots$

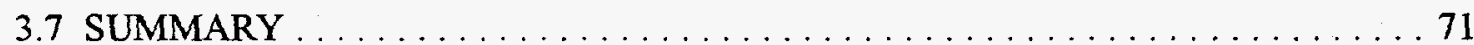

4. PUBLIC PARTICIPATION PROGRAMS: AN OVERVIEW $\ldots \ldots \ldots \ldots \ldots \ldots \ldots \ldots \ldots 75$

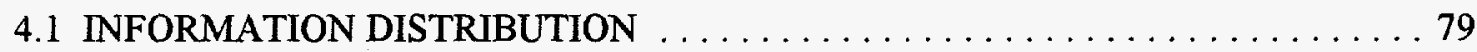

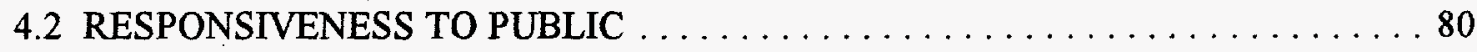

4.3 COMMUNICATION WITH PUBLIC $\ldots \ldots \ldots \ldots \ldots \ldots \ldots \ldots \ldots \ldots \ldots \ldots$

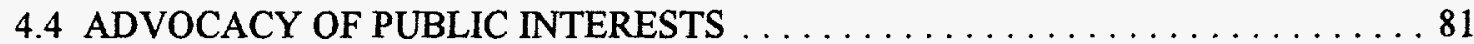

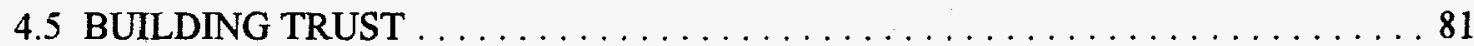

4.6 PROCESS AND POWER SHARING $\ldots \ldots \ldots \ldots \ldots \ldots \ldots \ldots \ldots \ldots \ldots \ldots$

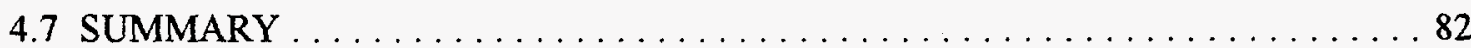

5. CITIZENSHIP, PUBLIC PARTICIPATION, AND

GOVERNANCE: A DISCONNECT $\ldots \ldots \ldots \ldots \ldots \ldots \ldots \ldots \ldots \ldots \ldots \ldots \ldots \ldots$

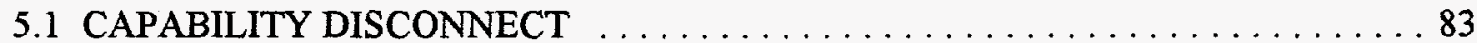

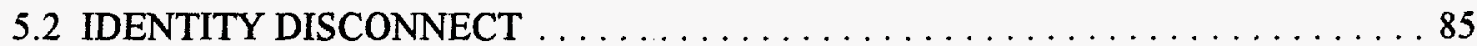

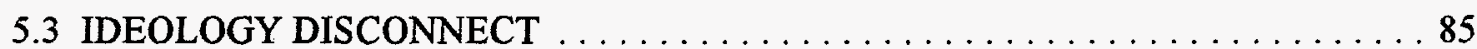

5.4 MENTAL MODELS OF GOVERNANCE DISCONNECT $\ldots \ldots \ldots \ldots \ldots \ldots$

5.5 SOCIAL NETWORKING DISCONNECT $\ldots \ldots \ldots \ldots \ldots \ldots \ldots \ldots \ldots$

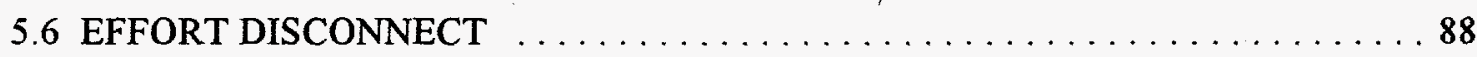

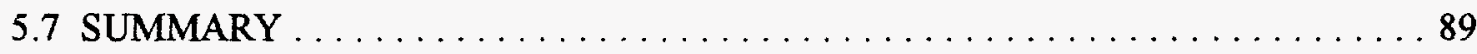


TABLE OF CONTENTS (Cont.)

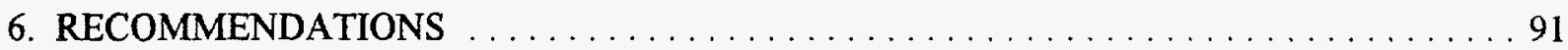

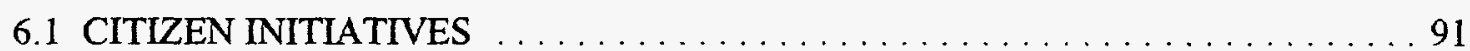

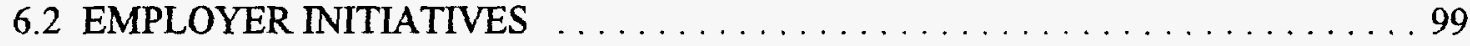

6.3 GOVERNANCE-RELATED INITIATIVES $\ldots \ldots \ldots \ldots \ldots \ldots \ldots \ldots \ldots$

6.4 NON-GOVERNMENTAL ORGANIZATION INITIATIVES AND OTHER

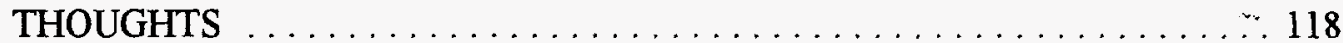

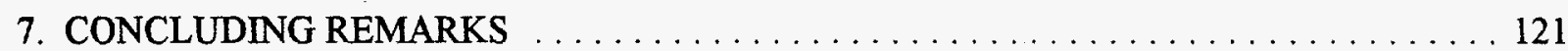

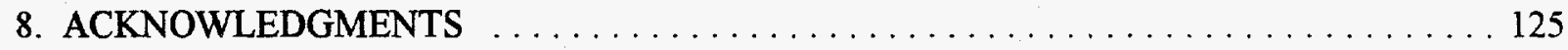

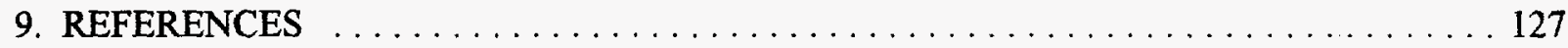




\section{EXECUTIVE SUMMARY}

This report addresses the topic of environmental citizenship in the United States. The term refers to responsibilities each of us have with respect to helping our communities and nation make sound environmental decisions. The topic is particularly timely given the efforts by government agencies at all levels to increase public participation in environmental decision-making processes. This research differs somewhat from other research in public participation in that this research centers on us, the citizens, and what we ought to be doing, as opposed to what the government ought to be doing for us, to improve environmental citizenship.

This report examines four central questions:

- What are the requirements (i.e., responsibilities) of citizenship vis-à-vis environmental decision-making processes?

- What constraints limit people's ability to meet these requirements? What does our form of governance do to help or hinder in meeting these requirements?

- What recommendations can be put forth to improve public participation in environmental decision making?

An active citizenry provides the foundation for a government whose powers are derived from the people. To better understand the meaning of the phrase active citizenry, this report distills from various literatures what democracy requires of its citizens and synthesizes these findings into six general requirements: capability, identity, ideology, mental models of governance, social networks, and effort. Each of these requirements is related to the environmental context. The first five represent prerequisites for the sixth. In other words, to effectively direct one's efforts towards contribution to environmental decision making, one needs to understand environmental issues, feel part of the community faced with the decision(s), have a guiding ideology to discern what is important and what is not, understand how decisions are made and could be made better, and be able to work with others to make decisions. 
Numerous factors constrain people's ability to meet their responsibilities as citizens. Constraints are related to work (e.g., long hours, disruptive schedules, transfers); consumerism (e.g., much time spent watching television, shopping, and engaging in entertainment activities); lack of social capital (e.g., communities are not "tight" enough to work together and help each other address environmental issues); personal fears and anxieties (e.g., fear of reprisals from neighbors); education (e.g., few people are scientifically literate); and the built environment (e.g., lack of meeting places, car- rather than people-oriented context). In combination, these factors greatly constrain the time and attention people can or will devote to environmental citizenship.

Agencies at all levels of government are working to better involve citizens in environmental decisionmaking processes. This report uses previous research on public participation in environmental decision making to categorize typical public participation programs into six categories: information distribution, responsiveness to public, communication with public, advocacy of public interests, trust building, and process and power sharing. It is observed that typical public participation programs help people become "better" citizens (i.e., more informed and active) in only a very limited and sporadic fashion. It is concluded that the relationships among citizens, government, and environmental decision making need to be reevaluated.

A great deal of effort and change is needed to loosen these constraints so that substantial numbers of people could be more able to participate in decisions that affect the environment. The recommendations presented in this report address citizen initiatives, employer initiatives, governance initiatives, and initiatives that could be undertaken by non-governmental organizations (NGOs) and others. Citizen initiatives include: adaptive work (e.g., examining the lifestyle cycle of work and consumption that constrains time and attention); finding-environmental citizenship mentors; downshifting lifestyles (e.g., consume less, work less); making personal investments (e.g., save more); changing built-environment preferences (e.g., for more community-friendly housing developments); pursuing life-long education; and making commitments to the community (e.g., through volunteer activities).

Employer initiatives include: changing time at work policies (e.g., less overtime, more flextime); letting, even encouraging, employees use employer resources (e.g., computers, phones) for citizenship activities; instituting community-friendly policies (e.g., establishing neighborhood offices); instituting 
employee friendly policies (e.g., increased training and retraining); and practicing openness and nonretaliation.

Several governance-related recommendations are presented and include establishing environmental protection communities, which would be spatially defined to be consistent with ecosystem boundaries and sustainability principles; fostering environmental neighborhoods, which would consist of one hundred to two hundred people devoted to discussing environmental issues; communicating to individuals their rights vis-à-vis environmental citizenship; establishing offices of environmental leadership to manage adaptive work decision-making processes; establishing collaborative programs to meet environmental goals among government, business, and industry; instituting environmental citizen certificate programs; implementing changes to the built environment (e.g., through zoning changes); and building computer-based community enterprise systems to foster all of the above. It is noted that NGOs and many other organizations can and are already helping to improve environmental decision making in numerous ways.

In summary, the demands of democracy upon its citizens are substantial. Environmental management represents only one of the numerous important issues facing U.S. citizens. Barriers preventing people from reaching their citizenship potential are also substantial. It is not clear that the recommendations presented above will be sufficient to overcome the time demands of work, the lures of entertainment, and a built environment not conducive to civic society. However, given that every person has a responsibility to society, and protecting the environment for current and future generations is an important component of that responsibility, every effort should be considered toward improving environmental citizenship. 


\section{INTRODUCTION}

We hold these truths to be self-evident, that all men are created equal, that they are endowed by their Creator with certain unalienable rights, that among these are life, liberty and the pursuit of happiness. That to secure these rights, governments are instituted among men, deriving their just powers from the consent of the governed (Declaration of Independence 1776).

Environmental citizenship is the term used herein to describe responsibilities citizens have to help their communities and nation make sound environmental decisions. This is an important and timely topic. The environment is an issue area that has popular support among a large majority of Americans. Many people are concerned about the state of the environment. The list of problems is long and familiar, and includes: global climate change; species extinction; disposal of hazardous and radioactive wastes; wetlands and habitat protection; soil erosion; depletion of ocean fisheries; deforestation; air and water pollution; and endocrine disruptors. These problems exist at different scales and engage various political jurisdictions. To decide upon policies and programs to solve these problems requires, in large part, concerted and effective political efforts.

Is the current political process in the United States meeting the environmental decision-making challenge? Many would argue that the answer is no. Across the political spectrum, there is widespread dissatisfaction with the state of democracy in the United States. Low voter turn-out and participation rates (Verba et al. 1995), increasing influence of special interest groups and money, and a ubiquitous cynicism towards politics and politicians (Gore 1992) are among many factors underlying the dissatisfaction. In response, numerous organizations, such as the League of Women Voters, are placing the improvement of democracy in the United States at the top of their list of priorities.

Fundamental problems with democracy become magnified in the environmental arena, often resulting situations charged with emotion and conflict. In Congress, environmental issues are viewed as being in a class by themselves when judged by their intractability and mean spiritedness (Tonn and Peretz 1997). Thus, it is probably an understatement to say that successful political efforts yielding 
reasonable decisions about the environment are perceived to be fewer than desired because of the problems plaguing democratic processes in the United States.

It is not surprising that environmental decision making is truly difficult for our democratic society to master. The environmental decision making system is composed of an unwieldy federal bureaucracy, fifty states, thousands of counties and local political jurisdictions, non-governmental organizations, the judiciary, the news media, hundreds of thousands of private firms, and over two hundred million citizens. Given the complexity of the system and the enormity of the problems, fruitful topics of study are numerous. Important topics include: federal environmental rule-making; judicial decision making; Congress and the development of environmental law; and devolution of environmental responsibilities from the federal government to the states.

This research focuses on citizenship and environmental decision making. We believe that governments instituted among men and women require active participation by men and women in the political process. Since everyone's behavior impacts the environment in some fashion, it is logical to argue that citizenship is an important, if not the most important, element in the environmental decision-making system. Driving this research is our hypothesis that society has evolved in ways that severely constrain environmental citizenship. This report probes this hypothesis, finds overwhelming support for it, and develops recommendations to overcome the constraints.

Though limited in scope, citizenship is still an extraordinarily challenging topic. Citizenship entails many issues of public concern in addition to the environment. Thus, to understand citizenship with respect to environmental issues necessarily requires a holistic understanding of citizenship. Conversely, environmental issues are not separable from other spheres of life. Ties are strong to other issues such as economics, land use, transportation, and education. Thus, to understand how citizens approach environmental issues requires an integrated understanding of a host of other issues.

Environmental citizenship is action-oriented. Democratic theory holds that citizens should take an active part in civic society. For democracy to work, citizens need to be more than passive taxpayers consuming government services (Kemmis 1995). They need to be involved (Etzioni 1967). Avenues for citizen participation in civic life are numerous. Voting is only the most obvious. Joining volunteer 
organizations, writing letters to elected representatives, attending public hearings, and commenting on proposed government rule makings are other ways that people can get involved. Both making the effort to become informed about environmental issues and the simple act of discussing environmental issues with fellow citizens are expressions of environmental citizenship.

It is important to understand barriers to public participation in general and to environmental citizenship in particular. It can be argued that the government itself presents institutional barriers to public participation. As explained by Yates (1982), the United States has evolved into a bureaucratic democracy, where efficiency of public administration is often, if not always, viewed as being in conflict with the goals of populism. From the classical bureaucratic viewpoint, public participation in administrative decision making can be seen as being time inefficient, at best, and leading to highly counterproductive and costly decisions, at worst. The result is that many environmental decisions are made by government agencies without input from citizens.

There are also socioeconomic and cultural barriers to citizen participation in environmental decision making. Barriers include work (Schor 1992), lifestyle, and lack of community. With respect to the latter, Putnam $(1995,1996)$ has concluded that Americans are now volunteering much less of their time to civic groups. People would rather go "bowling alone" than join bowling leagues as in the past is his signature observation. As discussed later in this report, isolated individuals generally cannot effectively participate in political processes concerning environmental matters. Numerous other constraints exist to limit or virtually prevent public participation in civic life, including the nationalization and mediaization of politics (Verba et al. 1995; Valelly 1996; Skocpol 1996), and the lack of places for political discourse (Schneider 1996).

The institutional barriers and everyday constraints have important consequences for environmental decision making in the United States, especially at the community and regional levels. In many cases, administrative environmental decisions unenriched by public input can lead to legal challenges, social conflict, loss of trust, and, paradoxically, inefficient decision making and unsatisfactory decisions. Recognizing this, attempts to involve the public in environmental decisions, which fall under the rubric of public participation, are being made. However, it has been observed that common citizens, as opposed to professionals representing special interests, often do not take part in public hearings, 
provide comments on technical documents, or in other ways make their views known to the bureaucracy (Carnes 1995). Instead, professional lobbyists, including those who promote business interests and those who promote environmental issues, along with the occasional informed retiree, fill the void.

One thesis of this research is that public participation efforts with respect to environmental decision making can be improved if designed to foster the broader goals of citizenship. In other words, it is not enough for bureaucracies to allow citizens to attend public hearings or provide comments on written documents to help the bureaucracies solve their problems. Those efforts are sporadic at best with respect to engaging citizens. It is not enough to involve the public early in government-led environmental decision-making. This is a paternalistic attitude and one which ignores the fact that millions upon millions of environmentally-related decisions are made everyday by firms and citizens without the involvement of government. Instead, efforts are needed to provide more intensive, continual programs that catalyze citizens to meet their responsibilities as put forth in democratic theory.

A second thesis of this research is that other spheres of modern life, primarily the economic and lifestyle spheres, have come to dominate the political sphere of the average citizen. Severe economic pressures on individuals and households and lifestyle choices highlighted by consumerism and entertainment preferences combine to reduce the amount of time, energy, and attention the vast majority of people devote to public participation in any policy issue, much less with respect to environmental policies. One can argue that substantial changes in the American society and economy are needed if environmental citizenship is to improve more than marginally.

The five major sections of this report address the two theses. Section 2 develops a model of citizenship. Outlined are six requirements for citizenship that have bearing on public participation in environmental decision making. The six requirements are distilled and synthesized from a wide range of writings on citizenship, community, politics, sociology, anthropology, and planning. General responsibilities of citizens that require active efforts on their part are most emphasized, as are more specific requirements with respect to environmental decision making. Broader sociopolitical issues such as voting rights and free speech are noted as appropriate but are not the central focus of this discussion. 
Section 3 comprehensively assesses the numerous factors in society that limit people's ability to meet their environmental citizenship responsibilities. The discussion benefits from a range of data sources and numerous commentaries on American society. Factors important in this discussion include: workrelated constraints; consumerism constraints; social-capital constraints; personal constraints; educational constraints; and built-environment constraints, found in Sections 3.1 to 3.6. A summary, Section 3.7, synthesizes the disparate factors into a comprehensive picture of constraints to environmental citizenship.

Section 4 summarizes public participation efforts in the environmental decision-making arena. Sections 4.1 to 4.6 discuss programs related to information distribution, being responsive to the public, communicating with the public, advocating public interests, building trust, and process and power sharing. Section 5 compares and contrasts the requirements of citizenship with the types of public participation programs implemented by government agencies. A serious disconnect is observed. The disconnect can be primarily explained by governments' focus on efficiency over populism.

In Section 6, the report puts forth several recommendations designed to foster both improved citizenship and improved environmental decision making. The recommendations pertain to citizen initiatives, employer initiatives, and governance-related initiatives. The recommendations extend from the mundane to the extraordinary. As a collection, one can conclude that major changes in American society are needed to foster environmental citizenship and, indeed, to promote broad public participation in all aspects of democratic society. 


\section{A MODEL OF ENVIRONMENTAL CITIZENSHIP}

The purpose of this section is to define the concept of environmental citizenship. The focus is on answering the following question: What can citizens do on their own and with each other to contribute to decision making regarding the environment in their communities and beyond? The quick answer to this question is that there is a great deal citizens can do. In fact, one can easily envision a set of requirements that could overwhelm even the most conscientious citizen. The purpose of this section is to set out a list of six general categories of requirements and activities that citizens can pursue. They are capability; identity, ideology, mental models of governance, social networks, and effort, discussed in the next six subsections, respectively. It must be noted at this point that not every person will be able to meet all six requirements to the same degree or even to a large degree. However, it is argued that every citizen should try to meet all the requirements to some degree, given their varying strengths and capabilities. With an understanding of what citizens can do to contribute to decision making regarding the environment, Section 3.0 catalogues the numerous constraints that limit most individuals' environmental-citizenship activities.

\subsection{CAPABILITY}

It is the responsibility of each citizen to build the capability to fulfill her or his responsibilities to civic society. Without the individual potential to participate in a positive fashion, no other efforts will have value. Van Steenbergen (1994a) argues that people need to learn to be intellectually autonomous and self-reliant. Generally, people need fundamental capabilities to: think broadly and for themselves; discern fact from fiction; understand arguments; communicate their values and viewpoints; interact with people in non-threatening manners; learn throughout life; make difficult judgments under uncertainty; and possess the wherewithal to act. Possessing these capabilities can help build feelings of self-efficacy. In 1816, Thomas Jefferson wrote, "Enlighten the people generally, and tyranny and oppressions of body and mind will vanish like evil spirits at the dawn of day." In other words, people must strive to build the capability to allow themselves to be enlightened and to pursue enlightenment on 
their own. They must pursue formal and life-long education to build the fundamental capability for citizenship.

Specifically, with respect to building the capability to participate in environmental decision-making processes, citizens need to pursue a broad-based education while grounding their education in real-life issues. They need grasp basic scientific principles and methods. They need to understand the concepts of risk and uncertainty. They need to be able to process the information contained in maps and statistical presentations (Sillince 1986). They need to internalize a systems model of the environment, human behavior and institutions, and the interdisciplinary training to enrich systems understanding. They need the confidence to demand that experts communicate without jargon. They need the abilities to discuss environmental issues with other people, and to appropriately communicate their values and beliefs about the environment and associated policy questions. As shown in the story in Exhibit 1, inability to tone down one's rhetoric can have damaging consequences.

Some people are "turned off' by the rhetoric adopted by the environmental movement as being too bellicose. Miners and loggers accuse the Clinton administration of waging "war on the West:" environmentalists accuse industry and Congress of declaring "war on the environment." In reality Federal agencies such as Forest Service offices have been bombed, and guns have been drawn on individuals on both sides of the altercation. The West is replete with such images: "range wars" or "water wars? The war metaphors, of course, do help validate struggles of the warriors on both sides (Christensen 1996)

But the war metaphor is an example of the forces that contribute to the polarization and divisiveness of debates about environmental issues. Christensen comments on how these degrade the discourse: "The most discouraging experiences for me have come when I called friends and acquaintances on both sides of the so-called war and found them dissembling attempting simple spins on complex stories. The most rewarding experiences have come when I have found people who are interested in talking about what is going on, even if it does not spin their way." When Interior Secretary Bruce Babbitt first tried to build a consensus on grazing reform he ran headlong into a similar wall erected by ranchers and environmentalists. While the ranchers and environmentalists that Babbitt pulled together in Colorado seemed to come to a consensus, those talks were attacked by both sides. Environmentalists constantly called up the image of welfare ranchers, ranchers said reform would turn them into paupers. Both sides drew lines in the sand and said, as one environmentalist told me, "we cannot work with these people?"

Exhibit 1.Polarizing rhetoric repulses/discourages potential activists

In addition to the effort of citizens to build their own citizenship capabilities, there are several other conditions that must be met. Educational institutions, both formal and informal, are crucial for capability building and must be available to all citizens (Turner 1994). Marshall (1950) mentions three rights that are central to capability building. The first one is the right to the prevailing standard of life 
and social heritage. The second is the right to individual freedom, and access to courts to protect those rights. The third is the right to participate in public debate. One reason democracy is so difficult to realize is that it is plagued by catch twenty-twos. With respect to building capability, it is necessary to already have a capable citizenry to establish the rights needed to foster capability building.

\subsection{IDENTITY}

Barbalet (1988) states that "citizenship can readily be described as participation or membership in a community." This requirement can be even more strongly stated: effective citizenship must be accompanied by sociopsychological ties to the community to which one belongs. Group belongingness is a basic human psychological construct (Rogers 1959; Maslow 1970). Most people benefit psychologically from family, ethnic/racial, and religious ties, and also enjoy the "being-in-the-world" feelings from being in natural settings (Fromm 1955, Binswanger 1963). People may tend to be more altruistic and less concerned with self-interest when they feel strong ties to the group or community. Thus, citizenship can provide powerful feelings of identity and provide the foundation for community participation if it can be tied to the emotional aspects of group belonging.

Citizenship can be difficult to internalize psychologically because, in many cases, it is legally defined to correspond to ad hoc, politically-drawn spatial boundaries that have little to do with the most important aspects of individual identity. Compounding this problem in the United States is the proliferation of jurisdictions in which people have citizenship rights. In addition to national and state citizenships, people are citizens of counties and often of cities within counties, and can possibly have citizenship rights within special flood plain districts, water districts, transportation districts, and school districts within cities and counties, if not across these jurisdictions. Citizenship identity can only be pulled in so many directions. Handy (1994) believes that people can have effective loyalties to only two politically defined communities at any point in time.

Local politics in the environmental arena are inextricably linked to larger issues. Climate change and stratospheric ozone depletion, for example, have local connections as well as global manifestations. Politically, citizens involved in seeking to influence the environmental decision-making processes are 
also inescapably destined to operate at several levels, to think globally and act locally. Harvard University government researcher Michael Sandel (1996) acknowledges this:

The growing aspiration for the public expression of communal identities reflects a yearning for political arrangements that can situate people in a world increasingly governed by vast and distant forces. Since the days of Aristotle's pholis, the republican tradition has viewed self-government as an activity rooted in a particular place, carried out by citizens loyal to that place and the way of life it embodies. Self-government today, however, requires a politics that plays itself out in a multiplicity of settings, from neighborhoods to nations to the world as a whole. Such a politics requires citizens who can abide the ambiguity associated with divided sovereignty, who can think and act as multiply situated selves. The civic virtue distinctive to our time is the capacity to negotiate our way among the sometimes overlapping and sometimes conflicting obligations that claim us, and to live with the tension to which multiple loyalties give rise.

The global media and markets that shape our lives beckon us to a world beyond boundaries and belonging. But the civic resources we need to master these forces, or at least to contend with them, are still to be found in the places and stories, memories and meanings, incidents and identities, that situate us in the world and give our lives their moral particularity.

Vogel and Moran (1991) argue, moreover, that interest in the concept of citizenship is growing because some peoples' identities are no longer tied to guaranteed membership in "some identifiable community enclosed within definite geographical, social and cultural boundaries" and that "the location of citizenship within the geographical and cultural boundaries of the nation-state . . has today disintegrated," in part because of fragmentation of multiethnic societies and the increase of supranational economic and political institutions. For example, people can feel as though they belong to numerous affinity groups that are non-spatial in nature and offer citizenship types of arrangements (e.g., professional associations, alumni organizations, special interest groups, non-governmental organizations, political parties). Tonn and Feldman (1996) argue that as a function of these trends nonspatial government may be the wave of the future.

Finally, environmental problems rarely are found to exist within neat jurisdictional boundaries. Groundwater contamination can spread across many jurisdictions. Tropospheric ozone problems spread over entire metropolitan regions. Even issues associated with remediation of hazardous waste 
sites can encompass multiple jurisdictions. Global environmental problems complicate this situation even more because of the emergence of a global ecological citizen who has awareness and cares and believes in earth as Gaia (Van SteenBergen 1994b). The problem is that citizenship is not often, if ever, coincident with political jurisdictions. To compensate, people who believe that there are environmental problems that warrant attention and action often join or organize grass roots and even national/international nongovernmental organizations to support environmental issues (but maybe not in enough numbers or entailing enough personal effort; see Section 3).

Despite these kinds of difficulties, there are many things that people can do to solidify their feelings of belonging (i.e., identity) to citizenship groups. First, people need to understand that political organization of modern society requires citizenship. As such, they need to understand that they will find themselves legally part of at least three, if not many more, citizenship-granting governmental communities. Second, with respect to environmental issues, they need to determine which jurisdictions they have citizenship in and what responsibility each jurisdiction has for each environmental issue. Clarifying these issues will help citizens know in which forums they can participate, which government(s) they need to interact with, and which other citizens to work with on the issue(s). Third, people can familiarize themselves with the history of the communities of which they are a part. Familiarity can work to create empathy and understanding. Fourth, citizens need to get out into the community, meet people, talk with people, develop relationships with people, and then educate themselves about environmental issues. More is said about effort in Section 2.6.

\subsection{IDEOLOGY}

Ideology is an important element in environmental decision making (Van SteenBergen, 1990). The sense of ideology is related to ethics, values, and morality. One's ideology needs to satisfy one's soul. Ideology is a filter which signals what is important in life, maybe important enough to die for. Citizens need an ideology to provide guidance in making difficult judgments and behavioral decisions. One's ideology does not need to have a conventional label, such as liberal versus conservative, or green versus business. "Ideology" is substantively different from "capabilities" needed to be a contributing 
citizen, although a knowledge of the humanities, literature, and the arts can significantly contribute to the development of.one's ideology.

According to Fukuyama (1989): "With the transition of the eighties to the nineties we are witnessing ... the endpoint of mankind's ideological evolution. . . Ideological struggle that called forth courage and idealism will be replaced by economic calculation, the endless solving of technical problems, environmental concerns, and satisfying consumer demands." Fukuyama is making a sweeping statement with reference to the demise of communism as a competing ideology to capitalism.

With respect to environmental citizenship, Fukuyama's view that ideology is limited to the great historical political ideologies is too narrow. Religion can provide the foundation for one's ideology, as can new age movements like integral culture (Ray 1996). It can be argued that consumerism itself is an ideology. James Pinkerton (1997) coined the term "environmanticism" to describe the emerging worldwide activism toward protecting the environment and argues that, indeed, environmanticism is an ideology comparable in scope and following to communism, socialism, and capitalism.

It should be stated that one does not need to adopt environmanticism as a prerequisite of environmental citizenship. One does not need to be an "environmentalist" to contribute to discussions about environmental issues in one's community. However, one's ideology should have an environmental reference point needed to provide ethical, moral, and values guidance.

One's ideology also requires a reference point to politics and participation in environmental decision making. In other words, engagement has to play a central role in one's ideology. Survey results by Verba et al. (1995) suggest that this component of ideology may be severely lacking for many Americans, given that many people reported that they are not engaged because: the important things of my life have nothing to do with politics; politics is uninteresting and boring; it is not my place; I should take care of myself and my family before I worry about the community or nation; I never thought of being involved; politics can't help with my personal or family problems; for what I would get out of it, politics is not worth what I would have to put into it; and I don't like people. These kinds of ideas are not very conducive to environmental citizenship. 
Ideology has both macro-level and individual-level considerations. At both levels, balance is a concern.

At the macro-level, one can be concerned about the balance between the ideologies of individualism and communitarianism, as evidenced in debates about markets and democracy. For instance, Mortimer (1996) argues that the current affinity to identify democracy with markets is a "deep and dangerous confusion." Private choices made by consumers, he cautions, are not the same as civic choices made by citizens, where collective, deliberative choices should be the norm. British political scientist David Beetham makes the same point in a recent paper: "The more we emphasize individual choice-in health, education, transport, etc.-the more we abandon any collective control over the consequences of these choices, and the shape and distribution of provision between different sections of the population" (Mortimer 1996). Mortimer concludes: “Too much democracy kills the market, because 'the people,' or an authority acting in their name, take all the decisions collectively, leaving nothing to the individual. But too much market may also kill democracy. If every choice is left to the market, the right to vote becomes meaningless, because the people you elect have no power to change anything."

Balance is also a concern at the individual level. It is preferable for the components of one's ideology to fit together with a strong coherence. Conflicts within an ideology can cause cognitive dissonance and possibly result in frequent uncomfortable psychological episodes. People need to understand that ideology cannot be created overnight. It takes effort and the understanding that one's views may change and mature over time. In addition, the process of building one's ideology may be cognitively trying, as when one finds, for example, that certain values and beliefs do not reflect one's self. A strong ideology requires reflection and the setting aside of quiet moments to contemplate the values and issues at hand. The assessment of when one needs to stick to one's ideology and when one needs to compromise is also not easy, as is demonstrated in Exhibit 2.

In the spring of 1996 the Utah Wilderness Association ended seventeen years of fighting for wilderness preservation. Financial problems and staff departures led to the decision by its board of directors. Unfocused fund raising neverl let it pay its staffers more than $\$ 15,000$ per year. The real failure was one of misreading the politics of one of the biggest issues to face it in its entire life: the Utah wilderness debate in 1996 . The group pushed for 3 -nillion-acre-compromise while the larger environmental community and the state of Utah's congressional delegation ignored its approach, with ofher regional environmentalists and a national coalition holding out for a 5 7-million-acre wilderness bill One of the Utah. Wilderness Association's founders assessed the group's demise. "They tried to craft a compromise when there is no spint of compromise. They lost their constituency by misreading the politics' (Solberg 1996). Such is the likelihood at the grassroots when funding woes limit the ayailable talent or time and energy of poorly paid staff.

Exhibit 2 Utah Wilderness Association 
Citizenship capabilities and identity can both foster ideology development. Capable individuals will be able to gain a knowledge of the humanities, literature, and arts, which can be sources of building blocks for one's ideology. Identity is important because people who share community feelings may also share important elements of their ideologies. Ideology is also linked to the next two prerequisites for environmental citizenship.

\subsection{MENTAL MODELS OF GOVERNANCE}

Once a citizen believes that something must be done, as guided by his or her ideology, then the next requirement is to know how to generate action. Citizens must have a "mental model" of the political process to guide their behavior. In this sense, a mental model is similar to what anthropologists call schemas, which define in part how individuals relate to the dominant institutions within their society (Treitler 1992). This model must incorporate how the citizen can participate in and influence the process. The model needs to encompass governance in its broadest sense, as well as other important institutions in environmental decision making, such as business, nongovernmental organizations, and the courts. The model must be shared by others, in the cultural sense, or else behaviors will be disjointed, disorganized, and/or inappropriate. It is desirable that the model have proactive elements, recognizing that in many cultures and subcultures schemas of political processes do not include participation by ordinary citizens. As illustrated in Exhibit 3, not understanding the process of government can work against one's interests.

Almond and Verba (1963) would use the term civic culture to describe a reasonable mental model of governance. Within a civic culture, a certain level of political participation is assumed but has an upper limit. Citizens know the extent to which they could and should participate, but also know when to leave matters to others. Ideally, civic culture increases engagement and also acceptance of pluralism and different opinions.

Mental models of governance can be quite general. Sandel (1996) presents the archetypal, Jeffersonian model of political philosophy that depicts "small and bounded places, largely self-sufficient, inhabited by people whose conditions of life afforded the leisure, learning, and commonality to deliberate well 
about public concerns." Sandel

also stresses civic virtue, character formation, moral judgment, and "self-government as an activity rooted in a particular place, carried out by citizens loyal to that place and the way of life it embodies."

Problems with the selfgovernance model arise from the emergence of the global economy and its large corporations, and from big government created to control big business.

For the purposes of guiding citizen decision making and In the mid-1980s, one of the authors experienced a public participation process that failed to reach its potential because of the lack of procedural sawy on the part of an "expert" advising the local affected public. The Western Mono Native A mericans in western California were participating in public meetings and field reconnaissance regarding proposed micro hydropower development in their area. An archaeologist from outside the region who had worked with this group before advised them to withihold Information as 'informants' until we offered to hire them for a substantial period of time to locate medicinal plants, sweathouse sites, burial grounds, and some sacred sites. His. prior experience with this tribe and hydropower development involved very large reservoir projects serving the City of Los Angeles. These were large-budget projects with significant impacts over extensive. areas. The archaeologist failed to understand that the projects in question here were very much smaller and that by holding out for nore opportunity to advise the researchers, the Western Mono would cause critical information to be omitted from the decision-naking process. We never were able to convince the Western Mono that this was their only chance to volunteer information or to receive modest compensation for providing site details. The process went forward according to schedule without adequate coverage of the requisite cultural resource information. Such an experience left the Western Mono dissatisfied with nuch of the process and, nost likely, reluctant to be forthcoming in the future.

Exhibit 3 Micro-hydropower in California behavior, more specific models are required. Bellah et al. (1985) present three more specific models of politics.

In the first understanding, politics is a matter of making operative the moral consensus of the community, reached through face-to-face discussion. . . C Citizenship is virtually coextensive with "getting involved" with one's neighbors for the good of the community. . . . In sharp contrast to the image of consensual community stands the second understanding, for which politics means the pursuit of differing interests according to agreed-upon, neutral rules. . . One enters the politics of interest for reasons of utility, to get what one or one's group needs or wants . . . the third understanding we call "the politics of the nation," which exalts politics into the realm of statesmanship in which the high affairs of national life transcend particular interests. 
They go on to comment, "What is paradoxical in this picture of the three types of American politics is that in an individualistic culture that highly values diversity and 'pluralism,' it is consensus that is appreciated and the conflict of interests that is suspect."

Through research on agenda setting, three kinds of mental models related to public participation in environmental decision making have been distilled (Cobb and Elder, 1972; Kingdon, 1984; Stone, 1989). The first model is a problem stream. People holding this model see environmental problems as having a scientific answer, and thus, are primarily concerned with the concrete achievement of environmental changes which they believe will directly solve a public or ecological health problem. The second model is a policy stream. People holding this model see solutions as having a legal/institutional answer, and thus, are primarily concerned with meeting legal requirements, milestones, etc. The third model is a political stream. People holding this model view environmental problems as political/social issues, and therefore strive to achieve outcomes that satisfy some group's perception of an overarching problem, independent of the legal mandates or the current scientific prescriptions regarding the particular issue on the table.

Tonn, English, and Travis (1997) present a third viewpoint on decision-making processes that has special reference to environmental issues. They postulate six different "ideal types" of decision-making processes: routine; administrative analytic; elite corps; conflict management; collaborative learning; and emergency response. Each process or mode of decision making is appropriate for different kinds of problem situations (e.g., collaborative learning is appropriate for high consequence issues that are poorly understood by the community). In addition, each process holds different roles and responsibilities for citizens (e.g., collaborative learning requires active participation in workshops whereas administrative analytic may only require attending a public meeting).

Synthesizing these viewpoints creates a model that has the citizen as a central and active figure in environmental decision making. The citizen is able to ascertain what type of process is being implemented to deal with a problem and even has the ability to judge and influence what type of process is needed. Within each type of process and within the context of being a citizen in a particular jurisdiction or jurisdictions, the citizen knows the extent she or he ought to participate. Thus, a citizen 
will know how to behave in a consensual process within a political stream model to help solve a local community environmental problem.

There are many things that a citizen can do that may lead to the emergence of something like the mental model envisioned above. First, one needs to learn about the different types of processes that can be applied to solve an environmental problem. Second, one needs to understand one's role in each type of process and the roles of the other important participants. One needs to accept the roles and act out the roles, even if one does not initially or maybe ever "feel" the part due to factors associated with the lack of identity. However, over time, it is possible that acting out the roles and interacting with other people will naturally evolve into strong and healthy feelings of belonging. Third, one needs to condition one's role based on constraints and/or requirements dictated by one's citizenship. One needs to be active in finding out in what jurisdictions one has citizenship rights and what those rights are.

\subsection{SOCIAL NETWORKING}

Citizens exist in a web of relationships in society. The relationships act as information conduits. The relationships allow the testing of ideas. The relationships provide leverage to build support for ideas and action. The relationships provide the means for action. A civil society is knit together through its social networks, with much overlap and redundancy. A capable citizen who understands how the system works and knows what must be done will nevertheless be ineffectual if not part of a strong social network.

Pam Solo, head of the Institute for a Civil Society in Newton, Massachusetts, manager of the presidential candidacy of former U.S. Representative Patricia Schroeder of Colorado, and recipient of a MacArthur Foundation award, elaborates:

A civil society is not just how we do the interaction on the street, at the toll booth, but it's the whole network of institutions, institutional relationships, structural relationships that really affect how we experience our lives on a day-to-day basis (Langner 1997). 
To build a social network, dialogue is needed. Schneider (1996) states that "conversation is the foundation upon which all political behavior is built." To support his point, he quotes John Dewey, who wrote in 1959 (as quoted in Post, 1993) that "democracy begins in conversation;" Barber (1984) who states that "there can be no strong democratic legitimacy without on-going talk;" and Ackerman (1989) who agrees that "dialogue is the first obligation of citizenship." Others who support this point include Pitkin and Shumer (1982), Stanley (1983), and Gamson (1992).

Social networks that hold communities together depend on a shared perception of the conditions, opportunities, and threats to the social fabric. The multiplicity of new channels and modes of input for assimilating the world can be seen as damaging to this shared perception. The instancy and localness of news provides news media consumers with a myriad of unprecedented choices. Jurkowitz (1997) comments:

It's been years since Walter Cronkite delivered one universally accepted version of the news. Fragmentation is in full swing. . . In a worst-case scenario, it will pander to personal passions rather than to civic instincts, render much of journalism as unreliable as barroom gossip, and leave the economically disadvantaged on the short end of the information gap. ... The coming on-line news culture will surely redefine community and may render the concept of geography obsolete, by linking people not by where they live but by what they care about.

On the other hand, modern news delivery can also rebuild beleaguered communities. The strategic placement, training in use of, and maintenance of thirty computers in a Newark housing development proved to stimulate neighborhood activism. This experiment helped to create a food co-op and the staging of a talent show, among other benefits, all while forging closer links to municipal institutions (Jurkowitz 1997).

Social networks can also be solidified by joining organizations. Bellah et al. (1985) observe that, the United States is a nation of joiners and that recent research confirms what de Tocqueville said 150 years ago:

Americans of all ages, all stations of life, and all types of disposition are forever forming associations. There are not only commercial and industrial associations in which all take part, but others of a thousand different types-religious, moral, serious, futile, very general 
and very limited, immensely large and very minute. ... In every case, at the head of any new undertaking, where in France you would find the government or in England some territorial magnate, in the United States you are sure to find an association (de Tocqueville 1969)."

Putnam $(1996,1995)$ also believes that civic volunteerism is a vital aspect of American political democracy. However, he argues that membership in civic organizations has dropped precipitously in the past several decades. While debunking common notions that people move too much or are too busy to join organizations, he argues that the real culprit is television. Not only does watching television take time, it also acts to remove people from places where discourse can take place.

Community leaders have a special responsibility for building social networks. Verba et al. (1995) stress that people often need to be asked to participate in political processes and social networks. For example, leaders of political parties and their organizers have to ask people to volunteer their time stuffing envelopes and making calls on behalf of candidates if they are to get any participation. Against this backdrop, both Valelly (1996) and Skocpol (1996) agree that political leaders are asking people less and less to become involved. Instead of personal interaction and volunteerism, political operatives are relying more on television ads and mail campaigns. Even political interest groups exist more as virtual, send-in-a-check organizations as opposed to face-to-face communities.

This last point is important as it relates to representative democracy. Ideally, people should choose candidates to represent their interests based on personal knowledge of the pool of potential representatives. The next best case is to gain insights from trusted friends or family members who in turn have personal knowledge of the potential representatives. Social networks are necessary to build the familiarity needed as the basis of representation.

Building a social network to promote environmental citizenship is straightforward yet not easily accomplished, managed or maintained, as is shown in Exhibit 4 on the following page. Effort is needed to meet and talk with people. A person needs to be somewhere to network with people, such as a community picnic or in a cyberspace discussion program. Joining a voluntary environmentally-oriented organization or two provides a place and an opportunity to talk with people. In this age of entertainment overload and time pressures, it is easy to spend one's money instead of one's time in 
Environmental goups do not always operate as smooth, seamless nechanisms for aligning opposition to proposed projects. In-fighting among major environmental groups hampers effective action at times and can demoralize grassroots organizers. Although details differ, the following general questions have beset the Save Our Salmon Coalition, the Utah Wilderness Campaign, and the Western Anctent Forest Campaign as well as the fight to protect the country's endangered species laws. The Endangered Species Coalition represents an array of 230 large and small national, regional, and local conservation organizations. The National Audubon Society was the coalition's legal sponsor Questions of leadership in day to-day strategizing centered on who should be the generals in charge of fights to designate wilderness in southern Utah, to save the salmon, to preserve old growth forests, and to protect the Endangered Spectes Act? Should the campaigns be led by onthe-ground activists, by the leaders of national environmental groups or by the foundations that fund most efforts? Or should? they be cooperative efforts that bring all parties together?

Inseparable from the question of who is in charge is the question of how the campaigns should be run Everyone agrees that the central struggle is in the Congress But should the Congress be influenced by grassroots groups rousing their fellow, citizens? Or should the environmental movenent in this desperate time put ts resources into media campaigns, telephone banks, advetisements and media events that swamp congressional detegations and the administration with telephone calls; letters, and faxes?

The coalition set up under the aegis of the National Audubon Society was led by former Indiana congressman Jim Jontz and a staff of seven, begining in January 1995 to face the threats of the newly elected Republican led Congress ont 0 campaignt style for protecting the law was based on daily communications between his staff and their grassroots counterparts throughout the country The local activists then used the information to pressure theit local congressional delegations The Pew Chantable Trusts committed $75,000 \mathrm{n}$ March of 1995 for the campaigh and promised to match that again in November:

Tew other foundations joined the coafition with financing, causing a crisis within three months of lont? hiring and amidst rey real hireats to the law s integnt, The Pew folks encouraged lontz to integrate a capital-intensive media campaign into its extant grassroots strategy Pew also suggested hiring the Environmental Information Center, which it funds, to direct the Whole campargen Jontz then began to collaborate with Phil Clapp of the Pew funded center to create a media and grassroots campaign with - now $\$ 600,000$ budget (Medbeny 1995 )

But Jont and Clapp fell out Faced with this split the coalition steering committee voted in August to retain Jontz rather than to hire Clapp Consequently, Pew pulled its $\$ 600,000$ off the table, tentative commitments from other foundations for nearly $\$ 400,000$ also disappeared But the money disappeared only for a moment Carl Pope, executive director of the Sierra Club, which is a member of the coalition said, This was not a good thing for the planet and I made a lot of calls to turn it around?

The following week the steering committee reversed itself and put deipp in charge Jontz and his campaign were to be phased out According to lont, Pew had convinced the heads of se veral environmental groups on the steening committee to work with Clapp instead of with him With clapp in charge, the million dollars would almost certainly be back on the table Money was the deciding factors Jonte sard Within anothet week. Audubon fired the entire coatition staff of seven Neither the steering committee nor any of the 230 groups they tepresented knew the firing $s$ were coming $\mathrm{According}$ to $\mathrm{Lt}$,

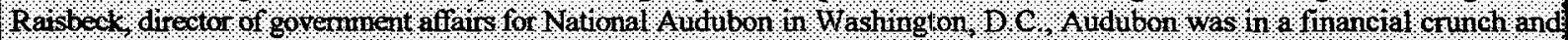
could no longer fund the coalition Sam Hit head of the Forest Guardians in Santa Fe New Mexico, says more is involved in the firings, When Pew steps in, it s like a death star in the solar sysiem, 7 hey set up their own gravitational field and evenone begins to revolve uround then 1 ye watched activists go throught this dance of naking themselves $100 \mathrm{k}$ fundable to Tew by altering their pronities to neet Pew's goals. A senior environmental insider also commented in Pew's yews, the ont y way to run a campaign is to grab the issue, get intense media coverage, and parachute organzers in to generate letters, calls and constituent pressure on key politicians, such an in and out strategy, he said, fails to recognize that environmental battles are won with passion and long-term commitment of activists.

Grassro ots canpaighs are difficul to organize Hindreds of independent groups all with separate agendas, nust be convinced to wort together Each group s agenda is the most mportant to 1 , making cooperation difficult By companson, If the money is there, political clout in the form of letters, calls, ard falxes, ear be generated almost instantaneously by a sophisticated media campaign, Sach on approach, towever, threatens the role of existing organizations and individuals Who have dedicated thenselves to protecting their plece of the environment They see themselves demoted to foot soldiers

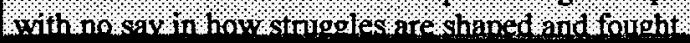

Exhibit 4. The Endangered Species Coalition and the effect of National Environmental Campaigns on local and regional environmental participation 
support of environmental issues given any ideological viewpoint. However, a check does little to build a social network.

\subsection{EFFORT}

Each of the five prerequisites of environmental citizenship mentioned above require effort. Capability building, ideological development, and understanding governance processes require intellectual effort. Maturation of identity and construction and maintenance of social networks require energy to meet new people, renew old acquaintances, and enter into more than superficial conversations. In combination, these prerequisites demand a great deal of effort.

However, these efforts are preliminary and complementary to actual efforts to participate in environmental decision making. At the most fundamental level, involvement is synonymous with voting and being informed. For example, the Manual for Citizenship by the Daughters of the American Revolution (1981) urges new citizens to "vote intelligently at primary and general elections" and that "a good citizen is an informed citizen." One of the more well-known comments on this point is attributable to J. Edgar Hoover (1939), who said: "Just as the price of liberty is eternal vigilance, the freedom of your community from the forces of crime that strike somewhere in the Nation every twentytwo seconds carries a sales ticket - to be bought by civic alertness, decency, energy, and self-sacrifice, not only for self-preservation but for the welfare of coming generations." Eternal vigilance takes effort.

More than voting is needed. Etzioni (1967) develops the concept of an active society. "Man is not unless he is social; what he is depends on his social being, and what he makes of his social being is irrevocably bound to what he makes of himself." His concept requires people to be self-conscious, knowing, and committed. He worries that passivity will lead to man's final objectivization and instrumentalization.

Effort can also entail behavior that some might label as confrontational and extreme. In his "Letter from Birmingham City Jail," Martin Luther King (1963) described his explicit efforts to create tension that would cause change, ultimately winning African Americans their civil rights. He said: "My citing 
the creation of tension as part of the work of the nonviolent-resister may sound rather shocking. But I must confess that I am not afraid of the word 'tension.' I have earnestly opposed violent tension, but there is a type of constructive, nonviolent tension which is necessary for growth. . . The purpose of our direct-action program is to create a situation so crisis-packed that it will inevitably open the door to negotiation."

Thus, effort can entail significant commitments of time, and lost opportunities for income and career. Accompanying effort can be psychological stresses, caused by uncertainties and direct confrontations with other people (detailed more in Section 3.4). In the case of leadership in the United States, effort also entails risk to ones health and life. As Fukuyama (1989) indicated (and history bears out), only a strong ideology can provide the foundation for such commitment.

To learn about how to apply effort and about the effects of effort in environmental decision-making situations, citizens need to expend the effort. They need to experience the stresses and learn what effort is appropriate in specific contexts. Strong social networks, citizenship skills and an understanding of how "the system" works can make expending effort easier. As shown in Exhibit 5, even small lapses in effort can work against one's interests.

The bottom line is that environmental citizens need to get involved. In most cases, involvement requires dedication of time to environmentally-related activities. The list of potential volunteer activities is limited only by one's imagination. Voluntary activities might include: attending meetings, in person or virtually; writing to government agencies and elected officials; voting; reading materials; explaining the materials to others; visiting nursing homes to update residents on environmental issues; visiting schools; and as appropriate, being a mentor. As discussed more in Section 6.3, citizens can work collaboratively with various government programs in many capacities. For example, many agencies find data collection expenses to exceed their budgets. Volunteers can help out by collecting water samples, reading air quality meters, counting birds, and. recording other pertinent observations about the environment. Data can be easily transmitted to agencies via the Internet. In fact, many K-12 classes around the country are already engaging in such activities. Citizens can volunteer to represent their neighborhoods, be they spatially defined or otherwise (see Section 6.3 on environmental neighborhoods), to participate on oversight committees, in visioning exercises, and in innovative 
exercises in direct democracy.

In summary, these activities

could demand at a minimum

four hours per week and many

more hours to achieve more

substantive environmental

citizenship goals.

\subsection{SUMMARY}

To summarize, the model of

environmental citizenship

presented herein has six

elements: capability, identity,

ideology, mental models of

governance, social networking,

and effort. The first five are

prerequisits for the sixth. All

must be achieved to some

degree to enable a person to

fully participate in processes

focused on resolving

community, regional, and

national environmental issues.

This framework contains

several elements common with

the Civic Volunteerism Model

(CVM) developed by Verba

et al. (1995). The CVM

contains elements such as: civic
An example of lack of local understanding of the environmental decision-making process occurred with the 1996 resolution of a ski area expansion issue onto Santa Fe National Forest Land in New Mexico. Local residents opposed the expansion of the private ski area into the Big Tesuque, an adjacent high mountain basin. The area is considered sacred by Native Americans and is popular in its undeveloped form by local urbanites. Both the City of Santa Fe and the county had passed resolutions against the expansion in 1992 and 1994. The issue became one of the few times Anglos, Hispanics, and Native Americans were united against a common opponent (Manning 1996). Environmental objections included traffic congestion, degradation of vildilife habitat. water quality and quantity problems, and general issues related to unwanted growth.

The U:S Forest Service issued a draft Environmental Impact Statement In 1994 that suggested a preferred alternative that allowed 75 aeres of expansion, but not into the Big Tesuque Then in late 1995, the Forest Service released its Final Environmental Impact Statement and reversed its position, now allowing the ski area to grow from 585 acres 10.891 acres by building three new chairlifts on public land, including the Big. Tesuque lift. Expansion plans also called for an 800-space parking lot and operation of a commercial mountain biking business in the summer

Why did the Forest Service shift its position? The answer is failed procedural follow through on the part of the of the local opposition coalition. Whetlier this was due to fatigue or lack of understanding of the decision-making process is unclear, A Forest Service spokesman changed his mind, in part, because he didn't get any support for the plan he endorsed in the draft environmental study. Only $3 \%$ of the written comments supported his 'compromise' option which called for opening up 75 new acres but not the Big Tesuque. On the other alternatives. opinion was polarized: Roughly $46 \%$ wanted to open up the Big Tesuque while $47 \%$ recommended the coalition's "citizen alternative"' a plan that would have limited development to upgrading the area's existing terrain.

Coalition members criticized the decision because most of the comments supporting the proposed expansion came from out of -town skiers who would not have to live with the project impacts. The Forest Service countered that its mandate lies, in part with having to consider national needs for recreation as well as local concerns. The local opponents believed that the Forest Service" sided with the ski area out of frustration when [it] realized the coalition wouldn't endorse his compromise"' (Manning 1996). Thus, the unwillingness of local project opponents to credit the Forest Service with trying to be responsive to all parties and to creatively accommodate opposing values ignited an impasse that looked as if it wonld likely end up in the courts. The Forest Service reconsidered its decision after strident opposition from the local coalition and has since vetoed any ski area expansion in the area?

Exhibit 5. Ski area expansion in New Mexico 
skills, education, vocabulary, partisanship, organizational affiliation, and religious affiliation, which roughly correspond to capability, ideology, and social networks, respectively. Other aspects of the CVM-free time and income-relate to constraints on volunteerism.

The models posit that citizenship and volunteerism, respectively, can be built only from the bottom up. In other words, initial conditions must be achieved before other conditions can be achieved. With respect to the former model, capability is a prerequisite for being able to intelligently develop ideology, and understand governance. Identity and ideology drive successful effort. In the latter model, factors such as gender and race provide a foundation upon which is built exposure to politics at home as a preadult, then affiliation with non-political organizations as an adult, then the development of civic skills and vocabulary, and finally participation in political activities. In the abstract, no requirement of environmental citizenship is insurmountable individually or in combination. When placed in the context of the United States in the late 1990s, the requirements can seem daunting. The next section discusses in detail the various constraints and lifestyle choices that work against people's efforts to become better citizens, irrespective of whether the issues at hand are environmental.

Even under the most optimistic of circumstances, it cannot be expected that every citizen will be able to contribute to equal degrees in equal manners. Life situations will act as constraints and personal attributes may lead people to contribute in different ways (e.g., as leaders, as analysts, as "intellectuals"). It may be that attending a public meeting or writing a letter to the editor represent the maximum extent of one's contribution. No contribution is insignificant.

Again, balance is a key concept. Knowing when to participate and to what degree takes experience. More effort is not always necessarily better. As democracy is still evolving in the United States, and people are continually experimenting and learning about what works and doesn't, it is not possible to say exactly how much effort each citizen should expend in each given situation. However, one can strongly argue, based on analysis presented in the next section, that Americans as a whole are not close to expending enough effort to make the balance issue an important current consideration. 


\section{CONSTRAINTS ON CITIZENS}

Americans do not participate in political activities in ways and at rates consistent with the tenets of American democracy. Unfortunately, in the United States, effort, as measured by voting, is on the wane. About one-third of the nation's eligible voters do not bother to register to vote, even though it has been made easier over the past thirty years. Voting rates in national elections have fallen into the sub-fifty percent range of eligible voters. In the 1994 Congressional voting across the country, average participation was only thirty-six percent. In U.S. presidential elections the trend is decidedly toward lowered interest. Registered voter turnout has declined in these nation-wide elections from sixty-three percent in 1960 to below fifty percent in 1996 (Hames 1996). Voting in local elections has fallen to under forty percent in most places.

In 1992, forty percent of Americans with incomes less than $\$ 10,000$, representing six percent of the population, voted. Of those with incomes greater than $\$ 50,000$ (ten percent of the population), eighty percent voted (Clymer 1996). A local primary election in Detroit in early August of 1996 attracted only seventeen percent of its registered voters. One of their representatives in the U.S. Congress, John Conyers, commented on this self-chosen disenfranchisement: "I'll tell you what surprised me. I have never heard any more complaints about the government's insensitivity to what people need in this country than there have been under the Gingrich leadership. Yet at the same time, instead of that translating into a remarkable turnout, an angry protest at the polls, it turns into a whimper" (1996). Fewer people still contribute their time to political campaigns, contact government officials, or devote time to the community (see Verba et al. 1995).

In their extensive study of political activism in American life, Verba et al. (1995) intensively interviewed several thousand subjects on all aspects of their involvement in America's political life. They found that numerous issues motivate political activity, including: human needs, taxes, economics, abortion, social issues, education, environment, crime and drugs, and international issues. Concern over these issues motivated people to engage in electoral activity, contact government, protest, and engage in community activity. Relative to other issues, environmental concerns motivated more people to give money to organizations (tied with abortion), to engage in local and national protest activities (second to 
abortion), and to participate on local boards (second to education). On the negative side, only one percent, .01 percent, and 0.3 percent of the national sample reported such activities, respectively. Relative to the other issues, environmental concerns were less motivating in the area of voting (taxes were highest), contacting government at the local level (human needs and education were highest), and informally helping the community (crime and drugs were highest). Absolute rates of engagement in these activities as motivated by environmental concerns were 2.5 percent, 0.5 percent, and 1 percert, respectively.

The numbers suggest, do the majority of informal reports from the field, that public participation in environmental matters, or with respect to most any social issue, is low. The thesis of this section is that numerous factors are constraining peoples' ability to meet the rigorous requirements of environmental citizenship outlined in Section 2 . These factors arise in almost every aspect of life and have synergistic relationships with each other. The approach taken in this section is to present six general constraining factors in a linear fashion, in Sections 3.1-3.6, respectively. Then, in Section 3.7, how these factors exist in a complex mosaic of forces is presented.

\subsection{WORK-RELATED CONSTRAINTS}

The sphere of life referred to as work greatly constrains people's ability to lead balanced lives, which would include opportunities to meet the requirements of environmental citizenship. The dominance of work in our lives tends to limit attention to work-related concerns, limit time available for other activities, and disrupt lives so that time and effort cannot be effectively allocated to other activities. Limits on attention, time, and control over lives constrain one's ability to focus on environmental citizenship matters, the sheer effort that can be devoted to citizenship, and the building and maintaining of social networks, respectively.

\section{Limits on Attention}

Economic adversity tends to cause people to pay less attention to politics, local or otherwise. Combs and Nimmo (1996) state, "Bad times alienate us. . . People desperate for work do not have the time or 
the will to volunteer for community activities or for participation-let alone leadership-in environmental agendas." They say that is the bad news about the bad times.

While middle-income Americans have far more material goods and economic benefits than they have ever had in the past, numerous surveys (e.g., see the Merck Family fund study reviewed in Section 6) have documented that people feel "less secure, less connected, and less fulfilled." That is, the surveys confirm the perception of bad economic times. Lerner (1996) believes that the perception of bad times has roots in other spheres of life, such as discussed in Section 3.3. "We feel far more vulnerable to economic danger because we can count less on one another to help out when times get rough. Ripped from the network of connectedness, unable to see the ways in which we need one another, assured that our only hope lies in fostering our interests even at the expense of everyone else, we perceive ourselves as alone and desperate to hang on to whatever flimsy reeds of connection remain" (Lerner 1996).

Of course, perception of bad times does have some basis in reality. Worries of downsizing and mergers, based on many actual stories in the local and national media, have left many uncertain about their jobs. People who used to think their jobs were secure and that their standard of living would rise each year can no longer take either for granted (The Economist 1996b). In the winter of 1996, the New York Times ran a lengthy, effective series (since issued as a book, along with responses to the original series) on the topic of downsizing. By the newspaper's own estimate, it had not devoted so much space to a single issue since it published the secret Pentagon Papers on the Vietnam War in 1971. The downsizing rationales that have been proffered frequently in the last several years can be summarized simply. Wall Street "greatly prefers a dollar of cost savings to a dollar of extra revenues" (Jackson 1996).

The stagnation of wages for the American middle class is receiving much talk, but little attention:

It is now 23 years since real weekly wages peaked in America. For a while, as more women joined the workforce, the increase in two-paycheck households kept family incomes rising even as individual incomes fell. Now family incomes are starting to suffer. And this is during an expansion. When the next recession comes-and it will, in spite of all the stockbrokers and congressional flimflammers who want you to think that the good times will roll on forever-the middle class will be standing in the path of a steamroller (Mead 1996). 
Economists Jared Bernstein and Lawrence Mishel of the Economic Policy Institute in Washington have been studying the impact of technology on wage and employment trends. They have found wage declines for the vast majority of workers, including those in the most technologically-advanced industries.

Those who argue that there is some kind of panacea in simply upgrading the skills of the technologically inept are deluded. The most startling thing about the so-called downsizing phenomenon is the high level of talent that is being shown the door. The United States already has the best-educated work force in the world. Twenty-five percent of all workers are college graduates. But no amount of college or sophisticated technical training has provided an adequate defense for workers in an era when nearly all of the workplace clout rests with the corporate powers that be. Said Mishel: "If everyone is afraid that the job they now have is the best job they can get, because if they lose it they go to a worse job, then no one-white collar worker, blue-collar worker, union or non-union-is able to put any pressure on the employer (Herbert 1996)."

Harvard University economist Juliet Schor (1992) maintains much the same position:

The trends in income have led to a public consensus that it is no longer possible for families to "make it" on a single income-a view that eight out of ten Americans now hold. . . In one sense, workers are choosing these extra hours. . . But the pressure to work the hours has come from companies. In return for a 1970s standard of living, employers are now demanding far more hours. For the production and nonsupervisory employees who make up 80 percent of the workforce, these demands have been substantial. According to our calculations, just to reach their 1973 standard of living, they must work 245 more hours, or 6-plus extra weeks a year. [emphasis is Schor's]

Only now are the consequences of labor's blindness to the hours question fully visible. Workers, both as individuals and through their unions, have been virtually powerless to stop the onslaught of work. Amidst the high unemployment and economic insecurity of recent years, there have been few solid impediments to long hours. And the problem is not only economic. The nation no longer possesses a culture of resistance to long hours or a political movement to press for government reforms. There have been few ideological vantage points from which to stake a claim to leisure. 
Into the public consciousness there has recently entered a growing sense of an uncertain world of fluctuating pay. The U.S. Census Bureau reports that fifty-four percent of the nation's workers, at all levels, experienced serious wage and salary fluctuation in 1994, up from forty-nine percent ten years earlier (Uchitelle 1996). For example, Uchitelle (1996) recounts an Iowa family where the sole income source, the father, lost his annual overtime pay due to a change in technology. To supplement his base pay, his wife took a job at a McDonald's counter last year at five dollars an hour. The main problem was that she works twenty hours one week, maybe forty hours the next, and then maybe thirty hours the next, never certain how much take-home pay she will have. She has had to cancel numerous family activities because of the uncertain schedule and/or the uncertain income. As Uchitelle noted:

More and more Americans accustomed to jobs with fixed wages and predictable raises are finding that all or part of their pay can fluctuate steeply, in ways often beyond their control. Income swings traditionally associated with traveling salesmen and Wall Street brokers are becoming"common in other occupations, too, and that could affect national behavior. "You are forced to take life more day to day," said David Popenoe, a Rutgers University sociologist. "Planning for a child's education or the purchase of a home can be very difficult. What we think of as the future becomes economically compromised for many families."

In response to many factors, with declining real incomes and income uncertainties being just two of them, more women have entered the labor force. The U.S. Bureau of Labor Statistics reports that the percentage of married working women with children under six has increased steadily from 38.8 percent in 1975 to 61.1 percent in 1995. Jude Wanniski (1996), a political advisor to 1996 Republican Party primary candidate Steve Forbes has looked at the two-earner family situation and concluded: "When both husband and wife must work full-time to make ends meet, many of the problems associated with hearth and home cannot be successfully addressed. Unless this economic problem is successfully addressed, there can be no solution to the social problems." University of Chicago psychologist Mihaly Csikszentmihalyi found through monitoring subjects with beepers that working mothers routinely juggle as many as seven things at once, while men handle only three (Sharp, 1996). It is unlikely that one in seven or one in three things being juggled are environmental citizenship concerns.

The latest analysis of the Bernstein and Schor data, coupled with new data, underscore that while American families are working more, their efforts are not being reflected in significant increases in 
their standard of living. A recent survey sponsored by the Washington Post, the Kaiser Family Foundation, and Harvard University reports that forty percent of American families have sent an additional family member into the paid labor force or had an existing working member undertake an additional job-simply to make ends meet (Bluestone and Rose 1997).

While many, if not most, workers would like more leisure, about sixty percent say they prefer their current work hours and pay if the choice means less pay. Bluestone and Rose (1997) report that of those who would like to change their work hours, by a ratio of 3 to 1 , most would rather work longer hours. Union negotiators are, of course, aware of this, and rarely push for reduced hours during bargaining. Bluestone and Rose (1997) report an actual test of these notions of preference to not choose shorter hours. Since 1984, New York state has allowed state employees to take voluntary reductions in their work hours-even moving in and out of this flexible time option-without prejudice to their careers. In the twelve-year life of the program, no more than two percent of the workforce has ever enrolled in this program.

Bluestone and Rose (1997) looked at longitudinal data tracking specific families' incomes over several decades and adjusted for business cycle effects:

We calculate that for all husband-wife working couples, family work effort increased by more than 32 hours per year for each year of the 1970s and 1980s. Hence, in the span of just two decades, working husband-wife couples increased their annual market work input by a cycle-adjusted 684 hours or 4 weeks of full-time work. The typical dual-earner couple at the end of the 1980 s was spending an additional day and a half on the job every week.

These researchers found that for prime-age working couples, real earnings rose by a total of only 18.5 percent from 1973 to 1988 , but that this modest increase was due largely to increased effort, not increased real wages. (Real hourly wages increased only two cents per year.) Education disparities are reflected in the increased hours worked and annual income changes:

For families headed by high school dropouts, the situation is the most dismal. Between 1973 and 1988 , such families increased their annual work effort by nearly $12 \%$ yet ended up with 
$8 \%$ less annual income. For families headed by high school graduates or some college, work effort was up by 16 to $17.4 \%$, producing less than a $4 \%$ increase in total earnings. . . . Families headed by a college graduate . . . increased their work effort by about the same percentage as those headed by high school graduates or those with some college, yet their material consumption standard increased by nearly a full third between 1973 and 1988.

Unfortunately, such well-educated families comprise less than a third of all American dualincome families (Bluestone and Rose 1997).

From further analysis of their data, Bluestone and Rose (1997) concluded that "men are working overtime to compensate for expected job loss in the future. Women have expanded their work effort to cover for what otherwise would be a sharp reduction in family living standards."

\section{Limits on Time}

Harvard's Schor (Sharp 1996) believes that the record levels of overtime in manufacturing and the extensive downsizing throughout the economy have led to longer hours for those who have jobs. Americans believe that working harder and longer is necessary to keep a job. Shortages of qualified labor in the manufacturing sector is causing increased stress levels, increased overtime, and the reassignment or redistribution of workloads (Quintanilla 1997). Companies do not want to pay benefits to part-time or additional workers, so they choose to pay the extra costs of overtime to existing workers. International Survey Research, a private Chicago firm, found similar staff shortage problems in consulting, telecommunications, law, and financial services. One telecommunications manager told this survey firm, "The company is suffering from self-imposed corporate anorexia. . . Top management just assumes that remaining staff will devote 50,60 , or 70 hours a week to get the job done" (Fortune 1997).

Handy (1995) confirms that within the past twenty years, working hours have gone up, in the United States by the equivalent of one extra month a year. Working hours are already longer than they were forty years ago. If present trends continue, by the end of the century Americans will be spending as much time at their jobs as they did back in the 1920s (Schor 1992). Schor comments on the breadth of this phenomenon: 
Contrary to the views of some researchers, the rise of work is not confined to a few, selective groups, but has affected the great majority of working Americans. Hours have risen for men as well as women, for those in the working class as well as professionals. They have grown for all marital statuses and income groups. . . Nationwide, people report their leisure time has declined by as much as one third since the early 1970s. Predictably, they are spending less time on the basics, like sleeping and eating.

In its starkest terms, my argument is this: Key incentive structures of capitalist economies contain biases toward long working hours. As a result of these incentives, the development of capitalism led to the growth of what I call "long hour jobs." The eventual recovery of leisure came about because trade unions and social reformers waged a protracted struggle for shorter hours. Some time between the Depression and the end of the Second World War, that struggle collapsed. As the inevitable pressures toward long hours reasserted themselves, U.S. workers experienced a new decline that now, at the century's end, has [sic] created a crisis of leisure time.

The pace of life has placed a high premium on speed. A recent Wall Street Journal poll found that eighty percent of respondents described their lives as busy to the point of discomfort. A nation in a hurry is composed of people who "are economically pressed, politically depressed and socially stressed" (Beeman 1996). A source of the problem with work overload is that we-particularly women-have set for our modern lives standards based on the traditional family model from the $1950 \mathrm{~s}$ and 1960s, "when the husband supported the family and the wife had time to look after the home and get involved in community and school activities," says Marcia Laswell, president of the American Association of Marriage and Family Therapists (Sharp 1996).

A Massachusetts mother comments on the numbness she feels regarding turning her four-month old over to day care for ten-hour days (Hale 1997):

The improved life (read: more convenient) that the author proclaims we have comes with a price, both literally and figuratively, that forces women to work outside the home.

It is insane to claim that life is better simply because we have made technological progress that is the natural by-product of our advanced brains. Just 20 years ago my mother and her 
peers, who also had very convenient lifestyles, worked outside the home by choice; today, my friends do so to live their modest lives.

I'm not talking about huge houses and luxury vacation lifestyles but simple lives in the 'burbs. I have yet to meet a family that does not need the equivalent of two incomes to survive: either two people working one job each; one person working two jobs; or one working one job at a high salary, 80 hours per week, with the other parent staying home with the kids.

My children spend more time at day care than at home; my cumulative time with them on the days I work is three hours. My alternative is to have my husband work two jobs and basically function as a single parent. At this point in the course of humanity, is this really the path we want to be on?

Another change in the work life frustrates environmental citizenship: moonlighting. According to the U.S. Bureau of Labor Statistics, about eight million Americans, or about 6.4 percent of those employed, self-reported working a second job in 1995, up from 4.7 percent, or 3.9 million people, in 1975. For women, the trend is most pronounced. They made up 46.9 percent of the multiple-job holders in 1995, up from 24.4 percent in 1975 and 38.3 percnet in 1985. Women are more likely to work multiple part-time jobs, as opposed to men, who often work one full-time and one part-time job. "Unlike employees laid off in the shutdown of smokestack America in the 1980s, many of today's workers are not waiting for people to give them a new job," said Ken Goldstein, an economist with the Conference Board. "White-collar and pink-collar workers are making their own jobs. They hustle two or three different situations together to approximate the kind of money they used to bring home" (Pomice 1996).

Moonlighting, thus, is no longer just for blue collar workers. Rates are now high among people with primary jobs in public administration and service, with college teachers having the highest moonlighting rate, 13.7 percent (Pomice 1996). Most people take on extra jobs for the money rather than as a creative addition to an otherwise unchallenging primary job. Thirty-seven percent of men and 44.2 percent of women and 63 percent of divorced, widowed, or separated women report they work multiple jobs to meet regular household expenses and to pay off debt (Pomice 1996). Second jobs tend 
to be low-level, easy-to-find work in the service sector. The implications to the potential for public participation are clear: with second jobs, total annual hours worked increases by an average of 300 hours.

Work-related pressures can be described in other ways, too. In the past twenty years, vacation time has decreased for the average American worker by three-and-a-half days and commuting time for the average American worker has gone up by twenty-three hours per year (Handy 1995). (From 1980 to 1990, however, the average American commute trip time increased by only 0.7 minutes, while the average commute trip length increased from 9.9 miles in 1969 to 10.6 miles in 1990 [Davis 1995].) According to the Federal Highway Administration, per capita hours per year spent in traffic jams, however, have increased from twenty-five in 1985 to forty-one in 1993 (Clark 1997). This figure could grow to 125 hours by 2005. According to an American Express survey, spending on international travel by U.S. businesses has increased by about two-thirds since 1990 (Smith 1994). Downsizing has forced business survivors to follow executive itineraries that place them on a global, round-the-clock time schedule, subject to laptops, modems, faxes, and e-mails at any time of the day.

Thus, time pressures associated with work, from long and growing hours on the job, to additional jobs, to increases in commuting and travel time, all impinge upon the quality life. A 1990 Fortune magazine cover story titled "Why Grade A Executives Get an F as Parents," observed that "children of successful executives are more likely to suffer a range of emotional and health problems than children of 'less successful' parents. For example, an Ann Arbor, Michigan study found that $36 \%$ of the children of executives undergo treatment for psychiatric or drug abuse each year versus $15 \%$ of nonexecutives in the same companies" (Senge 1990). Peter Senge, a noted management consultant, conducts leadership programs all over the country for executives. He reports that "finding balance between my work and my family" is cited as a number one priority by more attendees than any other single issue (Senge 1990). The Wall Street Journal even devotes a weekly column to this subject.

A frequent business lecturer mentions that workers are using information technology to shift the time and place in which they deal with electronic messages: 
When I give presentations on this subject, I ask people how many of them find themselves checking on voice mails after 10:00 p.m. About two-thirds of the hands go up. I worry about people who quickly shuffle young kids off to bed so they can log on to the company system. (Stuller 1996)

Another observer states that parents are spending forty percent less time with their children than they did thirty years ago (Thurow 1995; Turner 1996). A recent Catalyst survey found that sixty-four percent of senior female executives surveyed at Fortune 500 companies had families, and two-thirds of those had children under the age of eighteen (Lancaster 1996). Women executives are largely unavailable for community activities. Of top female executives in Fortune 500 companies, Sheila Wellington president of Catalyst, says, "They make very conscious choices about how they spend their time. Most talk about how they have two things in their lives-jobs and families-and they eliminate everything else" (Lancaster 1996). Eliminated activities include those related to environmental citizenship.

\section{Life Disruptions}

The U.S. workforce is moving steadily toward a 24-hours-a-day, seven-days-a-week economy, according to Harriet Presser (Kleiman 1996). She believes that standard work hours will soon be a notion from the past. These non-traditional hours are being created to benefit employers, not their workers, and will undoubtedly create havoc on the ability of workers to commit more easily to civic activities. Presser believes that the global economy, the need for round-the-clock health-care workers for the elderly, the growth of the service industry, and the need for evening and weekend services have created new demands and opportunities for the workforce. She found that in 1991, less than one-third of all employed Americans age eighteen and over regularly worked a standard work week-daytime employment, thirty to forty hours a week, Monday through Friday. She says that only fifty-five percent of U.S. workers are employed full-time during the day. Of those who worked nights and weekends, more than half said the only reason was that the job required it. The effects on female workers may become most pronounced because the projected growth in jobs over the next ten years is in occupations with high numbers of people working evenings, nights, and weekends, such as food service, clerks, and sales. 
There is a recent trend toward what management consultants term compressed work weeks-shortweek, extended-hours schedules. From 1985 to 1991 the U.S. Bureau of Labor Statistics reports that the proportion of full-time production and service workers with conventional eight-hour-a-day schedules had declined to 81.8 from 84.1 percent. There are no data since 1991 , but a private survey suggests that the trend is accelerating (Kilborn 1996). Labor unions see this trend as meaning "the week is being redistributed toward work; leisure is getting squeezed out," says Jerome M. Rosow, president of the Work in America Institute in White Plains, New York (Kilborn 1996).

At the Orlando Lucent Technologies factory, most office personnel work long shifts three consecutive days that total 34.5 hours one week and four days that total forty-six hours the next. Overtime is paid for anything over forty hours in one week. Everyone has one weekend day a week, Saturday or Sunday. Employees have to give up two holidays, Memorial Day and Labor Day, to make it all work out. The total of free days comprises one half the year off.

Workers appreciate the time off and the extra pay, but report being extremely tired. Many workers speak of a struggle to align the Lucent clock with the cycles of their personal lives. Tony Moreno, age 45, does not appreciate the extra time off. "I missed going to church. Being a family man, weekends mean a great deal to me. All my friends are off on weekends." Another unhappy worker is Martha Toler, age 34, who is single and the mother of a 9 -year-old boy and a 20 -month-old girl.

I'm a B-grade metals operator. I work the days, 5 to 5 . When I work I don't clean or cook. Everything's prepared already. I get up at 3:30. I get the baby ready to go to the sitter. We leave the house at 10 after 4 . She's dropped off at 4:30. I usually make it here 10 minutes before we have to start. Most people are in a daze. I've been more tired and more sick than ever before. I get upper respiratory infections. A lot is fatigue. I have back and foot problems. But I had to take the job that takes care of the kids. More money, more pain (Kilborn 1996).

Rosow of the Work in America Institute summarizes, "There's always been a tension in our society between work, family and leisure. I don't think industry plans its schedule around the leisure needs of the work force" (Kilborn 1996). The A.E. Staley Manufacturing Company in Decatur, Illinois, imposed one of the most extreme compressed workweek schedules on its labor force four years ago. It precipitated a thirty-month lockout before the workers finally gave in and returned to work. Staley's 
approach is known in management circles as "best cost scheduling." Under this concept people work twelve-hour shifts for three days and take three days off. They also work days half the month and nights half the month. Typically the schedules permit two Saturdays and one Sunday off one month and one Sunday and two Saturdays the next (Kilborn 1996). Clearly, such workers can accommodate little in the way of regular scheduling for participation in environmental decision making, being either too tired or unavailable.

In summary, work places major constraints on the amount and quality of people's discretionary time and attention. More people are working longer hours, seemingly by choice but in actuality with little recourse. Lives are harried and necessarily self focused. Responsibilities to their jobs of many of our most capable citizens prevent them from completely fulfilling their roles as citizens. Environmental issues are not neglected any more or less than other important issues; they all suffer equally.

\subsection{CONSUMERISM CONSTRAINTS}

The thesis of this subsection is that consumerism also constrains people's ability to meet the requirements of environmental citizenship. This ideology, if you will, is youth-oriented, antiauthoritarian, energetic, real-time, and consumption-oriented. Barber (1992) calls this the "MacWorld." Its relevant images are blue jeans, McDonalds, the MacIntosh computer, MTV, Madonna and Michael Jackson, and the Nike "Just Do It" advertising slogan. These values are consistent with behavioral decisions that are made to satisfy impulsive desires, and may have significant downsides (e.g., drug addition). These values are also consistent with distrust of large organizations and big government, difficult employer-employee relationships, disregard for the law, short-term economic horizons, and preferences for more free-flowing forms of social organization (Tonn and Schaffhauser, 1996).

Consumerism as a lifestyle takes time away from community pursuits and also requires time and effort to produce sufficient income to maintain the lifestyle. One indication that income is not keeping up with expectations is that America's personal savings as a percentage of disposable income has decreased from a high of eight percent to ten percent in the early 1980s to a fairly stable range over the past eight 
years of around four percent to five percent, i.e., a halving (The New York Times 1996). Another indication is that people are spending more time at work, as noted in the previous subsection.

In combination, consumerism has a dominant affect upon the range and flexibility of one's behavior. Schor (1992) observes:

The consumerism of the postwar era has not been without its effects on the way we use our time. As people became accustomed to the material rewards of prosperity, desires for leisure time were eroded. They increasingly looked to consumption to give satisfaction, even meaning, to their lives. In both the workplace and the horne, progress has repeatedly translated into more goods and services, rather than more free time. Employers channel productivity increases into additional income; housewives are led to use their labor-saving appliances to produce more goods and services. Consumerism traps us as we become habituated to the good life, emulate our neighbors, or just get caught up in the social pressures created by everyone else's choices. Work-and-spend has become a mutually reinforcing and powerful syndrome - a seamless web we somehow keep choosing, without even meaning to ...

The consumerism that took root in the 1920 s was premised on the idea of dissatisfaction. As much as one has, it is never enough. The implicit mentality is that the next purchase will yield happiness, and then the next. . . Consumerism turned out to be full of pitfalls-a vicious pattern of wanting and spending which failed to deliver on its promises.

The inability of the consumerist life style to create durable satisfaction can be seen in the syndrome of "keeping up with the Joneses." This competition is based on the fact that it is not the absolute level of consumption that matters, but how much one consumes relative to one's peers. The great English economist John Maynard Keynes made this distinction over 50 years ago: "[Needs] fall into 2 classes-those which are absolute in the sense that we feel them whatever the situation of our fellow human beings may be, and those which are relative only in that their satisfaction lifts us above, makes us feel superior to, our fellows." . .

Over time, keeping up with the Joneses becomes a real trap-because the Joneses also keep up with you. If everyone's income goes up by $10 \%$, then relative positions don't change at 
all. No satisfaction is gained. The more of our happiness we derive from comparisons with others, the less additional welfare we get from general increases in income-which is probably why happiness has failed to keep pace with economic growth. We may not even be aware that we are competing with the Joneses, or experience it as a competition. ...

In the choice between income and leisure, the quest for relative standing has biased us toward income. That's because status comparisons have been mostly around commoditiescars, clothing, houses, even second houses. . . . If free time is less of a "relative" good than other commodities, then true welfare could be gained by having more of it, and worrying less about what the Joneses are buying.

It is not easy to get off the income treadmill and into a new, more leisured life style. Mrs. Smith won't do it on her own, because it'll set her back in comparison to Mrs. Jones. And Mrs. Jones is just like Mrs. Smith. They are trapped in a classic Prisoner's Dilemma: both would be better off with more free time; but without cooperation, they will stick to the long hours, high consumption choice. We also know their employers won't initiate a shift to more leisure, because they prefer employees to work long hours.

Not only does consumerism require time to produce income, time is also needed to consume. It is particularly ironic that many people do not have enough time to consume. In Virginia, a state steeped in history and natural beauty, the most popular tourist attraction — far and away-is the Potomac Mills discount mall, thirty miles south of Washington, D.C. Other outlet malls around the country report similar record visitation. Pigeon Forge, home to 3,300 people, drew ten million visitors last year, one million more than the adjacent Smoky Mountain National Park (McDowell 1996). The Mall of America, outside of Minneapolis, drew forty million visitors in 1995, including twelve million tourists. The Travel Industry Association of America maintains that the most popular vacation activity is shopping (McDowell 1996). Part of the reason, again, is that vacations may be the only time that people have to shop.

The enormous success of the mail-order catalog business is an indicator of a population short on time. Trend-spotter Faith Popcorn explains, "Anything that can ease the strain of being over scheduled and over committed will find a market" (Pedersen 1996). As proof of this insight, consider what happened in 1995. For the first time in the country's history, Americans bought more gas barbecue grills (5.8 
million) than charcoal grills (5.3 million). The reason? Convenience, according to grill retailers. "What appeals to people is not having to wait," says a lawn and garden store manager in Houston (Verhovek 1996).

Consumer goods are not the only expenses dogging households. Compounding the effects of the workand-spend rat race is a new trend for middle class parents to seek private educations for their children, in part, as a means of bulletproofing them against future job insecurity. Typical private school applicants are no longer from wealthy families, as was the case only fifteen years ago. Around Boston independent private schools report enrollment is increasing at a rate of six to eight percent annually. Similar rates are reported in Florida and around Washington, D.C. (Kaufman 1996). Financing a private education for suburban, middle-class families is one more toll on the availability of parents for participation in environmental concerns:

The prospect of private school has ruled out any thoughts he and his wife had for a second child. Indeed, one reason why these parents can handle the tuition is that families are smaller. And many working couples with children nearing school age have become more accustomed to paying $\$ 15,000$ a year or more for child care. But even for many parents with good job security, private school bills are a stretch, squeezing budgets and requiring changes in lifestyle. "I never expected to be making two tuition payments for eight years even before my kids went to college," says Stanley Sdalak, a financial planner in Tolland [Conn.] who pays more than $\$ 30,000$ a year in tuition for his two children. [Kaufman 1996]

In an ironic commentary on American life, a national survey of American values found only a small fraction of respondents who said they would be significantly more satisfied with life if they had a nicer car, bigger house, or nicer things in their home. But a majority of Americans would apparently be much more satisfied if they were able to spend more time with family and friends (sixty-six percent rating eight or higher on a scale of one to ten) and if there was less stress in their lives (fifty-six percent rating eight or higher). Nearly half stated that they would be much more satisfied if they felt they were doing more to make a difference in their community (The Harwood Group 1995). This positive finding is an important element in several of the recommendations on how to improve environmental citizenship found in Section 6. 
What prevents people from satisfying these aspirations? What is keeping them away from family and friends, and causing stress in their lives? Trying to keep up or to get ahead, they say. 'I can't get it all to fit in right now as it is and keep it all straight. I've got work to do and I can't get it all done," commented a Los Angeles man. A woman in Los Angles also feels squeezed: "I work all the time. It's hard for me to have any spare time." With no time to spare, our non-material needs-such as family and community-become harder to fulfill. A Dallas woman explained, "That goes back to the fast pace because both parents are working and you have all this money but no time to slow down and enjoy it."

Despite the cost in time and stress, many people say they feel stuck on this treadmill-striving for material goals that seem ever-harder to attain. Much of that feeling of wanting more seems to come from comparing ourselves to others. A Los Angeles man agreed: "We go out to keep up with the guy that's across the street." People seem to believe this competition is unhealthy and unnecessary, but they get caught up in it nonetheless. Most focus group participants agree that money and possessions are not the main things lacking in their lives: "What we heard instead is that people seem to yearn for things money cannot buy: more time, less stress, a sense of balance."

None other than Adam Smith spoke to the baselessness of much of our current economic activity: "A profitable speculation is presented as a public good because growth will stimulate demand, and everywhere diffuse comfort and improvement. No patriot or man of feeling could therefore oppose it. [But] the nature of this growth, in opposition, for example, to older ideas such as cultivation, is that it is at once undirected and infinitely self-generating in the endless demand for all the useless things in the world" (Handy 1994).

Charles Handy, a world-famous management consultant, comments on Smith's observation:

Adam Smith, you should be alive today, to take a walk through the shopping malls or the tourist streets of our cities. You would see windows stacked high with trivia, with all the detritus of a throwaway society, where growth depends on persuading more and more people to buy more and more things they may want but can hardly need. Yet, without that induced demand, there wouldn't be the growth that would spread Adam Smith's "comfort and improvement" to those who really need it. We need our economies of glitz and sleaze to provide work of a sort for many of our people. 'Work of a sort' is, indeed, all that much of it 
can ever be. The best management in the world can't make meaningful work out of stacking shelves or packing boxes, or out of selling T-shirts, mugs or plastic toys, or even plastic food. This is toil and drudgery, not the decent work we demand as the right of all. It is toil done for money, the money that alone provides access to the rich economy we have promised ourselves. It is a strange irony, just one of many that itch away at our modern state. To give our people the necessities of modern life we have to spend more of our money and more of their time on the non-essentials, on the 'useless things,' the junk of life (Handy 1994).

Psychologist Mihaly Csikszentmihalyi believes that the sense of overload may have as much to do with too many choices as with too little time:

We're responding to the much richer set of challenges and options that are present now. We tend to think we have to read all the papers, watch all the news, take the kids to their games and fill up every moment. That's not something you have to do. The mix of stimuli we're exposed to is much broader and more insistent than before. If you let that run your life, you're surely going to feel more pressed (Sharp 1996).

The Merck Family Fund study (The Harwood Group 1995) found that once discussions move beyond recycling - an activity viewed as something that can be undertaken now-most people "seem to be waiting for somebody else to act first: their neighbors, big corporations, or the government." The study found a significant disconnect in people's views. Eighty-eight percent of the survey respondents believed that protecting the environment will require "major changes in the way we live." Yet people resist examining their own lifestyles too closely, with only fifty-one percent agreeing that "my own buying habits have a negative effect on the environment." In the focus groups, people recognized the contradiction in their thinking but were not sure what to do about it. An Indianapolis man explained, "We can all sit around here and talk till this time tomorrow about what should be done [about the environment], but would we do it? It goes back to selfishness-- 'I don't want to waste my time doing that."”

Despite their belief that our lifestyle must change, many people are skeptical of each other's willingness to take action. Lacking a collective sense that we are moving forward together, people sit and wait for someone else to act first. 
In summary, consumerism has a major impact on people's lives. They feel pressed for time and money. They feel guilty they don't spend more time with family, friends, and community. Many state that they believe their priorities may be misplaced. Even eminent social commentators portray the consumer lifestyle as rather fruitless and pointless. Breaking the cycle so that people can improve their environmental citizenship will be very difficult, but would yield a double bonus of reducing production, pollution, energy use, and natural resource depletions that generate environmental problems in the first place.

\subsection{SOCIAL CAPITAL CONSTRAINTS}

As discussed in Section 2.5, social networks are important for environmental citizenship. The thesis of this subsection is that numerous factors constrain the building of social networks, specifically, and the maintenance of strong communities, more generally. This subsection begins with a definition and discussion of the concept of social capital. It is argued that social capital is declining in the United States. Reasons for the decline include the mobility of the population, time pressures, lack of leadership, and economic stratification. All these factors act to constrain the development of social networks.

Harvard University political scientist Robert Putnam, originally a scholar of Italian regional politics, has turned his focus recently to U.S. civic life. He has examined social capital, by which is meant "the features of social life-networks, norms, and trust-that enable participants to act together more effectively to pursue shared objectives" (Putnam 1996). He also uses the term civic engagement to refer to people's connections with the life of their communities, not only with politics. Recent research on the sociology of economic development has focused attention on the role of social networks. The wellknown "network capitalism" of East Asia is perhaps not too dissimilar from the networks of collaboration exhibited in Silicon Valley. Putnam (1995) summarizes the meaning of social capital to vibrant communities: 
For a variety of reasons, life is easier in a community blessed with a substantial stock of social capital. In the first place, networks of civic engagement foster sturdy norms of generalized reciprocity and encourage the emergence of social trust. Such networks facilitate coordination and communication, amplify reputations, and thus allow dilemmas of collective action to be resolved. When economic and political negotiation is embedded in dense networks of social interaction, incentives for opportunism are reduced. At the same time, networks of civic engagement embody past success at collaboration, which can serve as a cultural template for future collaboration.

Putnam (1995) explains that tackling the social and economic ills that confront American cities involves investments in physical capital, financial capital, human capital, and social capital in a complementary manner. They are not competing alternatives. Numerous research studies show that investments in jobs and education, for example, will prove to be more effective when coupled with reinvigoration of community organizations. The flight of middle and working class families from inner cities largely eroded the social capital of those left behind. Putnam maintains that racial and class inequalities in access to social capital may be as devastating as inequalities in financial and human capital.

Putnam also argues that would-be citizens have taken on the mantle of "disgruntled claimant[s]" (i.e., frequently these are the people who call themselves "taxpayers") - as opposed to citizens working to define and enhance the public interest. Putnam notes (1996):

We are listening to each other less. We are shouting and pressuring and suing, but we are not reasoning together, not even in the attenuated sense that we once did, with people we know well and will meet again tomorrow. Financial capital grows in political importance, while social capital declines. To those Americans who have more money than time, this may seem a mere change in coinage, but the transformation is fundamentally debasing our society.

So, an indicator for the potential of environmental citizenship in a community might be targeted at measuring social capital. Potential candidate metrics might be participation in civic organizations, like the League of Women Voters, Kiwanis Club, Lions Club, and parent-teacher organizations. Other 
possibly valid indicators might include, as Putnam's data implied, some activities as seemingly whimsical as participation rates in league bowling. He explains (1995):

My claim, partly but not entirely tongue-in-cheek, [is] that the fate of the republic hangs on the fact that Americans are no longer engaging in league bowling. First, when you participate in a bowling league, interacting regularly with the same people week after week, you learn and practice what de Toqueville called 'habits of the heart.' You learn the personal virtues and skills that are the prerequisites for a democracy. Listening, for example. Taking notes. Keeping minutes. Taking responsibility for your views. That's what is different about league bowling versus bowling alone. Second, bowling leagues and sports clubs and town bands, whatever provide settings in which people can talk about their shared interests.

The classic example of political discourse in America is the New England town meeting. The erosion of community as represented by the quality of the national debate has inculcated this local institution. The deadening effect on potential local participation in environmental or other problem-solving is clear. In a report from Woodbridge, Connecticut, a Board of Finance member of this town of nine thousand explains the recent changes through her experiences with the annual spring ritual of budget hearings (Gross 1996):

These days, nothing about the process is appealing or uplifting. We do not sit as neighbors, questioning the merits of competing demands. We take on the demeanor of Newt Gingrich and pit bulls. Washington's nastiness and divisiveness have left the Beltway, drifted up I-95 and spread into our little red-brick community center, opposite the white clapboard Congressional church and manse.

What, then, arouses retired men in this former Republican stronghold to spew venom at the Board of Finance? Is it because Democrats are now in the majority? Because the First Selectwoman is a Democrat and a woman? Or, more likely, because of the mood in Washington?

Not many years ago, 300 to 400 people packed the hall. The questions were astute, difficult and relevant-most of the time. New residents introduced themselves and sometimes expressed pleasure in participating so directly in the democratic process. This year, barely $\mathbf{5 0}$ 
came to the preliminary meeting - and most were employees and officials who were there to answer questions. Some people who came in the spirit of civic pride were chased away within minutes by the hostile atmosphere. It doesn't have to be this way. If we can't keep cynicism from creeping into our view of national politics, we can at least keep it at bay in our towns. Unless we can return civility and honest disagreement to debate, and can focus on the issues and not indulge in personal assaults, grassroots democracy will turn to weeds, and spring will herald nothing more than warm weather.

In civil society, people construct arrangements of mutual cooperation based on commonly shared ideals, values, and goals. American society used to feel a greater sense of solidarity among ourselves. Americans were less willing to let others be left to their own fates. The dynamic present in American life currently is one of narrowing the "circle of caring" as Lerner (1996) calls it:

The flow of social energy tends toward smaller and smaller circles of caring; many of us imagine that we can build a good life by limiting our caring to the smallest possible arena-our immediate families. Yet much of what we want in the world-loving relationships, mutual recognition, friendships based on loyalty and commitment, physical and emotional safety, a sense of purpose and meaning for our lives-cannot be sustained in a world that is continually narrowing the circles of caring, because this very process of narrowing creates an ethos of selfishness that undermines loving relationships.

Francis Fukuyama (1995) has written recently on the economic effects of the erosion of trust in societies. His finding supports with Putnam's (and others') understanding of the role of social capital in sustaining prosperous communities. Fukuyama notes that the loss of social capital in the United States has more immediate consequences for American democracy than for the American economy. There is a lag before the latter becomes evident. He sees social capital as a ratchet that is "more easily turned in one direction than another; it can be dissipated by the actions of governments much more readily than those governments can build it up again." An implication of the art of association to urban sustainability is, according Fukuyama, that its inherent flexibility breeds economic benefits:

People who trust each other and are good at working with one another can adapt easily to new conditions and create appropriate new organizational forms. Globalization of the world economy has created new modes of marketing and production that have very different 
organizational requirements. No one at this point knows what the corporation of the early twenty-first century will look like. Whatever that form or organization turns out to be, however, will be discovered most quickly by societies that have a strong tradition of social cooperation. Conversely, societies that are riven with barriers of distrust, based on class, ethnicity, kinship, or other factors, will face extra roadblocks in their adoption of new organizational forms.

America's current malaise (Jimmy Carter's term; Bill Clinton calls it the national "funk") have at their heart two major concerns according to Harvard University government professor Michael Sandel (1996). The first chief source of our discontent is that we fear that, individually and collectively, we are losing control of the forces that govern our lives. The other is the sense that "from family to neighborhood to nation, the moral fabric of community is unraveling around us." Sandel calls for a square facing of issues, similar to the adaptive work described by Heifetz (see below): "If America is to recover its civic voice, it must find a way to debate questions we have forgotten how to ask." Sandel elaborates:
In recent decades the civic, or formative, aspect of our politics has given way to a procedural republic, concerned less with cultivating virtue than with enabling persons to choose their own values. For despite its appeal, the liberal vision of freedom lacks the civic resources to sustain self-government. The public philosophy by which we live cannot secure the liberty it promises, because it cannot inspire the sense of community and civic engagement that liberty requires.

Why is social capital declining? One reason is mobility. Americans are frequent movers. Bellah et al. (1985) observe that "the pressure to keep moving upward in a career often forces the middle-class individual, however reluctantly, to break the bonds of commitment forged with a community" and that 'the individual's need to be successful in work becomes the enemy of the need to find the meaning of one's work in service to others." Time commitments at work are certainly a big factor. In addition, frequent relocation of employees acts to split people from communities and prevent the development of ties that only time in a community can help establish. Thus, people often break ties to communitybased groups or simply do not grow ties in order to achieve economic goals. 
A second reason is lack of time, a topic which has already been mentioned and will continue to come up in this report. Job demands on executives (as well as others) are creating a society whose leaders have no time for anything but themselves and their work (Handy 1994). Dover, Massachusetts (a Boston suburb), and one of the country's most affluent communities, tried to put together seven little league teams in the spring of 1997 but could field only three. There were insufficient fathers available to coach all the teams. A local newspaper columnist (Ellis 1997) asks, "Where . . were the other fathers? What plans do they have in the spring that keep them from spending a few hours with their sons every week teaching them how to play baseball?"

Even when community organizations benefit from the participation of tired executives, they pay a price in the likely performance for setting strategy, clarifying discourse, arriving at creatively negotiated settlements, and thinking through arguments:

The symptoms of tired behavior are well established; it isfi't the bleary eyes or the dropping jaws; it is the imperative to make things simpler in order to operate. We do this by polarizing issues into black and white, right or wrong, no grays or in-betweens; we do it by stereotyping people and situations to fit them into familiar boxes which we know how to deal with; we shorten the time horizons and postpone all the difficult decisions until another day. When tired, we also talk rather than listen-it helps to keep us awake; we also let emotion rather than reason come to the fore, and to keep us going we look to drink and other stimulants (Handy 1994).

Thus, the lack of time factor leads into a third reason, lack of leadership. Making real progress on difficult problems in a community requires hard work on the behalf of a broad mixture of affected and concerned citizens willing, first of all, to face problems and their underlying contexts. Harvard psychiatrist Ronald Heifetz has studied the relationship between leadership and what he terms adaptive work (1994):

Adaptive work consists of the learning required to address conflicts in the values people hold, or to diminish the gap between the values people stand for and the reality they face. Adaptive work requires a change in values, beliefs, or behavior. The exposure and 
orchestration of conflict-internal contradictions-within individuals and constituencies provide the leverage for mobilizing people to learn new ways.

In this view, getting people to clarify what matters most, in what balance, with what trade-offs, becomes a central task. Values are shaped and refined by rubbing against real problems, and people interpret their problems according to the values they hold. Different values shed light on the different opportunities and facets of a situation. The implication is important: the inclusion of competing value perspectives may be essential to adaptive success.

As in human psychoses or other dysfunctional behavior, a community that chooses not to face its problems and not do the adaptive work of moving through and beyond them cannot long remain flexible, creative, and resilient. Its sustainability would be threatened at the core.

Leadership, which has long been linked to the exercise of authority or influence, usually suggests playing a prominent and coordinating role in an organization or society. To capture these uses of the term in a definition, we can use the word "mobilize," which connotes motivating, organizing, orienting and focusing attention.

Rather than define leadership as a position of authority or a social structure or as a personal set of characteristics, we may find it a great deal more useful to define leadership as an activity. This allows for leadership from multiple positions in a social structure. A President and a clerk can both lead. It also allows for the use of a variety of abilities depending on the demands of the culture and situation. Personal abilities are resources for leadership applied differently in different contexts. As we know, at times they are not applied at all. Many people never exercise leadership, even though they have the personal qualities we might commonly associate with it. By unhinging leadership from personality traits, we permit observations of the many different ways in which people exercise plenty of leadership everyday without "being leaders."

The common personalistic orientation to the term leadership, with its assumption that "leaders are born and not made," is quite dangerous. It fosters both self-delusion and irresponsibility. For those who consider themselves "born leaders," free of an orienting philosophy and strategy of leadership, their grandiosity is a set-up for a rude awakening and 
for blindly doing damage. Minimally, they can waste the time and effort of a community on projects that go, if not over a cliff, then at least in circles. Conversely, those who consider themselves "not leaders" escape responsibility for taking action, or for learning how to take action, when they see the need. In the face of critical problems, they say, "I'm not a leader, what can I do?"

So, we ought to focus on leadership as an activity--the activity of a citizen from any walk of life mobilizing people to do something. ... The hardest and most valuable task of leadership may be advancing goals and designing strategy that promote adaptive work. [author's emphasis]

Does this forsake the image of leadership as visionary activity? Not at all. It places emphasis on the act of giving clarity and articulation to a community's guiding values. Neither providing a map for the future that disregards value conflicts nor providing an easy way out that neglects the facts will suffice for leadership. Guiding values are interpreted in the context of problems demanding definition and action. People discover and respond to the future as much as they plan it. Those who lead have to learn from events and take advantage of the unplanned opportunities that events uncover. They have to improvise. (Heifetz 1994)

As mentioned above, time pressures constrain would-be leaders. Everyday stresses constrain people's ability to expend the effort needed to introspect, change their values, and deal with other people. As people move into and out of the community, experience is lost, perspectives are lost and/or change, and new people continually need to be brought into the group. Past a certain threshold, change of this sort makes community continuity difficult to maintain.

Leadership is also difficult in an unequal society. People in different strata may feel, or in fact be, constrained from communicating with each other, thereby reducing the potential for the development of rich social networks. Unfortunately, many observers of American society state that the US is becoming economically polarized. After presenting a few statistics to document the phenomenon, two ways in which economic stratification acts to reduce social capital will be discussed.

Former Secretary of Labor, Robert Reich, says that the top twenty percent of wage earners have done relatively well in the past twenty-five years while the earnings of the bottom quintile have stagnated in 
the same period. What is troubling to many is that in the twenty-five years before 1973 , median income more than doubled, with most of the gains going to this lower quintile. Two-thirds of the increase in U.S. national income during the 1980s accrued to the top one percent (Feenberg and Poterba 1992).

There is a worrisome threat in the U.S. economy that shows a decline in real earnings (1973 dollars adjusted for inflation) of the majority of workers along with increasingly unequal distribution of earnings among working people. In 1980 the gross hourly earnings of U.S. males close to the top of the earnings distribution exceeded those near the bottom by 4.8 to 1 ; by 1990 , however, the ratio had grown to 5.6 to 1 (Financial Times 1996). The real hourly wage of Americans without a high school diploma fell from $\$ 11.85$ an hour in 1973 to $\$ 8.64$ an hour in 1995 . In 1973 , the top five percent of U.S. households by income earned ten times more than those in the bottom five percent; in 1995, that differential was up to nearly fifteen times (Taylor 1996). Looking only at men with less than a high school degree there is a twenty-two percent decline in real incomes from 1979 to 1993. Once people come off welfare and become working poor, the issue of ability to climb out of their situation becomes a more durable, chronic problem (Holmes 1996). Their ability and propensity to participate in civic functions will likely remain minimal to none.

New research on income inequality has followed the same individuals for many years, permitting the interpretation to go beyond the typically reported research that shows rising income inequality. The findings suggest that as the economy stratified in the $1980 \mathrm{~s}$, workers at the bottom became less likely to move up in their lifetimes. For those with skills in high demand, those with higher educations and higher-end professionals, upward mobility is increasing. Bernstein (1996) reports that global competition, the declining influence of unions, and growing immigration have increased to more than twenty-five percent the group of workers whose earnings fall below the $\$ 15,000$ per year poverty line. There is probably another five to ten percent of the population who do not work at all. The unskilled and unqualified worker faces the probability of a continuing rapid decline in earnings relative to the rest of the labor market (Taylor 1996).

Decreasing mobility out of the bottom is even clearer by wage levels. Using the same definitions he employed for education, Bluestone and Rose (1997) found that men in the bottom fifth of wage-earners began to fare badly even in the 1970 s, when their ten-year average pay lagged inflation by eleven 
percent. But they fell out of bed completely in the $1980 \mathrm{~s}$, losing thirty-four percent. By contrast, men in the top fifth saw their ten-year pay soar by fifty-six percent in the $1980 \mathrm{~s}$, nearly twice as fast as their twenty-nine percent gain in the prior decade.

In the $1970 \mathrm{~s}$, the ten-year earnings of high school dropouts and graduates progressed at forty-five percent and forty-two percent, respectively. This was roughly the same as the fifty-three percent improvement in living standards that college graduates saw. In the 1980 s, however, less educated workers moved up much less than more educated ones. The ten-year average for dropouts' crept along at only fourteen percent, high school graduates by twenty percent, while college graduates continued to advance at a fifty-five percent pace.

Massachusetts Institute of Technology's Lester Thurow argues that for many in the United States, the education route no longer works. He argues that while wages of males with only a high school education are falling faster than the pay of those with college degrees, "investing in a college education doesn't get one off the down escalator-it merely slows one's descent"' (Thurow 1995).

Since 1970 more working women help many families offset the slump in men's earnings. But because people tend to marry at their own earnings level, low-income families have gained less. More poor families also are headed by single parents. Throughout the $1970 \mathrm{~s}$, though, the average inflationadjusted incomes of such families still advanced by sixteen percent. But the ride ended in the 1980s, and families in the bottom fifth moved down the economic ladder by four percent. Meanwhile, the upper fifth scored gains of more than sixty percent over both decades.

The end product of these shifts in income is that the middle-class has shrunk, from sixty-one percent of families in 1969 to fifty percent in 1992, according to the Economic Policy Institute. What makes the decline-perhaps, collapse-in upward mobility startling is that in prior decades the gains were so equitable. Census data on annual wages show that the incomes of families in the bottom fifth "actually rose faster-2.95\% a year-from 1947 to 1973 than those in the top fifth, whose incomes climbed by $2.48 \%$ a year" (Bernstein 1996). 
Lester Thurow (1995) believes that the current income disparities in the United States are without precedent:

No country without a revolution or a military defeat and subsequent occupation has ever experienced such a sharp shift in the distribution of earnings as America has in the last generation. At no other time have median wages of American men fallen for more than two decades. Never before have a majority of American workers suffered real wage reductions while the per capita domestic product was advancing.

One way that economic stratification damages social capital is through its tendency to dissolve families. Thurow argues that falling real wages have severely damaged the American family as the oneearner middle-class family becomes increasingly scarce (Thurow 1995). This demise is linked to the educational opportunities requisite to climbing the economic ladder. Educations are increasingly more costly and take ever-longer periods of time to complete just as families are increasingly more expensive to support and as earnings are plunging. Thurow reports that thirty-two percent of all men between twenty-five and thirty-four years of age earn less than the amount necessary to keep a family of four above the poverty line. A result of the nexus of these trends is that:

Men have a strong economic incentive to bail out of family responsibilities since when they do so their real standard of living rises by 73 percent-although that of the family left behind falls 42 percent. . . L Living thousands of miles apart, families lose track of one another. The family is no longer the social welfare system when one is disabled, old or sick, and it will not resume these duties even if the state were to withdraw. The traditional family is being destroyed not by misguided social welfare programs coming from Washington ... but by a modern economic system that is not congruent with "family values." [Thurow 1995]

In 1960, one American baby in twenty was born to an unmarried woman. By 1989 the figure was one in four. Many single mothers never marry or remarry. Those who do usually spend about six years as a single parent. Of the ten million women with children in father-absent homes, two-thirds receive no child support. The U.S. Bureau of the Census reports that in 1991, 50.8 percent of the nation's children lived in families with married biological parents and no one else. This also means that nearly half live in some other family relationship, such as single parents, step-parents, half-siblings, etc. This 
is a substantial change over the past two decades: in 1970, the number of children in so-called "nuclear" families was sixty-six percent, and in 1980 it was fifty-seven percent.

This begins to explain why so many people can feel so fearful and ungenerous, which can be referred to as the attitudinal effects of economic stratification. "Affirmative action, foreign aid, concern for immigrants-all these things start to look like someone else's generosity at your expense. What we've seen instead is an erosion of faith in the system, an unwillingness to trust the politicians or anyone else, a refusal to get excited about mutual sacrifices for the common good. It isn't that Americans no longer care about the common good but that they have lost faith in mutuality. They're afraid of being played for suckers" (Raspberry 1996).

Bernstein speaks to a possible implication of this phenornenon: "An increasingly class-segregated economy could one day hurt America's stable, centrist society. Already, the concepts of civic society and collective responsibility are fraying, as frustrated taxpayers lash out at Washington as the emblem of economic decline." If America continues to stratify, "you'd expect our democratic identity to diminish," says political science Professor Carey McWilliams of Rutgers University (as quoted in Bernstein 1996). "Some trapped on the bottom may explode with resentment. Some may succumb to apathy. Either way, all Americans will suffer."

In summary, social capital is a prerequisite for environmental citizenship, as exemplified through the development and maintenance of social networks. A high amount of social capital in a community allows discussions to be more civil, more focused on collective than individual concerns, and deeper in meaning. Mobility, time pressures, and lack of leadership impinge on social capital. Economic stratification may be the most pressing problem, though, as it combines with time pressures, anxieties, and growing resentments to produce a situation where the 'have-nots' will become openly hostile toward the 'haves,' a situation not conducive to civil peace or reasoned discussions about social issues, including those about the environment. 


\subsection{PERSONAL CONSTRAINTS}

Powerful personal constraints act to limit people's ability to become involved in environmental decision-making and other political processes. One reason is that people's natural inclinations may be hard to overcome. Verba and Nie (1972) classify people into six types with respect to public participation: the inactives, the voting specialists, the parochial participants, the communalists, the campaign activists, and the complete activists. It may be very difficult, nor is it necessarily desirable, to move some inactives to the complete activist category, if indeed innate personality factors play an important role in shaping political behavior.

In addition, many people fear public speaking, sticking their necks out in public, being labeled a rebel, and rocking the boat. In social situations, there are enormous pressures to conform. People intuitively feel society's tendencies towards intolerance, which cuts across ethnic, age, income, and class distinctions. In general, there are hazards of personal sacrifice associated with being ideologically driven and active in community decision-making processes.

Michael Lerner, editor of Tikkun magazine, has written of a political philosophy that he believes holds promise for the American future (Lerner 1996). He calls this the politics of meaning. He discusses the cynicism and sense of powerlessness many Americans have regarding their ability to effect change:

I contend we have also bought into a set of ideas about the nature of the world that makes us believe that nothing fundamental really can be changed. Consequently, quite apart from our real powerlessness, we also bring a certain amount of surplus powerlessness into each situation, making ourselves far less able to imagine ourselves changing reality than an impartial analysis of our relative powerlessness would yield.

Cynicism disempowers and powerlessness corrupts. Powerlessness makes us feel that we are going to get hurt by others who will overpower us and take advantage of us, unless we do it to them first. As a result, we are often ungenerous to others, whom we see as our competitors. We fear that to trust them will make us more vulnerable to manipulation and defeat of our own interests. But when this fear becomes widely shared, we find it impossible to mobilize people to defend one another's interests, leaving each of us with considerably 
less power than we might have had. Because most of us doubt the possibility of people standing strongly in solidarity with one another, we rarely think we can change much about the big picture of the economy or the realities of social and political life.

Lerner believes that many former participants in social movements are ready to commit to renewed activities if they believe in the possibility of building a more humane and loving society. "Having been burnt by past failures, these former activists will not quickly jump into new political movements" (Lerner 1996). He uses the antiwar activities of the 1960s as an example of the way circumstances align against a sense of viable action:

A classic case is the media's systematic lies and distortions about the meanings of the $1960 \mathrm{~s}$ in general and the movement to end the Vietnam War in particular. The repression of collective memory of the Vietnam War, the continuing refusal to acknowledge the millions of deaths caused by American intervention, and the inability to seriously confront the idealism of those millions of young people who protested at the time, have helped shape our current period and its despair. This enforced historical amnesia has made it impossible for anyone who lived through that period to integrate his or her own life with some larger sense of its historical meaning.

The media has [sic] developed a "master narrative" that focuses on momentary youthful enthusiasm and idealism, mixed with a distorting dose of sex, drugs, and rock and roll. Retrospectives define a generation's memories of itself, and how that generation quickly "grew up," recognized that it was on the wrong path, and except for a few dropouts and many drug-scarred casualties, went on to become a yuppified success story. Whenever a story is told about someone from the $1960 \mathrm{~s}$, that person is assimilated into the master narratives, and the parts that do not fit are ignored or denied. Measured against this media version, anyone who has remained committed to social change (and there are literally millions of baby boomers who are) must see herself or himself as an oddball who has no likely set of allies should she or he move from memory and fantasy to contemporary political action. Most often, however, it is not the specific political slant of any particular television show or movies, so much as the quashing of our sense of hopefulness and possibility, that makes the media a crucial meaning-deadener. 
Lerner claims that corporations and circumstances of modern life have also permitted Americans to be in a state of collective denial and unable to stay focused on environmental problems. He believes that most people are in such immediate pain in their lives (because of a lack of meaning in their lives) that they are unable to pay attention to larger but less pressing problems such as this. Lerner's (1996) sense of "surplus powerlessness" (above) is operative here, too: "I often have heard people tell me that they cannot imagine trying to deal with the ecological crisis because it seems to overwhelming. Meanwhile, they would go on to say, 'I can't even get my own personal life together; I've made such a mess of that. So until I get that together, don't expect me to deal with the big issues."'

Harvard psychiatrist Robert Coles has followed the lives of committed volunteers for more than three decades. He has recently pulled together some observations on the toll that active participation in service to others takes on the personal psyche. These are real problems that must be endured and possibly overcome by volunteers. In the case of environmental activists, many of these themes are known and feared, and may perhaps be perceived as reasons to avoid such service. So, they function as potentially real barriers to public participation.

Those answering their internal calls to serve others as activists urge that people know what the risks are and recognize that "the deck is stacked so high against you," that the wearing down is real, even when battles are being won (Coles 1993). Idealistic, youthful exuberance erodes, demanding a mature foundation to combat mental burnout. According to one of Coles' interviewees:

I'll get up some mornings, and I wonder what the point of it all is. I mean, will it make any difference? I know, I know the answer: yes, it will. But I don't feel it in my bones. It's not that I'm physically tired, no. It's upstairs, in my head. I'm sort of resigned. I'll stick with it, but I've lost something, some kind of hopeful, alive confidence. [In speaking of a colleague, the same interviewee notes] when he sighs a lot, and stares into space just a few seconds too long, even if it's only once or twice a day, then I know this guy is beginning to wonder whether his earlier expectations are going to come about, and whether he shouldn't be thinking of something else to do, some other way to be useful to this fight.

One of Coles' volunteers, discussed above, speaks to the emotional overbearance of the detailing of problems needing fixing in today's society that the media bring to us: 
There are days when I look at the New York Times or I read one of the magazines I get, and I wish I wasn't literate-I think I'm a fool for telling those kids about the glories of being able to peruse newspapers and periodicals and books. For what-so you can feel really down, because you know why you should feel down, and because you've been reading about twenty problems facing America that we haven't really decided to tackle the way we should and the way we could, and the way we do when there's a war facing us, or some disaster strikes, and everyone says let's fight back!

Coles remarks that the above and the following are sentiments he repeatedly hears:

Their talk is of uncertainty, of "reevaluation of objectives," of doubts about what is to be done. They speak about the need for rest and rehabilitation, for a "clearer formulation of procedures," for retreats where the participants would share their ongoing difficulties, their battle fatigue, their "tendency toward a more passive posture over time." The longer I listen to those "debriefings," those "breaks for reflection," the more I realize that even in communities where reasonably comfortable people are able to do reasonably conventional work without harassment, beatings, ostracism, or jailings, a measure of hesitation, of tiredness, of relative apathy can begin to take root. Of course there are fluctuations-a spell of the old, unqualified optimism will prevail yet again - but in all, many doing service comment on their second thoughts, their lagging interest in the work being done, their feelings of being winded or out of breath, footsore and just plain beaten.

Sometimes what starts as weariness becomes hardened into a form of cynicism-a doubtfulness about the world, about people and their possibilities. I use the word "cynicism" because I have heard others use it rather often, sometimes as an epithet directed squarely at themselves. Indeed, cynicism is often touted as "the enemy" by volunteers as they have given themselves to service but worry about the personal consequences. [As one volunteer describes this] "I'd begin to wonder, What's the use? Like that lady said, if you start asking that question too often, you're getting into some real trouble!" [Another volunteer speaks of a reaction to a newcomer to the cause] "He's full of ideals, idealism. He makes me feel like a first-class cynic. When I talk with him, I try to connect with him-connect with my own childhood. But the more I hear him, the happier I am that I've lost all that. I'm a little callous these days, maybe, and you lose something being like this, like I am, I know. But 
we're in a fight, and the fight is with a very cynical world, and if you don't have a little in you of what you're fighting in your enemy, then you stand to lose, that's what I guess I feel. The only problem is if you let your cynicism take over-you're down a road that could get you into some trouble that way."

Coles believes that when cynicism takes over, other emotions closely follow. Anger comes from defeats, anger at the moderate to liberal world. He notes that some feel an angry righteousness that can turn quickly into self-righteousness. In some volunteers this leads to heated scornfulness of colleagues. He has observed that some people "become all too attached to bitterness, to the constant inclination to put down others-thereby, of course, giving themselves a boost." After cynicism and anger can come despair. That theme is often mentioned in connection with despair: the volunteer believes that he or she will learn a lot, "get" a lot from the experience, but that what is being done will not amount to much.

A much more serious condition for volunteers is burnout, a factor reported by many people who were surveyed by Verba et al. (1995). Here the mood is less transitory and more burdensome. But any number of individuals who have talked of the despair they feel about a child or a grownup or a group they are working with have, alas, gone beyond such pessimism to a more pervasive and tenacious despair-of a kind that shapes their entire social outlook, their view of what is possible and what is impossible. The phrase "burnout" for many is a shorthand way of saying, "This work can become exhausting, and I am on the way to an exhausted state of mind, and once there, I will be 'burnt out,' worn down quite badly, and so not able to do the kind of service I formerly offered." Another volunteer expresses it differently: "The fun has gone out of it all, the surprises, too. And the cold, hard truth is that we're not making nearly as much of a difference as we'd hoped."

A civil rights activist comments:

You can get down without being in a state of burnout. The people who are burnt out are really wasted. They're depressed: they are in trouble the way you are when you are depressed! They're also pretty angry—and I think what happens is this: they become like the people they're fighting. They call each other names; they fight all the time; they've become victims now of each other. It's a pretty sad sight. You tell me, what comes first-the 
squabbling or the depression? Do we fight each other because we're tired and depressed, or do we get tired and depressed after we start forming our cliques and going after each other?

Coles (1993) relates a 1964 conference in which he heard Dr. Martin Luther King address the issue of burnout among activists. King called burnout a surrender:

We have just so much strength in us. If we give and give and give, we have less and less and less-and after a while, at a certain point, we're so weak and worn, we hoist up the flag of surrender. We surrender to the worst side of ourselves, and then we display that to others. We surrender to self-pity and to spite and to morose self-preoccupation. If you want to call it depression or burnout, well, all right. If you want to call it the triumph of sin-when our goodness has been knocked out from under us, well, all right. Whatever we say or think, this is arduous duty, doing this kind of work; to live out one's idealism brings with it hazards.

To the degree that people anticipate such hazards or experience the hazards personally, environmental citizenship will suffer and probably has suffered to a very large extent already.

\subsection{EDUCATION CONSTRAINTS}

As discussed in Section 2.1, education plays a very important role in building environmental citizenship capability. They need the desire to be educated and the educational system needs to have the capacity to meet the demand. To understand environmental issues, people need a general background in environmental topics. People also need a general background in science to be able to understand the technical aspects of environmental issues. Thus, constraints on scientific education and "scientific literacy," in the United States can also constrain environmental citizenship. Examination of this topic, and that of environmental literacy, represent the bulk of this subsection. This subsection concludes with the topic of constraints imposed by having too much information.

To begin, the scientifically-literate citizen has an important role to play from the view of the entire political system. That role is one of balancing expert opinion with more general public concerns. In a demanding, long Swiss case study, Webler et al. (1995) found that participants in the environmental 
decision-making process often laughed and made fun of the experts as Fachidioten (a German word which implies one-track expert competence, but ignorance of the big picture).

Theodore Roszak (1993), in a particularly heavy-handed criticism of American culture, had a straightforward view of experts that predated the O.J. Simpson trial by twenty-one years:

Does our democracy not continue to be a spectator sport in which the general public chooses up sides among contending groups of experts, looking on stupidly as the specialists exchange the facts and figures, debate the esoteric details, challenge one another's statistics and question one another's prognostications? It is difficult to see that, in the long run, such a counter-balancing of expertise can be a real victory for the democratic autonomy of ordinary citizens. They remain expert-dependent.

Others call for the general populace to become sufficiently scientifically literate to arrive at their own conclusions and to challenge the experts. Since we know this is a dead-end proposition, that it is unreasonable to expect the evolution of a fully, scientifically-literate public, judicious reliance on expert scientific advice seems the rational route. Shamos (1995) cautions that experts should be used:

$[\mathrm{N}]$ ot as surrogates for the public in determining the proper course of action on science/technology-based social issues, but as advisors on the purely technical aspects of such issues, from which the public might hopefully reach better-informed judgments. The problem is that in most cases experts have been called into adversarial, even confrontational, proceedings, often having political agendas as well-whether these be legal matters, community issues, in legislative hearings-and with opposing sides already drawn there is little chance of resolving the scientific issues among the experts beforehand. If there were an opportunity for the scientists to seek a common understanding before stating their positions publicly, many of the perceived differences might be settled early on. At the very least, one should expect that where differences still remain these could be spelled out in plain enough language so that nonexperts can make the final choice based on reasoned alternatives.

Scientific literacy is a concept that arose during the post-Sputnik discussion of the late 1950 s. Over the intervening decades it has, for social scientists, come to mean "an ability to cope with societal implications of science, from understanding what science does to exercising control over it" (Shamos 
1995). Shen (in Shamos 1995), a physicist-educator, distinguishes three forms of scientific literacy - practical, cultural, and civic-referring to the last of these as the "cornerstone of informed public policy." He says: "The aim of civic science literacy is to enable the citizen to become more aware of science and science-related issues so that he and his representatives can bring their common sense to bear upon these issues." Prewitt (in Shamos 1995) uses the interesting phrase "scientifically savvy" to describe the individual who acts "on the basis of a shrewd understanding of the deeper principles and structures that govern complex situations," asserting that "from the perspective of democratic practice, the notion of scientific literacy does not start with science itself. Rather, it starts at the point of interaction between science and society. My understanding of the scientifically savvy citizen -in contrast to the scientifically savvy parent, consumer, employee, or producer-is a person who understands how science and technology impinge upon public life."

Shamos (1995) would add that a scientifically literate person also needs to understand (1) the process of science, that is, a prescription for seeking out and organizing the factual information in the unique manner that is characteristic of science, and (2) the fundamental role played by theory in the practice of science. Specifically, Shamos (1995) describes scientific literacy as follows:

The individual knows something about the overall scientific enterprise. He or she is aware of some of the major conceptual schemes (the theories) that form the foundations of science, how they were arrived at, and why they are widely accepted, how science achieves order out of a random universe, and the role of experiment in science. This individual also appreciates the elements of scientific investigation, the importance of proper questioning, of analytical and deductive reasoning, of logical thought processes, and of reliance upon objective evidence.

Most people learn little science in school. On the other hand, those exposed to science in school "come out of school with an understanding of science that is to real science what arithmetic is to mathematics" (Holderness 1996). Even those who learn substantial science in school, forget most of it and have difficulty applying it to societal questions later in life. Shamos' estimate of the fraction of Americans who might qualify as true scientific literates is four to five percent of the adult population, nearly all being professional scientists or engineers. However, many individuals trained in science or engineering lack the skill or interest in societal matters to be able to contribute constructively to technical 
controversies affecting the public. Hence the fraction based on this group is likely to be less than three percent.

Reasons for such a low rate of scientific literacy are easy to hypothesize: children, especially young females, get turned off of mathematics and science in their middle years of K-12 education; it is not "cool" for kids to be "nerds;" there is a lack of trained science teachers; and there is a lack of science equipment in the schools. How much of the blame to place on the lack of desire on the part of the students and how much to place on the supply-side of the equation is unknown. In any case, Shamos concludes that with nearly one hundred years of trying to teach science as part of the general education curriculum, we have little to show in terms of a scientifically-literate populace. "Perhaps it is time to give up the idea that such literacy can be achieved merely by exposing all students to some form of compulsory science education, rigorous as that might be made, and hoping that enough of it sticks with them to make us a scientifically literate nation. There is no reason to believe this is feasible."

The story is probably similar with respect to environmental education. Only recently has the United States formally embarked upon a national effort in environmental education, as signified by the signing by President Bush of the 1990 National Environmental Education Act. As reported by Schmidt (1996), many efforts are underway to bring environmental issues into the schools and into textbooks on subjects like math, geography and history. There is much controversy, however, about the quality of the information being provided to teachers and students about the environment. Given the infancy of the efforts in the area of environmental education, it is probably a reasonable assumption that the percentage of the environmentally-literate population does not exceed, and is probably less than, the percentage of the scientifically-literate population.

The constraint can be considered serious if it severely impacts the quality of environmental decisionmaking processes and environmental citizenship. In other words, not every person in the United States needs to be scientifically and environmentally literate. The question then becomes, how many is enough? Shamos has pondered this question with regard to scientific literacy in book-length form.

The following graphs in Figure 3.1 denote estimates of the probability of the presence in any interactive, deliberative group of one or more scientific literates-however defined-to help inform and 


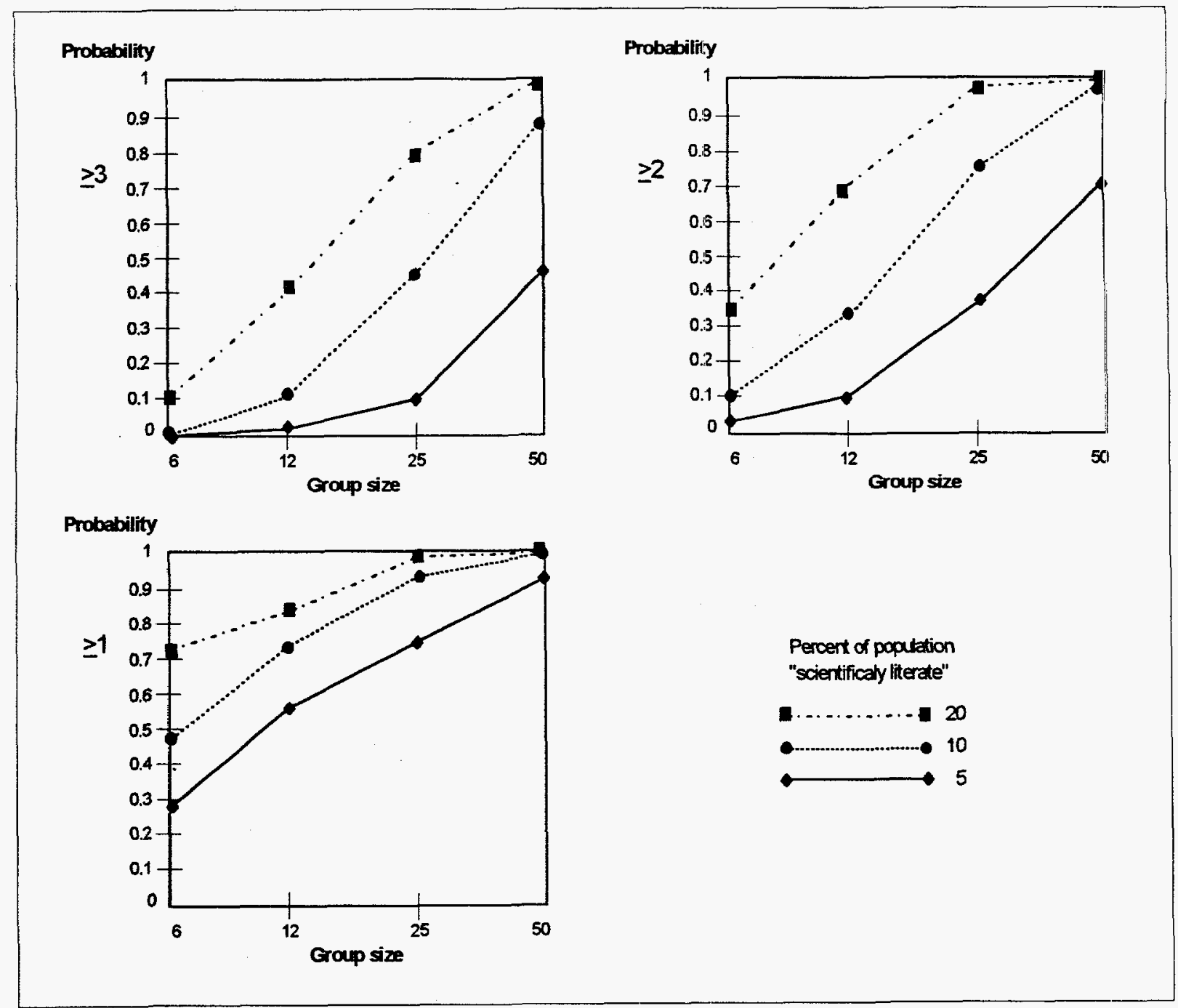

Figure 3.1 Assuming that three different percentages of the overall population are considered scientifically literate under some definition, the three graphs show what the probabilities are that at least one (or two or three) scientifically literate person(s) will be a participant in groups of the different sizes displayed. (after Shamos, 1995, The Myth of Scientific Literacy)

possibly guide the overall groups toward reasoned conclusions and actions on issues involving science or technology. This is not to say that people skilled in conflict resolution or gifted with a timely sense of humor would not be equally or more useful to any group, but that all are most helpful in meeting group objectives, doing adaptive work if necessary. These scientific literates would not be there as outside experts, who are often not trusted, but as fellow group members (colleagues, friends, neighbors) who happen to have some specialized-or general--knowledge that might bear on a topic 
under discussion. Individuals could help focus the group on the real issues and deflect unfounded rumor and speculation.

Using the graphs, one can see that in a community gathering of, say, six individuals, to discuss an environmental problem, there is only about a twenty-six percent chance that any one individual will be literate in science, or alternatively, only about one in four community gatherings would have anyone speaking up who is scientifically literate, given a scientifically literate base rate of five percent. Similarly, a jury would have only about a fifty-four percent chance (or one in every two impaneled juries) of having such expertise. Shamos (1995) draws some inferences from viewing the probabilities from this perspective:

[O]ne can easily see that for a typical randomly selected committee or panel, or any factfinding body numbering fewer than a dozen members, it is unlikely that anyone in the group will be competent to reach an objective independent judgment on a science-or technologybased issue, or to help fellow members form knowledgeable opinions on such matters. Thus, the conventional wisdom that to be manageable committees ought to be small may actually work to society's disadvantage when the committee's charge involves technical matters and the group is not specifically selected for expertise in the particular subject area being considered.

If as a society we were somehow to double the scientific literacy rate to about ten percent, one can see that scientific literates would still not be found in all reasonably-sized groups. Doubling it again, to twenty percent would nearly give us that guarantee. Even a six-member family group or civil jury would have about a seventy-four percent chance. But, to have a ninety-nine percent chance of having at least one scientifically literate person in a random group of twelve, such as on a jury, would require nearly a thirty-two percent national scientific literacy rate; for a group of six, it would take a national rate of about fifty-four percent.

Compounding this discussion is that the nature of group dynamics suggests that having only one scientifically-literate person in large groups of, say, fifty members may not satisfy society's needs. Having only one participant in a large group who is literate in science by our criterion, but is not a 
recognized expert on the particular issue being considered, will not necessarily comfort those members of the group who have a fixed contrary opinion based on rumor or personal belief. Having two such literates in the group would be more convincing, of course, provided they agree with each other. Should they not agree, as often happens when assessing the societal impact of technology, rather than having the group decision turn on their relative rhetorical skills, the preferable alternative would be a third such literate. While one is virtually certain of finding two or even three literates in a group of fifty individuals, given a scientific literacy rate of twenty percent, the probability remains poor of finding such representation in groups smaller than twelve.

The good news, of course, is that we do not need total scientific literacy to profoundly alter the way that society deals with technical matters. Only about a twenty percent national literacy rate would achieve this objective. The bad news is that it appears we have no better prospect of achieving this literacy rate than the total (one hundred percent) literacy everyone agrees is impossible. It should be noted, by the way, that a scientific literacy rate of twenty percent is very nearly the same as the percentage of college graduates in the U.S. adult population (twenty-five years old or older). (In 1996, the U.S. Department of Education reported that fifteen percent of the adult population have four-year degrees and another seven percent have advanced college degrees.) Hence, if all college graduates were literate in science, there would be no problem. Unfortunately, while they are a tempting target, we presently do not know how to motivate college students for such a formidable responsibility, any more than we do secondary school students. Nor do we know what minimum education in science and technology is actually needed to prepare them for this role in society. Considering that despite all of our efforts over the past half-century or so, we have not managed to budge the five percent literacy rate, this "twenty percent solution," enticing as it may seem, is likely illusory.

While it is desirable to have more people who are scientifically literate, it is also desirable to try to manage the potentially high volume of information that people receive. In the non-stop coverage of the Persian Gulf War by CNN television, we find an ironic twist in what wall-to-wall information about a real-time event does to cognition. Researchers found that knowledge of the facts of the conflict "varied inversely with the amount of time spent watching the coverage-that is, only $16 \%$ of light viewers mistakenly believed Kuwait was a democracy, a fraction that increased to $32 \%$ among heavy viewers" (McKibben 1992). Coping with "the rapidly changing future" by reading every news item or watching 
constant television accounts without taking the time to ponder meaning takes on a new interpretation given this Gulf War finding.

There are about 150,000 books published in the United States every year along with 10,000 periodicals. Electronic facts and figures and connections via the Internet and e-mail and their associated list servers mean people are swamped with data that expands every year. When people mention a book or magazine they have read we feel a sense of anxiety that we should know about it, too. This "information anxiety," as architect Richard Saul Wurman (1989) calls it, is produced by an everwidening gap between what we understand and what we think we should understand. It is another keeping-up-with-the-Joneses. Wurman calls this the black hole between data and knowledge, where information does not offer us the information that we want or need, and we are "inundated with facts but starved for understanding."

Compounding the information anxiety is the sense of a need to stay on top of it or fall disastrously behind in the competitive nature of work. Says John Cage, chief scientist of Sun Microsystems, one of Silicon Valley's top performing companies (Rapaport 1996): "The more information you get, and the more quickly you get it, the more likely you are to adapt and survive. It's like accelerating the evolutionary cycle. Speed is the only form of security." It may be that the best strategy for the average citizen to avoid information overload anxiety and stress induced by the speed of information technology is avoidance. Thus, paradoxically, the technology which can help people become scientifically and environmentally literate may work against, to a certain degree, improving environmental citizenship.

In summary, the typical citizen of the United States does not possess a high degree of scientific literacy, which can be argued is an important prerequisite for environmental literacy. One reason is that formal education in those areas falls short in the secondary and post-secondary schools. There is a general lack of interest on students' behalf, to be sure, but one could also hypothesize that few science course are designed to provide fundamentals related to environmental citizenship. In addition, Informal efforts may be dogged by a counter-intuitive problem, too much information of unknown credibility. 


\subsection{BUILT-ENVIRONMENT CONSTRAINTS}

The built environment contributes a constraining factor to environmental citizenship. The term built environment is being used to describe land use, building designs, and transportation systems. Mid-town Manhattan, with its high rises and subways, represents one type of built environment; San Jose, California, with its highways and single family homes, represents another. There are several ways that the built environment constrains human behavior. Of interest in this discussion are factors related to time use and social interactions. As has been shown above, constraints on time affect the amount of effort that can be devoted to environmental citizenship, and constraints on social interactions can damage social networks and social capital.

The 1990s have witnessed the suburbanization of the United States. For the first time in history, over fifty percent of the population lives in the suburbs. This is a landmark in a process of suburbanization fueled by the automobile, the interstate highway system, favorable financial incentives for home ownership, and anti-discriminary housing policies. As those who live in the suburbs, as well as in urban areas in general, can attest, the built environment constrains people's time simply by requiring ever increasing amounts of time to travel from place to place. The number of cars and car-miles driven is increasing, causing a great increase in traffic and associated delays. A typical commuter spends an average of ten forty-hour weeks in the car annually (Kay 1996). "We have traded time behind the wheel for space in the exurbs as workbound Americans travel back and forth from ever-more sprawling homes, " says Jayne Holtz Kay, architecture critic for The Nation.

\footnotetext{
... only one out of five of the miles we drive is spent on the round trip to work. Vacation travel, the other rationale, accounts for merely eight percent of the total on the odometer. For the most part, our 2,000-pound chariots are unceasingly performing more mundane chores: Chauffering and consuming-driving children to sports or buying a gallon of milk-use almost two-thirds of our vehicle miles, and hence our days and lives.
}

The car has had political consequences for those living in the San Fernando Valley. "You have to take a day off work to get to your local government," says Paula Boland, a Republican in the California Assembly who leads the secessionist charge. "You have your life endangered, and maybe you can park and maybe you can't" (The Economist 1996a). Many residents of the Valley never go downtown 
anyway. As a result, the San Fernando Valley is trying to secede from Los Angeles. An independent city of the San Frenando Valley would have more residents than Detroit, Dallas, or even New Hampshire. This is a powerful expression of the impact that the built environment can have on citizenship.

In addition to leading to more time spent on the roads, suburbanization has resulted in more socially sterile built environments. As has been documented in many places, the suburbs are generally devoid of pedestrian life, as workers commute to jobs in the central city or to work in office parks scattered around the central core. Children are off at school, participating in after school activities, or are in day care/after school care. Constant moving in and out of subdivisions reduces the already low social capital. Members of extended families rarely congregate even within a few miles of each other. There is little of the richness of the best of urban life described by Jane Jacobs in her seminal book, The Death and Life of Great American Cities (1961). Thus, the suburbanization of America has adversely affected people's ability to build, grow, and maintain the social relationships necessary for environmental citizenship.

It must also be noted that social capital is built in geographic-specific places. These are community gathering places, "homes away from home," where unrelated people interact with sufficient frequency that participants know one another. Sociologist Ray Oldenburg (1991) has studied the functions of these places-bars, cafes, beauty and barber shops, coffee shops, general stores-and calls them Great Good Places, or Third Places: neither home nor work. His research helped him to understand that when the good citizens of a community find places to spend pleasurable hours with one another for no specific or obvious purpose, there is purpose to such association. Further, the most important of the purposes or functions served by informal public gathering places cannot be supplied by any other agencies in the society.

The essential requirements of this Third Place include that:

It must be neutral ground; rank is forgotten there; conversation, rather than music or video games, is the central source of entertainment; it is frequented by a core group of regulars; and it fosters playful interpersonal exchange. In other words, it is the bar setting in the TV series "Cheers." 
In cities blessed with their own characteristic form of these Great Good Places, the stranger feels at home-nay, is at home-whereas in cities without them, even the native does not feel at home. Where urban growth proceeds with no indigenous version of a public gathering place proliferated along the way and integral in the lives of the people, the promise of the city is denied. Without such places, the urban area fails to nourish the kinds of relationships and the diversity of human contact that are the essence of the city. Deprived of these settings, people remain lonely within their crowds.

... America does not rank well on the dimension of her informal public life and less well now than in the past. Increasingly, her citizens are encouraged to find their relaxation, entertainment, companionship, even safety, almost entirely within the privacy of homes that have become more a retreat from society than a connection to it. In their kind and number, there has been a marked decline in gathering places near enough to people's homes to afford the easy access and familiar faces necessary to a vital informal public life. The course of urban development in America is pushing the individual toward that line separating proud independence from pitiable isolation, for it affords insufficient opportunity and encouragement to voluntary human contact. Daily life amid the new urban sprawl is like a grammar school without its recess periods, like incurring the aches and pains of a softball game without the fun of getting together for a few beers afterward. Both the joys of relaxing with people and the social solidarity that results from it are disappearing for want of settings that make them possible (Oldenburg 1991).

As a final speculative point, it is interesting to expand the definition of the built environment to include media space and cyberspace. Television, a human built technology that shapes the social environment, has already been implicated as a time waster and social isolator. National programming, on one hand, and the lack of local programming (due to high production costs per viewer) on the other, combine to reduce focus on community and signal a higher importance on national, but less influential issues. This situation tends, then, to reduce participation in local affairs.

Cyberspace, through its present incarnation, the Internet, can cut both ways. On the positive side, much information of value to capability building is available on the Internet. In addition, evidence to date suggests that cyberspace increases the magnitude of human communications (e.g., through e-mail, user groups, chat rooms). However, those communications are typically impersonal if not anonymous, 
shallow, and disjointed. Plus, few conversations take place within "communities" of people living in the same spatially defined communities. Thus, one can argue that cyberspace also works against environmental citizenship in the areas of identity, ideology, social networks, and effort. Cyberspace is still rapidly evolving and could prove a substantial benefit to improving environmental citizenship through the development of community enterprise systems (See Section 6.3).

In summary, the built environment can play a significantly positive or negative role vis-á-vis environmental citizenship. Suburbanization and sprawl can be negative factors simply by requiring increasing amounts of time for transportation, time that could be used to relieve other stresses in life and for environmental citizenship. More seriously, the built environment can act to keep people from developing social relationships necessary for community identity and social network development. The loss of great good places and the retreat of people to their homes only exacerbates difficulties in building social capital.

\subsection{SUMMARY}

This subsection provides a synthesis of the material presented in the previous six subsections, which discussed constraints on environmental citizenship resulting from work, consumerism, diminished social capital, personal predispositions, education, and the built environment. In combination, these constraints greatly influence the physical and psychological ability of people to meet environmental citizenship responsibilities. One area where three of the constraints-work, lifestyle, and built environment - converge most clearly is in the area of individual time use. A great deal of time is spent at work, and the aggregate amount per person spent at work in the United States is increasing through longer hours at work and increased participation in the labor force by women. Much time is spent in areas that fall under the rubric of consumerism-e.g., time spent shopping, eating away from home, watching TV and movies. Transporting oneself from place to place is requiring ever more amounts of time. Not forgotten is time spent with family and friends, home maintenance, cooking and cleaning, sleep, recreation and those hundreds of other activities that make up our daily lives. Thus, one conclusion is that there is precious little time to devote to environmental citizenship. Indeed, time was 
the leading reason reported by subjects in the Verba et al. (1995) study on why they did not participate in political activism.

The statistics in Table 3.1 bear this out. What seems like a reasonable allocation of time to various activities for any given day does not leave much or any time for environmental citizenship. Work and sleep account for approximately two-thirds of a typical day. Not much time is left for discretionary activity. Indeed, from the Verba et al. (1995) study, on average respondents gave 0.6 hours to campaigns, 1.7 hours to charity, and 0.9 hours to voluntary work per week.

Table 3.1. Typical time expenditures for 25- to 49-year-olds on a typical weekday. (Totals are based on logs kept by 12,000 participants for the same week over four years. Totals are per-day averages for a five-day week for those who participated in that activity; not all activities are tallied. [Source: Harry Balzar of the NPD Group, Rosemont, IL; Sharp, 1996, "So Many Lists, So Little Time," USA Weekend, March 15-17])

\begin{tabular}{|l|cr|rr|}
\hline \hline Daily Activity & \multicolumn{2}{|c|}{ With Kids } & \multicolumn{2}{c|}{ Without Kids } \\
\hline Sleeping & Men & Women & Men & Women \\
Bathroom/Dressing & $7: 39$ & $7: 36$ & $7: 09$ & $7: 32$ \\
Preparing Food & $: 54$ & $: 56$ & $: 55$ & $1: 02$ \\
Eating at Home & $: 47$ & $1: 07$ & $: 42$ & $: 50$ \\
Eating Away & $: 56$ & $: 59$ & $: 54$ & $: 53$ \\
In Transit & $: 55$ & $: 52$ & $: 58$ & $: 58$ \\
Working for Pay & $1: 27$ & $1: 25$ & $1: 23$ & $1: 22$ \\
Household Chores & $8: 12$ & $6: 35$ & $8: 34$ & $7: 37$ \\
Food Shopping/Errands & $1: 54$ & $1: 55$ & $1: 35$ & $1: 42$ \\
Non-Food Shopping & $: 58$ & $1: 05$ & $1: 02$ & $: 55$ \\
School/Class & $1: 24$ & $1: 23$ & $1: 16$ & $1: 14$ \\
Home Entertainment & $3: 40$ & $1: 54$ & $2: 15$ & $2: 40$ \\
Hobbies/Crafts & $2: 52$ & $2: 31$ & $2: 38$ & $2: 18$ \\
Exercise/Sports & $1: 52$ & $1: 40$ & $1: 51$ & $1: 26$ \\
Not Specified & $1: 29$ & $1: 24$ & $1: 06$ & $: 51$ \\
\hline
\end{tabular}


A second area where several of the constraints converge is in the area of human psychology. The most salient constraint here has to do with the powerful hazards of public participation to individuals in environmental decision-making processes. A lack of social capital and social networks can work to remove social supports that could help individuals overcome their fears. Not having a sound educational background in science and environmental matters can add to fears of being embarrassed at one's ignorance of important issues. At times, there may arise a conflict of interest for an individual when one's employer may be part of the environmental problem under consideration.

In addition to converging to cause an overreaching constraint to environmental citizenship, it must also be noted that the constraints also can have significant positive and negative feedbacks on one another. As has been discussed, work and life style can be insidiously related. Demand for more consumer goods creates a desire to work longer hours, which in turn creates demands for additional consumer goods designed to save time. Longer hours at work has to negatively impact the development and maintenance of social capital. Lifestyle preferences, such as for single family homes on large lots and for driving one's car instead of taking public transit, impact the built environment, which at its worst, impact one's time allocations, which in turn impact social capital and time spent on education. Thus, to overcome any constraint may require a concerted effort to simultaneously overcome several constraints at once.

Taken together, it is not hard to understand how these constraints can work to limit public participation in environmental decision making. After all, how many people can escape work-related pressures, change consumer-related behavior, live in supportive social environments with access to great good places, have the personal constitution to withstand the emotional pressures of environmental citizenship, have the educational background to positively contribute, and are not overly encumbered by the built "human" environment?

For the sake of exposition only, let's make some ball park assumptions about the percentages of people who could overcome each constraint. Maybe fifty percent of the adult population can overcome workrelated constraints, either because they are retired, are in school, or have flexible jobs. Maybe sixty percent of the population is concerned about the environment, a number which is consistent with 
findings by Brechin and Kempton (1994). Maybe thirty percent of the population live in an environment rich in social capital, given that over fifty percent of the population lives in the suburbs and given the loss of great good places in all social environments. Maybe fifty percent of the population has the emotional capability to actively participate in environmental decision-making processes. Instead of five percent, let's assume that ten percent of the population has the educational background to participate. Lastly, let's assume that fifty percent of the population is not overly encumbered by the built environment. Multiplying these numbers together results in 0.2 percent of the population being relatively unconstrained to participate in environmental decision making. This number is consistent with the findings of Verba et al. (1995) reported in the beginning of this section.

The point of this exercise is to show how a set of constraints can work to greatly reduce the percentage of the population that could most feasiblely overcome constraints. Much juggling of the numbers would be necessary to get the result even above the ten percent level (e.g., in one scenario, each number would have to be at least seventy percent!). The obvious conclusion is that much work is needed to reduce these constraints if citizens are to contribute to a healthy environment through participation in the decision-making process. 


\section{PUBLIC PARTICIPATION PROGRAMS: AN OVERVIEW}

Public participation in bureaucratic decision making is a relatively new field of study. It was not an issue in the early days of the United States. Back then government was quite limited in size and scope and the ideal of local self-governance was more attainable. According to Sandel (1996), the size and influence of U.S. government grew in tandem with the size and influence of the corporation. One could add that the activism of the federal government during the Great Depression, the expansion of government during World War II, the fighting of the Cold War through massive military and R\&D programs, the activism of government in the 1960s and 1970s, large increases in the U.S. population, and the explosive complexity of the global stage have all contributed to the growth of government in the United States. The overall size of government makes it difficult for individual citizens to believe that their contributions could ever make a difference.

In addition, Yates (1982) argues that how bureaucracies have come to be administered also has discouraged public participation. This is because the field of public administration has given efficiency paramount value. Bureaucracies have been designed and managed to "rationalize" decision making and expedite the delivery of services. Involving the public is not an important element of this classic model of bureaucratic behavior. Indeed, according to Sillince (1986), the bureaucratic model posits numerous problems with involving the public in administrative decision making. Specifically, public participation bypasses elected representatives; can raise public expectations to unattainable levels; creates time inefficiencies; and allows people who do not have the ability to understand complex issues to influence decision making.

For many years, the bureaucratic model flourished in the United States. Its heyday was probably in the first half of this century, which was marked by a trust in government, expert opinion, planning, and science and engineering. It is hard to pinpoint when attitudes began to change or identify the reasons for the change. As the United States heads into the twenty-first century, there is a deep cynicism about government (Gore 1994). Expert opinion is often ridiculed, planning departments no longer have a free hand to shape human environments, and scientists and engineers have lost their lofty perch. McKnight (1995) argues that it is a natural reaction to the over extension and impersonality of services in general, 
to the professionalization of society. Others blame government inefficiency. Still others will blame the haughty overconfidence of experts in selling science and technology, such as with the "wonders" of nuclear power or the presumed benefits of any new technology-based industry (Berry 1987). Suffice it to say, there is widespread distrust of experts and government alike, strong counter reactions to authoritarianism in all spheres of life, and an increase in political activism by the few, though not necessarily in public participation by the many.

In a new book on the power of multinational corporations, William Greider (1997) laments that today's political leaders are defaulting on making decisions about some of the great political issues of our times - the distribution of wealth and power within and among societies, the treatment of citizens, and human rights challenges. And where does the defaulted decision making end up? Private markets, for the most part, because of political leaders' sense of powerlessness, their neglect, or their ignorance. Jeffrey Garten, Dean of the Yale School of Management and former Undersecretary of Commerce, notes, "Surely it is a sad state of affairs when the marketplace is seen as a better place to sort out large public problems than the chambers and hallways of enlightened governments" (Garten 1997).

In response to the growth in national government, and the perceived unresponsiveness of government bureaucracy, an issue of popular discussion in recent years has been the potential for "direct democracy." For example, Newt Gingrich has called for an end to "professional government" because the problems of modern society are too complex and therefore they must be devolved and decentralized to "local citizens, local voluntary associations, and private businesses" (Gingrich 1995). Movements for term limits, and increased use of state initiatives and referenda are other manifestations of this trend.

The direct democracy movement has its detractors, despite the intuitive democratic appeal. For example, the populist experiment with term limits and citizen-legislators in the California State Legislature has resulted in the 1995 session being termed "probably the most mean-spirited and unproductive in memory, a unique combination of instability, bad behavior, political frenzy, and legislative paralysis" (Schrag 1996). 
One detractor commented: "We were all supposed to become full-time citizens, spending all our time at meetings. They tried it in Portugal after the 1974 revolution, with the result that the Communist Party almost came to power: a well-organized minority, with members prepared to stay at meetings until everyone else had gone home" (Mortimer 1996).

In a response to that proposition, a reader (von Uexkull 1996) commented with experiences similar to those described above:

Are most Americans really so "frustrated and intimidated by government" that they want to make all the decisions themselves? Gingrich's vision reminds me of the small leftist groups I used to know as a student. There, too, the state was always the enemy and citizens should decide for themselves. These groups tried to practice what they preached. The result was endless debate. Decisions were usually made by a fanatical minority who stayed at the meetings when everyone else had left due to other commitments. Gingrich's "opportunity society," where all are responsible for their own safety, will be an opportunity for such bullies to reassert themselves.

Another account of the downside of hyperdemocracy is equally pessimistic (Combs and Nimmo 1996), but points up the benefits in the form of social capital that may accrue with the current situation:

In the first instance researchers argued that, strictly speaking, if all citizens acted consistently as Good Citizens it might actually constitute a threat to democratic survival: How could a mass democracy work if all the people were deeply involved in politics? Lack of interests by some people is not without its benefits too. Extreme interest goes with extreme partisanship and might culminate in rigid fanaticism that could destroy democratic processes if generalized throughout the community. An important balance between action motivated by strong sentiments and action with little passion is, in practice, met by a distribution of voters rather than a homogeneous collection of "ideal" citizens.

What a blessing! And it is even more bountiful. When people are occupied by matters other than politics-mowing the lawn, coaching Little League, hitting the Las Vegas Strip, jostling about at Disney World, pigging out at McDonalds-there is a social bonding that lends stability to the polity. 
People in government are becoming aware of citizen attitudes toward government. In response to calls for more direct democracy and to improve their own operations, governments at all levels are working to involve citizens in their activities. Public participation is now seen as being able to produce "better" agency decisions under certain conditions (Phibbs 1996). Most public participation efforts focus on community and regional environmental issues and are implemented and managed by local and state governments, although U.S. government agencies such as the Department of Energy and the National Oceanic and Atmospheric Administration are also carrying out public participation programs (e.g., restoring the Florida Everglades: [U.S. GAO 1995]). A sizable literature exists to advise those responsible for environmental decision making on how to involve the public in environmental decisionmaking processes (see Thomas 1995; Howell, Olsen, and Olsen 1987).

The purpose of public participation is to promote the productive use of inputs and perceptions from private citizens and public interest groups to ultimately improve the quality of decision making. Peelle (1988) defines success in a public participation process as "any outcome which reduces conflict between stakeholders and agency proponents and results in a legitimate and lasting decision." Some of the success factors that Peelle and Farhar (1995) have identified include early involvement of the public; inclusiveness in stakeholder involvement; adequate information; two-way communication; sufficient resources (funding as well as logistical support) and time for the public participation process; availability of mechanisms other than public meetings; degree of citizen control; incentives and/or compensation; prior citizen education; etc. Most of these are dealt with here in terms of the implications of their deficiencies. Peelle et al. (1996) also identified the need for project or program managers to take charge of the public participation process through use of "iterative, intensive, interactive involvement between internal and external stakeholders."

Many of the essential factors for public participation success in agency settings emerge from personal commitments of agency managers within either a mandated public participation process or permissiveness (toward public participation) agency environment. In these cases, managers and project leaders perform additional nonmandated public participation to overcome bureaucratic inertia and constraints against meaningful involvement with outside non-expert stakeholders. Agency managers and staff can only proceed in this manner when their managers and bureau chiefs encourage or permit these activities that contravene 
hierarchical imperatives and the usual proscriptions against non-hierarchical inputs and activities (Peelle et al. 1996).

A failed public participation process can affect further effective participation on the part of any stakeholders. Citizens can become skeptical and confused rather than better informed. They can begin to believe (or have the idea reinforced or affirmed) that public officials are incompetent, insincere, or too wedded to hiding behind technical detail. Similarly, officials could go away with the belief that citizens are poorly informed, uncooperative, unreliable, or merely obstructive to process progress.

Below, ideas found in this field, drawing on the work of Peelle et al. (1996), as well as ideas found in the field of planning, are summarized into six general categories of public participation methods.

\subsection{INFORMATION DISTRIBUTION}

In the spirit of Jefferson, most public participation programs encompass some form of information distribution. The working hypothesis in such organizations is that an educated public will both be better able to assist agencies in making better decisions and better able to understand an agency's sophisticated technical rationales. Information that routinely is distributed covers agency programs (e.g., outlining the goals of the program, providing eligibility requirements), the outputs of agency studies, and proposed and final agency rule-makings. Information distribution methods are numerous, and include brochures placed in public spaces or mailed directly to citizens; bill inserts; print and television commercials; reports; videos; store-front offices where the public can have questions answered and pick up materials; toll-free telephone numbers; and more recently, home pages on the Internet.

Most information distribution activities are ad hoc. Yates (1982) recommends the establishment of an Office of Public Service within large bureaucracies. With respect to information dissemination, the office would "make an inventory of tasks performed and programs supplied by a department" and provide this information to the widest possible audience. 


\subsection{RESPONSIVENESS TO PUBLIC}

It is important for agencies to acknowledge public concerns and to avoid providing the appearance of being beyond the reach of ordinary citizens, as was Kafka's Castle. Agencies need to respond to public complaints; Yates (1982) suggests that the Office of Public Service offer ombudsman services to the public, to process complaints and grievances that are usually handled informally. Prompt and friendly citizen services (often described using the misnomer "customer" services), special efforts to meet public needs, and direct and visible involvement of top management (e.g., through television interviews, speeches, and editorials) are all ways to be more responsive to the public.

\subsection{COMMUNICATION WITH PUBLIC}

Information distribution and responsiveness are important, but still fall short of actual communication between an agency and its stakeholders. Tools such as surveys and focus groups are ways of allowing citizens to communicate with the agencies. However, the ultimate goal is two-way communication. Agencies need to establish processes to foster communication. Public hearings, town hall meetings (and now electronic town hall meetings), electronic mail and discussion groups, and workshops offer venues for two-way communication. A general theory of agency-citizen communication is known as transactive planning (Friedmann 1973). This process is needed when planners or other technical types who possess relatively abstract and mathematical knowledge need to communicate with citizens who have more practical and operational knowledge. To overcome this potential communications problem, much dialogue, reciprocity, mutual obligation, commitment and partaking in the interests of others is needed.

Agencies also need to learn how to communicate technical information. Communication of risk information has drawn a great deal of attention (e.g., Covello, von Winterfeld, and Slovic 1986). Use of graphics, colors, and other methods are active areas of research. 


\subsection{ADVOCACY OF PUBLIC INTERESTS}

Citizens want to feel as though their government acts to satisfy their interests and the public interest as opposed to bureaucratic interests. Within the planning field, this process is known as advocacy planning (Davidoff 1973). Within this paradigm, choices remain in the public purview and their determination is open to public participation. All interest groups ought to be represented in the process. At times, planners might need to "advocate" value positions for those unable to participate in the decision-making process. Along these lines, Yates' (1982) Office of Public Service would be the home of citizen advocates within the agency, and would "create a network of communication with interests of all kinds-mayors, women's groups, neighborhood groups, chambers of commerce, public interest groups, and so forth-so as to stimulate open debate about policy in the bureaucracy."

Within the field of public participation, achieving the goal of representation is extraordinarily difficult. Often, it is unclear who ought to be represented. With respect to environmental issues, it is conceivable that in some situations the people from around the world may have a stake in the preservation of a rare ecological resource. Another difficult question is how to represent future generations in the public participation process. Ideas to overcome this problem include a proposed Guardian to represent posterity's interests (United Nations 1992); a Council for Posterity, which has been formed in the United Kingdom; and the proposed establishment of the Court of Generations (Tonn 1991).

\subsection{BUILDING TRUST}

Citizens need to trust agencies. Building trust is painstaking and time consuming; losing trust is relatively simple and quick. Trust is built through honesty and openness. Maintaining an air of openness within the agency, clearly stating public participation goals, and clearly stating stakeholder roles are all ways to help an agency build trust (Peelle et al. 1996). Kasperson (1986) states that the public needs to be involved early in the process and on a continual basis. Accurate and timely information distributed as effectively as possible, obvious and sincere responsiveness, direct and effective two-way communications, and consistent and clear advocacy of the public interest also help to build trust. 
Citizens who do not trust agencies will be less likely to participate. They will be less forthcoming and less cooperative. They will be skeptical of efforts to rebuild trust. Their cynicism can be counterproductive, even going so far as to sabotage the process. Several federal agencies have persistent public image problems despite vigorous efforts to rebuild trust with their constituents.

\subsection{PROCESS AND POWER SHARING}

Probably the most difficult challenge for agencies is to simply let the public participate in decisionmaking processes. Citizen advisory boards and citizen working groups are common ways to directly bring into the decision-making process citizen concerns, without ceding decision authority to the public. Citizen juries (Crosby 1995, Armour 1995) and values juries (Brown, Peterson, and Tonn 1995) are methods to allow the public to share in decision making. The direct democracy movement in general seeks to move citizens closer to making their own decisions.

\subsection{SUMMARY}

The most natural response to the issue of public participation by government agencies is to ignore it. The goals of perceived short-term expediency and efficiency are likely to be seen as compromised, otherwise. However, due to changes in society and concomitant changes in public attitudes and expectations, public participation is being taken more seriously by all levels of government. There are numerous options opẹn to government to achieve this goal, as outlined above. 


\section{CITIZENSHIP, PUBLIC PARTICIPATION, AND GOVERNANCE: A DISCONNECT}

This section explores the question of whether public participation programs directly support the kinds of efforts citizens could make to become better citizens. In other words, do public participation programs help citizens: build their citizenship capabilities; establish identities; craft their ideologies; better understand governance; construct and maintain social networks; and facilitate and reward effort? Do these programs help people overcome the constraints discussed in Section 3 ? The balance of this section discusses how the six modes of public participation either support or do not support each requirement of citizenship introduced in Section 2.

\subsection{CAPABILITY DISCONNECT}

Information campaigns and special attempts to communicate complex risk information can help educate citizens about environmental problems confronting agencies and their communities, and therefore, help citizens build citizenship capability. To the extent that these types of programs also work to educate citizens on more fundamental matters, such as how to read maps, how to interpret statistics (e.g., to help overcome various biases detailed by Kahneman, Slovic, and Tversky 1982), and how to behave in public meetings, working groups, and advisory panels, these programs can do an exceptional job in capability building. Unfortunately, these latter types of activities are not common.

At times, an agency's best intentions do not help citizens improve their capacity for environmental citizenship. In two proposed federal actions, one to provide long-term stewardship of the stockpile of weapons-grade enriched uranium and the other to examine final disposition of weapons-grade fissile materials no longer needed by the nation, an Oak Ridge, Tennessee, environmental watchdog group complained that DOE simultaneously issued two voluminous draft documents on the unrelated activities without providing adequate time for public study before convening back-to-back public meetings to elicit comment (Williams 1996). The criticism also included the DOE's choice of meeting rooms as being among the smallest in the town. 
In the case of a proposed in-situ (solution) uranium mine in New Mexico, language difficulties impeded community education and participation in public hearings and in drafting formal responses to draft documents (Reitz 1995). Most elderly Navajos do not speak or read English; the majority of younger Navajos are not highly educated, nor is English typically their first language. As one commentator at a public meeting asked, "We need to have correct translation for words like 'half-life.' How do you translate 'half-life?' Half a person, half alive, half dead? But radioactive, chemical, how do you translate those?" (Tilden 1995).

Obtaining copies of draft documents involved another difficulty for citizens in this remote area of New Mexico (Reitz 1995):

The information in the Draft Environmental Impact Statement has not been widely distributed nor readily available on request. Enclosed is a copy of each of the addresses from which 1 requested three copies of the DEIS. Only three of these resulted in a response. Two of these resources told me I would have to pay approximately $\$ 20.00$ each for copying, plus mailing expenses, and I would have to make a day-time long-distance phone call to arrange to have the copies sent to me. Thirty dollars is not a reasonable expense for most citizens in Crownpoint. Ultimately, the NRC sent me three copies free of charge, but I was told that there were not many copies available for distribution. I called on January 5th, 1995, and received the copies three weeks later.

There are several other goals that public participation programs typically do not achieve. One is continuous education. Raising a theme that is repeatedly mentioned below, public participation programs revolve around very specific issues facing an agency. When the issue reins, then the agency gears up its public participation programs. When the agency perceives the problem is solved or has diminished in importance, the public participation programs also gear down. Agencies do not generally engage in long-term, continual programs to provide information, communicate with the public, and assist citizens in building fundamental capabilities to participate in environmental decision-making processes. The agencies rarely form partnerships with educational institutions at any level to provide citizenship-based education, either formally or informally. Lastly, the partitioning of the nation's problems into agencies for the environment, housing, commerce, and science, as examples, tends to limit the ability and motivation of any one agency to explain the entirety of any problem to the public, 
much less work hard to mentor the public in an interdisciplinary manner about the systems aspects of environmental problems.

\subsection{IDENTITY DISCONNECT}

Advocacy, trust building, and process and power sharing programs have the capability to create feelings of belonging to a group within a citizenry. Each activity acts to create positive bonds between an agency and citizens. Sharing the power to make decisions helps to empower citizens and facilitates feelings of ownership for the problem and the eventual solutions.

Can these activities be a sufficient complement to other identity building forces in culture and society to overcome the numerous forces that act to destroy feelings of identity in modern America? Can the vast majority of citizens ever feel sufficient identity to contribute as citizens to solving environmental problems facing their communities? The sporadic nature of the public participation efforts works against these two goals. Identity is best fostered through continuous ties that become internalized within the psyche. The multi-jurisdictional nature of environmental problems also works against these two goals. This is because the jurisdictional boundaries act to divide people with respect to political criteria rather than unite people with the purpose of solving environmental problems. In addition, in multijurisdictional situations, where authority is shared or in question, it is more difficult for leaders to provide a unifying focal point for identity-building efforts.

\subsection{IDEOLOGY DISCONNECT}

In so far as agencies distribute materials that represent different viewpoints, seek to learn about and advocate a range of constituent interests, and facilitate wide-ranging discussion on important matters, then agencies can help citizens develop, examine, reflect on, and nurture their ideologies. Given that most agencies do not engage in these activities well or often, they do not significantly help citizens in the area of ideology development. 
One could argue that agencies have incentives not to help citizens develop strong ideologies. From the viewpoint of an agency, a public that possesses strong and diverse ideologies will be disagreeable, argumentative, conflict-oriented, and prone to legal challenges. At the very least, this means delay and inefficiency. Ideology development also needs continuous attention, not sporadic attention associated with a pressing agency environmental problem, time schedule, and budget. Thus, agencies are not necessarily predisposed to assist people in the area of ideology development.

It must also be pointed out that most agencies are not capable of providing such leadership. The task requires the patience of a good teacher and the wisdom of Solomon. Agencies are not practiced at leading philosophical discussions or leading adaptive work processes, using the terminology of Heifetz (1994). It might be difficult balancing ideology development in others with maintaining a stable ideology or culture within an agency needed for effective organizational decision making. Heads of agencies are not elected representatives, and it might be presumptuous for agencies to take such a strong position in the community. In summary, helping citizens develop the ideologies needed to anchor their contributions in environmental decision-making processes is not a task easily undertaken or achieved by agencies and their public participation programs, nor necessarily a proper task for government (as opposed to schools, NGOs, and other forums for learning).

\subsection{MENTAL MODELS OF GOVERNANCE DISCONNECT}

Every major type of public participation program can help people understand how an agency governs. Information can be distributed to inform citizens about how programs work, how to become involved, how to comment on pending proposals, and advise them on what will happen when. Responses to the public can further explain reasoning and modus operandi. Two-way communications can do the same. Significant aspects of advocacy and trust-building processes involve educating people about the process. Finally, implementing processes to share power with citizens requires that citizens understand the processes, the timing, and their roles.

A major problem that an agency may have in helping people understand governance is dealing with models of governance that are at odds with the agency staff's own mental model of governance. The 
staff cannot necessarily be expected to teach what they do not understand, practice and/or believe in. Of course, citizens do not have to rely on government to provide information on governance and different potential models of decision making. However, a second major problem arises when there is a disconnect between the model being implemented by an agency and alternative models that citizens believe ought to be applied to address a problem. If the agency and citizens clearly understand what models each thinks ought to be implemented, then maybe a reasonable discussion can be held to choose what model to implement. If there is any doubt or confusion about the models themselves, the entire process may dissolve into confusion marked by frequent miscommunication and mistaken expectations.

As an example, in an action regarding the previously described New Mexico in situ uranium mining project, the notification of a site visit by the Nuclear Regulatory Commission staff was to be made in the local newspapers of record ten days before the visit (Brenner 1995). Apparently the NRC placed a notice in the Federal Register, all it is required by its regulations to do. Of course, few if any Navajos - or any other constituent group-are frequent readers of the Federal Register.

For agencies to help people understand other potential government processes, agencies first need to broaden their definitions of governance. They need to understand when to implement conflict management processes and when to work problems in the traditional administrative fashion. Understanding clearly what type of model to apply, and when, will help to prevent confusion about an agency's role in governance, and allow it to more confidently help citizens understand and apply the different models of governance.

\subsection{SOCIAL NETWORKING DISCONNECT}

Social networks are conduits for communication and cooperation among people. To the extent that communication, advocacy, trust building, and process and power-sharing programs create and solidify communication avenues and build cooperation among citizens and between the agency and citizens, then these programs will be successful in helping people build social networks. 
Even if agencies do a respectable job in these four program areas, their efforts can still be improved upon with respect to helping citizens build and maintain social networks. Maintaining networks is a key problem. If a network is built around a specific environmentall issue, with an agency as the hub of the network, then when the problem goes away, the network among the citizens may be weakened or destroyed. If an agency is to be a hub, then it has to be engaged continuously in a network designed to tackle all manner of issues over time. Agencies can have a most challenging time defending even the most modest budget requests for maintaining a given network once the "heat of the moment" for various pressing, high visibility issues passes. Creating such a hub or even fostering a network is usually difficult for an agency because it typically offers no place for communication and discussion. City Hall is not the usual gathering place for citizens seeking casual talk, a cup of coffee, or a quick sit-down with neighbors.

An even more challenging problem relates to the need, perceived or real, for governments to be distanced from politics. The main concern is that politics and rational administrative decision making do not mix. The risk is that special interests will overwhelm the public interest if agencies become too involved or have to be too involved with the community at large. Indeed, it is the case that many agency decision makers would prefer that politics not influence their decision making. To the extent that politics and social networks are intertwined, and one can make the case that they are intimately intertwined, one can conclude that agencies have a philosophical incentive to stand apart from social networks. To the degree that this conclusion is true, one could also conclude that agencies would have little interest in helping citizens build social networks to address environmental issues in their communities.

\subsection{EFFORT DISCONNECT}

To foster citizen effort, barriers need to be reduced and expenditures of effort need to be rewarded. It takes effort to attend the right and sufficient number of meetings, whether or not the meetings are held during working hours or after work, or convened in City Hall or in different locations in the community. It takes effort to acquire and carefully study the relevant materials that describe the environmental problem and potential solutions under consideration. For many, it takes a great deal of 
effort to communicate in public settings and risk the alienation of fellow citizens. It takes effort to overcome cynicism, to bear stress and anxiety that may arise in conflicting situations, to appreciate others' viewpoints, and to change one's mind. Many citizens who understand what level of effort is needed to have a positive influence on the process may judge that the minimum effort required is so great that it is not in their best interests, given other considerations in their lives, to participate. Because of the extraordinary effort needed by common citizens to participate in agency decisionmaking processes, the trend is for "professional citizens" to attend the meetings, present the arguments, and in other ways represent their slice of the public interest. Agencies are working toward lowering the effort threshold (e.g., by providing information and communicating with citizens through electronic means), but much more can be done.

With respect to rewards, every time an agency responds to a public inquiry or complaint, it rewards a citizen's effort. Every instance where an agency listens to citizens' worries, communicates that the concerns have been understood, and acts positively on citizens' suggestions, citizens' efforts are rewarded. When agencies share decision-making authority with citizens, citizens' efforts are rewarded. Thus, the potential is there for agencies to reward citizens' efforts in a meaningful fashion.

\subsection{SUMMARY}

As noted in Section 4, there have been numerous public participation success stories. That does not mean, however, that these programs were successful at improving environmental citizenship capabilities of the few participants and the much higher number of non-participants. Public participation programs support actions that citizens can undertake to make themselves better citizens only to a limited extent. Some programs can be educational, and some can foster identity and ideology development. Agencies naturally want to explain to citizens their model of governance. They will help create temporary social networks around an issue. They have the potential to reward citizens' efforts to become involved.

Several features of the way public participation programs are conceptualized and agencies are designed significantly impede their helping citizens become more involved and responsible. The sporadic, 
problem-oriented nature of public participation programs constrains education, identity building, ideology development, and social network maintenance. Agency incentives to achieve their decisionmaking goals work against attempts in the areas of ideology development, diversifying models of government, and allowing substantial citizen involvement and effort. The tendency for agencies to want to stand apart from the public impinges identity development and the creation and maintenance of social networks. The models adopted by agencies to accomplish their work and the people they employ are not conducive to long-term efforts in the areas of citizen capability development, ideology development, and social network development. Progress in helping to create be better citizens risks bureaucratic confusion about modus operandi and loss of control. Yates (1982) sees continual conflict between the goal of bureaucratic efficiency and the populist roots of the United States. 


\section{RECOMMENDATIONS}

The question addressed in this section is: what can be done to improve environmental citizenship in the United States? People face numerous constraints to building their citizenship capabilities and finding the time and attention required for effective citizenship efforts. Government participation programs, while many time successful from an agency viewpoint, do not often help people become better citizens.

Fortunately, to improve environmental citizenship, there are numerous initiatives that can be undertaken by citizens, employers, government, NGOs, and other organizations, which are described in Sections $6.1,6.2,6.3$, and 6.4 , respectively. To continue one major theme of this research, many of these initiatives are not directly related to environmental issues, but can be seen as necessary to improve citizenship and governance with respect to all issues before the public, including environmental issues. The majority of the recommendations can be implemented individually, although in many cases, there is value-added in implementing related citizen, employer, and government activities. Many of the recommendations do entail economic costs, especially to employers and government. Taken as a set, the recommendations call for substantial changes in the attitudes and behaviors of citizens, and in the concepts and operations of work-places and government. Whether the changes might, on balance, be beneficial is addressed at some length in Section 7.

\subsection{CITIZEN INITIATIVES}

The challenge here is to develop recommendations that link citizens' concerns about the environment to changes in behavior related to improving their involvement in environmental issues. A Merck Family Fund study in 1995 (The Harwood Group) concluded with four key findings in this regard:

1. Americans believe our priorities are out-of-whack. People of all backgrounds share certain fundamental concerns about the values they see driving our society. They believe materialism, greed, and selfishness increasingly dominate American life, crowding out a more meaningful set of values centered on family, responsibility, and community. People 
express a strong desire for a greater sense of balance in their lives-not to repudiate material gain, but to bring it more into proportion with the nonmaterial rewards of life.

2. Americans are alarmed about the future. People feel that the material side of the American Dream is spinning out of control, that the effort to keep up with the Joneses is increasingly unhealthy and destructive: "The Joneses is killing me," declared a man in one focus group. People are particularly concerned about the implications of our skewed priorities for children and future generations-they see worse trouble ahead if we fail to change course.

3. Americans are ambivalent about what to do. Most people express strong ambivalence about making changes in their own lives and in our society. They want to have financial security and live in material comfort, but their deepest aspirations are non-material ones. People also struggle to reconcile their condemnation of other Americans' choices on consumption with their core belief in the freedom to live as we choose. Thus, while people may want to act on their concerns, they are paralyzed by the tensions and contradictions embedded in their own beliefs. In turn, they shy away from examining too closely, not only their own behavior, but that of others.

4. Americans see the environment as connected to these concerns-in general terms. People perceive a connection between the amount we buy and consume and their concerns about environmental damage, but their understanding of the link is somewhat vague and general. People have not thought deeply about the ecological implications of their own lifestyles; yet there is an intuitive sense that our propensity for "more, more, more" is unsustainable.

Lemer (1996) reports that his surveys and research reveal that middle Americans often experience more stress from feeling that they are wasting their lives doing meaningless work than from feeling that they are not making enough money. He found middle-income people are deeply unhappy because they hunger to serve the common good and to contribute something with their talents and energies, yet find that work gives them little opportunity to do so. They often turn to demands for more money as a compensation for a life that otherwise feels frustrating and empty.

It should also be noted that the majority of Americans favor policies to protect the environment. As reported in Brechin and Kempton (1994), a Gallup survey found that fifty-one of Americans believed 
that environmental problems are a very serious concern for the nation and eighty-five percent believed that environmental problems are a very serious concern to them(Dunlap, Gallup, and Gallup 1992). Concern over water, forests, and air topped the list. To continue, fifty-nine percent favored environmental protection over economic growth and sixty-five percent favored higher prices to protect the environment. In a Harris survey also reported by Brechin and Kempton (1994), eighty-one percent of the subjects stated that they would be willing to pay more taxes for environmental protection. As an aside, Schwartz (1991) sees environmentalism as a strong movement among the billions of people who will pass through their teens in the 1990s. Indeed, Brechin and Kempton (1994) found strong environmentalism in both developed and developing countries.

As noted in Section 2.3, conflicting ideology has the potential to thwart effective citizenship. Indeed, it appears that a powerful obstacle to active environmental citizenship is rooted in the American sense of freedom and choice; people are strongly opposed to impinging upon the freedom of themselves and others to live as they choose. Because to a large, but not complete, degree results of environmental citizenship efforts may indeed result in new regulations and restricted freedoms, this ideological conflict is real. This country's double-edged sword is: "a high sense of personal responsibility, independent initiative and volunteerism;" on one side and on the other side, "self serving behavior, atomism and a disregard for communal good" (Pinkerton 1996).

The Harwood Group (1995) continues:

Despite their criticism of others' materialism and greed, people are reluctant to say anything about it, to hold one another responsible. "We have a social responsibility to do certain things to help move things along," said a Frederick man. Yet they have difficulty applying this principle beyond the doors of their own households; they don't know how to hold one another responsible anymore. "People have either lost interest [or] their community doesn't help," said a Dallas woman. Another Dallas woman explained what seems to have changed: "You used to feel responsible for your neighbors and friends. We don't anymore; people are afraid. They just don't want to get involved." A critical challenge for moving ahead on this issue will be to find a way for people to come out of their houses and talk about what is going on-about the values they want their communities to live by. 
Individualism versus communitarianism is only one source of ideological conflict. Competition versus collaboration is another. Consumerism versus thrift is a third. Work versus family and community is a fourth. The list can go on. The point is that these conflicts need to be resolved in favor of environmental citizenship if citizens are to meet their responsibilities in our democracy.

Here are seven recommendations: adaptive work; downshift lifestyles; make personal investments; change built-environment preferences; pursue life-long education; find environmental citizenship mentors; and engage in community commitment.

\section{Adaptive Work}

For the vast majority of individuals who are fully capable of becoming involved in environmental issues but who do not get involved, it is not a simple matter to change their ways. Many are locked into the work-consume cycle, find themselves isolated in their communities, and know they lack the capability to participate effectively. To devote time to citizenship capability building and actual involvement, they may need to address difficult economic and personal trade-offs and sacrifices, as based on their current ideologies and values. These need not be all or nothing decisions, but decisions not to work overtime, not to relocate, and not to accept shift work, for example, so as to have time, maintain social networks, and have predictable schedules within which to fit citizenship activities can be quite significant.

Heifetz (1994) would argue that adaptive work would be needed as a precursor to making such significant decisions. With regard to individuals, adaptive work would involve reflecting upon what is important, one's self identity, and the role of money and consumer goods in one's life. It can be a very trying process for a competitive, career-oriented person to, first, admit that those values conflict with maybe stronger values related to community and commitment, and second, to consciously alter what may be habitual competitive and career-oriented behavior. It can be just as trying for a person living in a low-income ghetto who believes he is on the margins of society, may be functionally illiterate, and has a low self-image, to summon the effort and self-assurance to fight for environmental justice, while also literally fighting for survival. 
It is quite difficult to undertake adaptive work alone, although the results of adaptive work are found in changes in individual values and behavior. As described next, finding mentors can help. NGOs can also provide assistance, as noted in Section 6.4. It can be argued that adaptive work is required before many people will undertake any of the recommendations in this subsection.

\section{Citizenship Mentors}

Mentorship is an extremely important member of the recommendation set. Mentors can help lead would-be environmental citizens through the potentially wrenching process of adaptive work. They can describe the psychological benefits of citizenship. They can provide unconditional self-regard to compensate for potential losses of self-regard due to changing one's values and behaviors. They can just be there. People need to work hard to find such valuable mentors.

Mentorship is also a form of education. Only so much can be learned in class and through books. People need to augment their theoretical knowledge with first-hand, practical experience. As mentioned in Section 3.4, being actively involved in political activities can be personally trying, even if one has a good idea about how the processes work and what role one can play in the processes. Having a mentor to help one to become involved, to explain the "real" workings of governance, to assist in developing ideology, to meet and deal with the personal challenges, and to keep situations and emotions in perspective is an excellent way to overcome the fears and anxieties of environmental citizenship. Thus, it is recommended that novices to environmental decision-making processes, be they in their teens or sixties, find people to act as mentors. It is also recommended that the educational establishment and local governments facilitate mentoring through educational programs and on-line programs (discussed more in Section 6.3).

\section{Downshift Lifestyles}

An important result of an intensive, personal adaptive-work initiative undertaken to improve environmental citizenship is a decision to change lifestyles to free up time and attention. Such a decision means not competing with the Joneses. It means breaking the cycle of consumption, debt, more work, less discretionary time, more consumption, etc. It means changing consumption habits and deciding to work less. This also means possibly foregoing the consumption of some entertainment, mainly some television watching, in order to free up personal time. 
In conjunction with moving away from consumer-oriented, work-intensive lifestyles, people need to have an idea of what their adaptive work efforts are moving them towards. A desire to improve their environmental citizenship, while certainly laudable, may not be a sufficient reason to motivate significant lifestyle changes. Indeed, people will need a guiding ideology as the underpinning of such lifestyle changes. If a person does not have such an ideology, a catch- 22 situation could exist, where a lifestyle change is needed to allow people the time and reflection to develop ideology, but a strong ideology is needed to guide the lifestyle change.

In any case, taking a positive view, one approach people can take is to adopt an ideology that stresses simplicity in life. The term "voluntary simplicity" was coined by Gregg (1936) and popularized by Elgin and Mitchell (1976). The latter describe five basic values that form the heart of the concept: material simplicity; human scale; self-determination; ecological awareness; and personal growth. The basic values map well to the prerequisites of environmental citizenship. Self-determination and personal growth relate to capability building. Human scale connotes community identity and social networks. Ecological awareness requires efforts to learn and get involved. Finally, material simplicity, although not the driving motive behind this recommendation, can help to lessen environmental problems facing their communities, the country, and the planet.

It may be that changes in lifestyle and efforts to simplify allow people to free up only a few hours per week, but even an extra three or four hours per week will allow people to significantly improve their environmental citizenship. Employers can also help to free up time, as discussed in Section 6.2. The extra time can be used for capability building, learning about government, building social networks, expending effort, and possibly providing the leadership needed to help their community solve environmental problems.

Because in current American society personal well-being and sense of worth are so intimately tied to one's material belongings and job and because money does provide the ability to influence politics, voluntary simplicity is a particularly difficult decision. Nevertheless, about four percent of baby boomers have opted to "downshift," or to personally cut back on their paychecks in order to have more time with their families (Beamon 1996). That downshifting is a legitimate social phenomenon is 
reflected by the fact that there is a two-year-old newsletter with 1,100 subscribers devoted to the issue (The Boston Globe 1997).

Flex-time arrangements or part-time schedules are freeing up some managers, while others are working as consultants or for multiple employers. With the lower pay comes a voluntary choice to downsize homes to bring them into line with new realities. Used cars and even second-hand clothes can follow. It is unclear whether these downshifters have reallocated some of their time to environmental citizenship, but presumably they now have more of an opportunity to do so.

\section{Personal Investment}

A downshifted lifestyle needs to be complemented by other behaviors designed to prevent life disruptions that draw attention inward and away from community concerns. Threats of unemployment and loss of income are salient regardless of how much time someone puts in on the job. Indeed, personal savings rates are falling (down from twenty-four to nineteen percent of gross domestic product between 1977 and 1992 [Thurow 1997]). Thus, it is recommended that people increase their savings for those rainy days so that paying off debt is not the driving force behind one's strivings.

In Section 3.3, it was noted that growing income disparities at a national level lead to dissolution of families. Increased personal investments in education and skill development can help to improve income, as well as environmental citizenship skills.

\section{Built-Environment Preferences}

In addition to reducing overall consumption, people can demand a different built environment, one that increases the potential for community belongingness and the development of social networks, and acts to reduce unnecessary time devoted to transportation. An improved built environment could possess the following characteristics: higher residential densities; more urban environments; mixed-income housing; mixed land uses, including more opportunities for employment in neighborhood settings (see also Section 6.2); innovative great good places; and more opportunities for walking, jogging, and other activities that allow people to see and interact with each other. Changes in the built environment can then lead to changes in the transportation system to reduce commuting time and other time spent on the 
road. Finally, changes in the built environment can reduce stress on the environment and use of natural resources, which in turn can help reduce the severity of environmental issues facing the community.

\section{Life-long Environmental Education}

Continual education is another key recommendation. By education, we do not mean that more people must obtain their GEDs or college degrees or undertake additional job training. Life-long education with respect to environmental citizenship is not so degree-oriented and economically utilitarian. Instead, people can take specific classes to improve their environmental citizenship capabilities, in areas such as interpreting charts and graphs, basic principles of environmental science, and working in groups. People can attend seminars and/or organize informal groups to discuss government, ideology, and the latest books on the environment and society. To satisfy the tendency of Americans to be goal-directed and achievement-oriented, it is also recommended that governments (or NGOs) establish a environmental citizenship certificate programs to reward people for making the effort to become better environmental citizens. This idea is discussed more in Section 6.3.

\section{Community Commitment}

People need to commit themselves to their communities. In most instances, this means that people need to commit to those communities in which they live. This does not also preclude concerns about issues at the state, regional, national, or global levels. Commitment is important to foster community identity; its relationship to environmental citizenship was discussed in Section 2.2. Commitment makes it easier to build the social networks and expend the required effort.

Commitment can be difficult to muster. People may know they will be moving in a short period of time. They may aspire to live in other communities. They may be new residents without a sense of the community and its inhabitants. To overcome these and other problems, people need to adopt an ideology about community and commitment that makes it possible to see beyond immediate individual needs. Such an ideology might include the following:

- strong communities benefit their inhabitants;

- members need to commit to their community for it to be strong, to build up the requisite social capital; 
- all communities undergo change as people leave and join the community; few people in the United States live in only one community their entire lives, and even if they do, the community may change so significantly over time that one could argue that they indeed did live in several different communities;

- because change is inevitable, people ought to address it squarely;

- people committed to the community ought to make newcomers feel welcome and eager to become involved;

- newcomers to a community ought to believe that they will be accepted into the community; and,

- commitment to the community, no matter how short in duration, is better than no commitment at all.

\subsection{EMPLOYER INITIATIVES}

In Section 3, work was implicated as a major source of constraints to environmental citizenship. Employers are described as working their employees too long and hard, requiring employees to work life-disrupting schedules, and transferring them from place to place. The ever present threat of downsizing causes anxiety and tends to keep employees' attention on work rather on other aspects of life. Given this story, is there any evidence that employers can support citizenship in general and environmental citizenship in particular? In addition, what can employers do to specifically support environmental citizenship?

The answer to the first question is that there are numerous corporate efforts in the area of citizenship. The renewed call for volunteerism among the corporate world has won praise from President Clinton's "Summit For America's Future." Corporate leaders have promised both funds and time off for their employees to participate. One-third of large companies have some sort of formal policy to pay workers or give them time off for performing volunteer work (Jones 1997). Some employees, however, question if this call for volunteer activities won't create "yet another burden to the already stressed corporate citizen" (Neuborne 1997). Employees who have feit downsizing affect their job loads believe such 
cutbacks have violated the unwritten social contract between workers and their companies. The result can be a dulled desire to give more of their time-whether paid or not-in the name of the corporation.

But this is not the whole story. In her recent dissertation for a doctorate in sociology from Boston University, Maria Poarch recounts interviews that she conducted with 200 "ordinary" Americans as part of a research project on middle-class morality. Her interviewees in suburbs of Boston, Atlanta, Tulsa, and San Diego described their real sense of membership as being not in their neighborhoods or subdivisions, or even in their churches, but rather their meaningful social ties were with their co-workers, whom they typically know much better than their neighbors. They expressed a sincere concern and desire to want to help the less advantaged, but their lives were packed solid with their family and work responsibilities. As Poarch (1997) puts it:

It is not the spirit of caring that is missing in America, but our understanding of how to use it. To make civic engagement work today, our efforts must engage people where they feel most collectively empowered. For a great many, this lies in the organizations where they work. Just as family issues have invaded the workplace, so have matters of community. By placing work organizations at the center of our civic initiatives, the power of our caring can be harnessed to address complex social problems.

If considered from an organizational perspective, civic engagement centered in work can benefit both society and business. Some of today's fastest growing and most effective volunteer service organizations, such as Habitat for Humanity and Boston Cares, recruit volunteers directly from workplaces. They also develop volunteer opportunities that cohere with the schedules and interests of working adults.

Some corporations report that joining the volunteerism bandwagon pays off in higher worker morale and strong consumer approval (Jones 1997). “A 1997 Cone/Roper survey of 2000 consumers shows $76 \%$ will switch to brands of stores that seem concerned about the community, up 14 percentage points from three years ago. . . Workers who volunteer at something they find meaningful return to work more fulfilled and motivated, and with ties to the community, which stunts turnover and helps recruitment" (Jones 1997). Poarch (1997) reports that civic engagement that centers in work can help heal the pains and alleviate the stresses of the downsizing phenomenon. She found that 
company-centered civic engagement can ease such insecurities by repairing trust and loyalty in novel ways. LensCrafters' CEO, Dave Brown, has his staff regularly survey employees and customers on their satisfaction. He has found, as Poarch suggests, that workers who participate in the firm's volunteer programs are "noticeably more satisfied with their jobs, and customers of those stores are noticeably more satisfied with the service" (Jones 1997).

Poarch (1997) reports that workers with knowledge and special skills are looking for more than financial carrots to lure their loyalty: "Other organizations will always be able to offer higher salaries, but they may not be able to offer a particular community, social identity, or vehicle for civic engagement. By investing in workers' social concerns, an organization generates loyalty."

Companies are also realizing the benefits of aligning volunteerism with skills and interests inherent in their workforce (Jones 1997). More than 150 workers from five Home Depot stores in the Los Angeles area pitched in to renovate a Long Beach women's shelter. A district manager of one of the participating stores says that when customers ask about a product, Home Depot employees can often tell them they have personally used the product on a recent volunteer project and can then offer tips beyond those advertised in the product literature.

Company leaders and shareholders alike have found that corporate volunteerism is remembered not just by consumers, but also by legislators, regulators, and even juries. As Bob Goodwin, CEO of the Points of Light Foundation, says, "Many companies subscribe to the unofficial idea that you have to make deposits in the bank of goodwill in order to make withdrawals when the company is faced with a difficult situation" (Jones 1997). Harvard Business School's Rosabeth Moss Kanter sounds a similar theme (Leonard 1997): "I don't think it's cynical to say businesses have a stake in enlightened self-interest. When you can tap a real business motivation into corporate values and a desire for civic involvement, that's real power."

Large corporations appear to be abandoning their old strategy of spreading their charitable moneys widely and thinly for a more strategic approach, one that targets investing in "fewer high-impact projects that provides a specific, even measurable benefit to both the community and the company" (Leonard 1997). This objective can be taken to extremes that engender cynicism in customers and 
employees. In the 1980s, American Express named the phenomenon "cause-related marketing." It can aggressively drive product promotions, profits, and public relations. Charitable-giving budgets used to be determined in the CEO's office, often based on the seemingly arbitrary whims of senior management and given with a paternalistic "Here's your money and a pat on the head" (Leonard 1997). While the total amount of corporate charitable giving has remained approximately constant at $\$ 7.5$ billion over the last decade, the amounts now budgeted out of corporate marketing departments are over $\$ 1$ billion, up from only $\$ 200$ million in 1984 .

Some fear that strategic charitable giving will benefit the big, popular charities at the expense of smaller groups or of those who support controversial causes. Corporations have learned that employees must perceive that volunteer work undertaken in the company's name is worthwhile for the company to win their respect. A brief accounting of how some major corporations are supporting volunteerism follows and illustrates innovations that let employees help chcose projects (Point of Light Foundation 1997).

Through its Helping Hands program, Allstate Insurance encourages families and friends to join them in volunteer activities so that children will develop alternative perspectives on their own problems. Combing company and family volunteerism is an attempt to enable workers to leverage scarce time with their families. Shell Oil provides employees time off from work to plan and attend departmental community service activities and to attend school functions involving employees' children.

AT\&T encourages its employees worldwide to devote one paid workday to the communities the company serves. Its AT\&T CARES is the country's largest publicly-announced corporate volunteer program. Initiated in 1994, this program is designed to reinforce employees' volunteer activities. When an employee gives at least fifty hours of service annually to a nonprofit group, he or she can request a grant of $\$ 250$ from AT\&T CARES. Teamwork is promoted through maximum grant awards of $\$ 2500$ for four or more workers who volunteer at the same organization. Another program begun in 1994, American Express' Volunteer Action Fund (VAF), awards grants on a competitive basis to eligible organizations where employees regularly volunteer their time. Grants of up to $\$ 1000$ per employee or $\$ 2500$ for teams of three or more can be awarded to any nonprofit charitable, civic, health, social 
welfare, educational, cultural, or community organization or project where employees volunteer. Applications in the United States are evaluated by employees/advisors.

Polaroid Corporation matches time given to charitable groups with cash donations, instead of matching cash with cash, as was its previous practice (The Wall Street Journal 1996). Timberland Company, the footwear manufacturer of Stratham, New Hampshire, offers employees forty hours per year for community work on company pay and company time (Lexington 1997).

There are numerous other policies and programs that employers can undertake to support the efforts of their employees to become better environmental citizens. It must be stressed that the five general categories of recommendations listed below pertain to all employers, be they in the private, public, or non-profit sectors. These recommendations relate to time at work; employee use of employer resources; community-friendly policies; employee-friendly policies; and openness and non-retaliation.

\section{Time at Work}

There are a number of ways for employers to allow employees to design their own workdays to balance citizenship, family, and work commitments. Most straightforwardly, employees can be given a window, of, say, ten hours, in which to complete their day's work. They can be allowed to telecommute for onehalf a day, attend a meeting associated with environmental citizenship, and then work on-site for onehalf day. They can be given a fifty to sixty hour weekly block of time in which to complete their forty hours of work. Employees can post their intended work schedules on on-line systems in order to facilitate hours swapping, as appropriate (especially in the manufacturing environment), and the scheduling of specific tasks and meetings.

Corporate downsizing and outsourcing-farming out of work once performed within the company-have helped to generate many new home-based businesses, including a new suburban status symbol of the home office. The home office-made possible through modern computers and telecommunications-is also used by telecommuters, those who stay in a corporate structure but spend most of their worktime working from home and therefore minimize time and resource wasting commutes. Companies benefit from more efficient utilization of expensive office space. Telecommuters 
can "hotel," i.e., get assigned desk space at the office via a reservation system. "Hot-desking," a variant on this, has several employees sharing the same desk but at different times.

One 1993 study for the Small Business Administration found that telecommuters actually get promoted at greater rates than those remaining in the office (Warner 1997). The out-of-sight, out-of-mind potential drawback can be managed. Jobs that demand quiet reflection and other independent work are a natural fit. Frequent contact with others, especially those requiring ad hoc, unscheduled meetings, functions poorly for telecommuters. Management positions can work if the coordination involves more senior-level employees, who need mostly "big picture," not day-to-day direction.

Studies have shown that people believe they are anywhere from five to twenty percent more productive when working at home, largely due to the uninterrupted time to think clearly and the lack of distractions. According to the Regional Plan Association, on any given day in 2010, ten percent of Americans will "commute" by wire (Pollan 1997). One telecommuter elaborates on the communal benefits, particularly for suburbanites, from this change in his work habits (Pollan 1997):

One of the great advantages of working at home is the added time with one's family it affords, once you realize how much day is left after you've lopped off those hours for commuting and water cooler schmoozing.

The loss of this ritual is often cited as a drawback of working at home, and isolation (social and office-political) is certainly a problem. Yet I've discovered that the lack of society during the day whets ones appetite for social activity at night-going out, having people over, even getting involved politically.

The rap on bedroom communities has always been that a society of commuters, with one foot in the city and the other in bed, had no time or energy lef: for local politics and community activities; the commuter's sense of attachment to a place was attenuated. I find that after a day spent in the solitude of my hut, the prospect of a P.T.A. or zoning board meeting begins to look pretty exciting. A society of home-office workers could wind up actually revitalizing our communities. What might look like a formula for social atomization could prove precisely the opposite. 
A recent development that may allow some workers more time with family and community work involves companies allowing workers to take compensatory time in lieu of pay for overtime hours worked. Overtime accounted for fifteen percent of the pay of the average manufacturing worker in 1995 (Siwolop 1996). On average, these workers clocked 4.4 hours of overtime a week, up from 2.5 in 1960 , according to the U.S. Bureau of Labor Statistics. Since 1985, federal, state and local government employees have had this option of taking "comp time" in lieu of overtime pay; additionally, some unions have negotiated this option in their contracts. Changes to existing federal legislation that currently restricts employer options regarding these issues is, as of this writing, being debated in Congress.

TRW, Inc. recently gave its workers at a Sunnyvale, California, plant the option of replacing eight hours of overtime pay over a two-week pay period with a Friday off every other week. The initiative received the endorsement of eighty-four percent of the employees (Siwolop 1996). Not all employees nationwide are as sanguine about such opportunities. An AFL.-CIO survey of hourly workers conducted in June 1996 found that sixty-four percent of hourly employees preferred time-and-a-half pay to comparable time off. Time off was favored by only twenty-two percent of the respondents. This indicates that preferences, constraints, or inertia for work and consumption over time may be very difficult to overcome without adaptive work.

Employers can also work to reduce overtime by spreading the work among more employees. Schor (1992) states:

Ironically, the tendency of capitalism to expand work is often associated with a growth in joblessness. In recent years, as a majority have taken on the extra month of work, nearly onefifth of all participants in the labor force are unable to secure as many hours as they want or need to make ends meet. While many employees are subjected to mandatory overtime and are suffering from overwork, their co-workers are put on involuntary part-time. . . The rational, and humane solution-reducing hours to spread the work-has practically been ruled out of court.

Currently, it is very difficult for employees to reduce the time they devote to their jobs. Basically, the choices are full-time with benefits and possibly regular overtime and part-time with no benefits. It is 
recommended that employers follow the federal government's lead and give the option of choosing work hours and commensurate benefit packages. Thus, employees could opt for thirty-five-hour weeks or thirty-hour weeks and receive 87.5 and 75 percent of the regular benefit packages, respectively.

As mentioned in Section 3.1, shift work, extended hour schedules, frequent travel, and rotating daily schedules all work to disrupt family and community life. It is recommended that employers reduce the impact of such activities on employees. When shift work and/or rotating schedules are necessary, it is recommended that shifts or schedules be designed to take advantage of the latest health research to maximally reduce disruptions of sleep patterns, so that what time workers do have off the job can be as free of sleep deprivation-induced fatigue as possible. Travel can be reduced through the use of teleconferencing.

On the topic of benefits, companies can expand their benefit packages to include activities, programs, and policies that can save their employees time. Such potential benefits include, but are not limited to, the following: on-site day care, commutes in non-rush hour periods, and personal shoppers. Flextime, less disruptive work schedules, and use of employer resources, discussed next, all help to save employees' time. The Eli Lilly pharmaceutical company in Indianapolis has allowed third-party dry cleaners, film processor, and "hot meals to go" operations to locate on-site to reduce employees" errands in their busy daily schedules.

\section{Employee Use of Employer Resources}

There are numerous resources that employers can provide to help their employees become better environmental citizens. Most simply, employers can let employees use the phone during non-work periods. In addition, employers can let employees use their supplies, computers, printers, reproduction machines, and fax machines to do such things as write letters, check the Internet for information, copy newsletters, attend virtual classes, engage in teleconferences, and send e-mail to people in their social networks. In much the way that churches and schools are now doing, employers can let employees use conference rooms and other appropriate space during off hours for meetings and other gatherings related to environmental citizenship. 


\section{Community Friendly Policies}

Agglomerations of businesses in central cities and thousands of employees in large office buildings made sense in an era when face-to-face communication was paramount. While communication among employees and among business is even more important than ever in this dynamic world, advanced telecommunication technologies greatly reduce the need for agglomeration. There is the possibility for employers to allow their employees to work closer to their communities, either in their homes or in neighborhood satellite offices. In fact, telecommuting from home is on the rise, with the development of neighborhood centers still in the nascent stages.

The neighborhoodization of corporate America has many benefits vis-á-vis environmental citizenship. By bringing jobs closer to where employees live, employees can save time in commuting, make better use of flextime to participate in community activities, and promote community identity and social networks.

Employers can adopt numerous other community-friendly policies. They can transfer employees less frequently from one community to another. They can allow employees to contribute to community activities on company time (e.g., as experts on a specific environmental technology). They can work with agencies in a collaborative fashion to allow employees to assist in data collection and analysis activities, as mentioned in Section 6.3. For significant contributions of employee time and employer resources, governments may consider tax breaks.

\section{Employee-Friendly Policies}

Numerous social commentators warn that domestic harmony is threatened by the growing income inequalities in our society. Several factors have lead to this situation, some of which are under the control of companies. One big factor has been the growing gap between the pay levels at the highest levels in an organization and the lowest levels. At the expense of executives, but to the benefit of lower level workers and the increased potential for social harmony, this gap can be narrowed at the discretion of employers.

Employee-friendly policies can include embracing the inherent high intentions and concerns of most employees to do good in and for their communities. This includes market initiatives. Monsanto's CEO, 
Robert Shapiro, is actually

implementing such policies in his global firm (see Exhibit 6). In 1994, he

challenged a group of twenty-five

critical thinkers within Monsanto to

examine the firm's role in the world and make recommendations. The result is

140 people participating on seven

"sustainability teams." Shapiro

(Margretta 1997) elaborates:

People came away from

the meeting fired

emotionally up. It wasn't

just a matter of okay, you

threw me an interesting

business problem, I have

done the analysis, here is

the answer, and now can

I go back to work. People

came away saying,

“Damn it, we've got to

get going on this. This is

important." When some
Three of Monsanto's sustainability teams are working on tools and methodologies to assess, measure, and provide direction for internal management. The Eco-efficiency Team asks, in relation to the value produced, what inputs are consumed, and what outputs are generated. The Full-Cost Accounting Team is developing "a methodology to account for the total cost of making and using a product during the product's life cycle, including the true environmental costs associated with producing, using, recycling, and disposing of it" (Margretta 1997). The Index Team is developing "criteria by which business units can measure whether or not they're moving toward sustainability. They are working on a set of metrics that balance economic, sccial, and environmental factors. Units will be able to track the sustainability of individual products and of whole businesses."

Three teams are looking externally to identify sustainability needs that Monsanto might address. The New Business New Prodiucts Team is "examining what will be valued in a marketplace that increasingly selects products and services that support sustainability" The Water Team is "looking at global water needs, . Mariy people don't have access to clean drinking water, and there is a worsening shortage of water for Irrigation as well " The Global Hunger. Team is "studying how Monsanto might develop and deliver technologies to alleviate world hunger?

Monsanto's seventh team develops materials and training programs The Communications and Education Team is developing the "training to give Monsanto's 29,000 employees a common perspective. It offers a framework for understanding. what sustainability neans, how employees can play a role, snd how they can take their knowledge to key audiences outside the company?

Exhibit 6. Monsanto's seven sustainability teams

of your best people care intensely, their excitement is contagious . . .

Today in most fields I know, the struggle is about creativity and innovation. There is no script. You have some ideas, some innovations, and you try to align what people believe and what people care about with what they're free to do. And you hope that you can coordinate them in ways that aren't too wasteful—or, better still, that they can self-coordinate. If an institution wants to be adaptive, it has to let go of some control and trust that people will work on the right things in the right ways. That has some obvious implications for the ways you select people, train them, and support them. . 
I believe we must see what ideas really win people's hearts and trust that those ideas will turn out to be the most productive.

People in large numbers won't give their all for protracted periods of time- - with a cost in their overall lives-for an abstraction called a corporation or an idea called profit. People can give only to people. They can give to their co-workers if they believe that they're engaged together in an enterprise of some importance. They can give to society, which is just another way of saying they can give to their children. They can give if they believe that their work is in some way integrated into a whole life.

Historically, there has been a bifurcation between who we are and the work we do, as if who we are is outside our work. That's unhealthy, and most people yearn to integrate their two sides. . . .

I'm fascinated with the concept of distinctions that transform people. Once you learn certain things - once you learn to ride a bike, say-your life has changed forever. You can't unlearn it. For me, sustainability is one of those distinctions. Once you get it, it changes how you think. A lot of our people have been infected by this way of seeing the world.

Other policies that can be adopted by employers include: improving employee training and retraining (the United States spends a relatively low amount on employee training); working to give employees several skills to promote job assignment flexibility; and attempting to reduce layoffs and merely strategic downsizing.

\section{Openness and Non-Retaliation}

As summarized in Section 3.7, numerous factors associated with environmental citizenship can cause anxiety and fear. With respect to the topic of employment, employees can fear losing their jobs or even of being sued for participating in environmentally-related political activities, especially when the views of the employee and the interests of the employer are at odds. Employers can assist their employees to become better environmental citizens by being as open as possible about their operations vis-à-vis environmental issues. Reporting emissions via the Toxics Release Inventory is one such example of openness. In addition, the employers can establish a formal non-retaliation policy. These two recommendations go hand-in-hand. Openness reduces the need for secrecy. Reducing the need for 
secrecy reduces the potential number of instances where employees might feel anxious when their views run contrary to employer views and cause a reluctance to act on their views. Non-retaliatory policies will help encourage openness.

In summary, most of the employer-related initiatives are designed to lessen time and attention constraints on environmental citizenship. However, the potential to marry corporate community-based efforts to environmental citizenship issues is enormous. Companies could give time off specifically for employees to engage in environmental issues and citizenship capability building. Companies can bring in motivational speakers whose message is focused on citizenship. The ideas listed in this subsection only begin to tap the potential of employers to help their employees in this area.

\subsection{GOVERNANCE-RELATED INITIATIVES}

As suggested by the discussion in Section 5, assessment of on public participation programs vis-à-vis citizenship can lead to more fundamental concerns about government and bureaucratic administration. In many cases, one can argue that change in the underlying conceptualization of government agencies is needed before the agencies can implement the kinds of public participation programs needed to foster citizenship. For example, agencies that stand apart from society will be less likely to implement programs to improve social networks. Agencies that have a circumscribed view of the processes available for environmental decision making will not act to help citizens develop ideologies or understand the value of other types of decision-making processes. Agencies that view public participation as necessary only when the agencies have problems to solve will be less likely to implement continuous and comprehensive education programs to build capability.

With these thoughts in mind, the seven general categories of recommendations below represent a mixture of ideas aimed at substantive changes in bureaucratic administration and associated public participation programs potentially useful for helping people become better citizens with respect to environmental decision making. How each recommendation relates to capability, identity, ideology, mental models of governance, social networks, and effort is explained. 


\section{Environmental Protection Communities}

The first issue to be addressed is the difficulty people may have with community identity. The recommendation is to create environmental protection communities (EPCs) throughout the United States. EPCs would be spatially defined consistent with ecosystem and sustainability principles. As such, the EPCs would be regional in nature. Each EPC would be given an evocative name that would emotionally resonate with citizens. Residents living within the boundaries of an EPC would be "citizens" of the EPC although the EPCs would have no associated new levels of government or other trappings of formally-defined political jurisdictions. Consistent with the latest thinking about environmental protection, environmental programs would be coordinated across receiving media and political boundaries to holistically address environmental issues in an EPC. Most environmental problems will be able to fit this model, including regional air pollution, drinking water, surface water, solid waste disposal, hazardous waste disposal, storm water, urban run-off, and pesticide problems. Creating a recognizable environmental community to which people can belong will help to create conditions where people will naturally work together as citizens on difficult environmental issues.

Although EPCs will not be formal political jurisdictions, some form of environmental protection community governance is required. There are numerous options to choose from, including letting one existing agency in one of the political jurisdictions in an EPC take the lead in coordinating the EPC's environmental programs, to having a Council of existing agencies handle the task, to creating a metagovernment within the boundaries of the EPC to be the environmental czar of the EPC. Whatever form is decided upon, the governance structure ought to be responsible for coordinating and possibly delivering environmental citizenship programs, such as those mentioned below.

\section{Environmental Neighborhoods}

To complement the EPCs, which would typically be regional in scope, there is also a need for neighborhood-based institutions. An environmental neighborhood should be a relatively small number of people, say between one hundred and two hundred. The small number of people in a neighborhood helps people get to know each other. This helps to create trust and empathy to the extent that people who know each other are less likely to fear each other's ideas. The hypothesis is that familiarity will help to foster substantive discussions about environmental issues. Frequent and substantive discussions 
can lead to strong feelings of identity, ideology development, and, of course, social network development.

Environmental neighborhoods need not be bounded by a city block or a suburban subdivision, although such neighborhoods are to be encouraged when coincident with localized environmental issues, such as urban creek restoration, and as preferred by citizens. Neighborhoods could include people from over an entire EPC who share affinities that draw them together with respect to the environment. Environmental neighborhoods need to be envisioned as local grassroots organizations. Charters may be useful, but there is no need for formal government involvement in their creation and dissolution. Citizens need the freedom to join the environmental neighborhoods of their choice. The best role for formal government would be to facilitate environmental neighborhoods through the community enterprise systems discussed in detail below.

Healthy environmental neighborhoods will foster capability building, identification, ideology development, and social network construction and maintenance. Governments can foster effort by specifically including neighborhoods in environmental decision-making processes and building implementation programs to involve neighborhoods.

\section{Environmental Bill of Rights}

Citizens need to know their rights and responsibilities as citizens vis-à-vis applicable environmental laws and regulations. Given the plethora of federal, state, local, and special district political jurisdictions and the fact that citizens may not appreciate their rights and responsibilities under the accumulation of laws in any case, creating an environmental bill of rights (EBR) for citizens, tailored to their particular situation (e.g., based on where they live), could be very useful and informative. The EBR will help people understand law and governance and theilr roles and opportunities to influence environmental decisions. The EBR will also further identity development by providing procedural substance to environmental citizenship. The EBR does not entail new legislation, constitutional amendments, or any other additional legal requirements, just a better explanation of existing laws, rights, and regulations to promote citizenship. 


\section{Office of Environmental Leadership}

There is a need for new institutions to provide leadership with respect to environmental and other matters of public concern. As discussed in several places above, agencies are typically not capable nor designed to provide the patient leadership needed to engage a public that is dividing along economic and cultural lines in substantive and emotional discussions about environmental matters. In addition, at times, politicians appear reluctant to take the lead in such matters, preferring to follow when public opinion on a matter clarifies. The role of new leadership institutions is to focus on process while being outcome neutral.

It is recommended that Offices of Environmental Leadership (OELs) be established at the EPC level or within smaller political jurisdictions. An OEL needs to have credibility, be non-biased with respect to outcomes, and have a staff trained in leadership methods, adaptive work, transformative facilitation (Maser 1996), alternative dispute resolution, and coordination methods. OELs can be both reactive and proactive.

With respect to the former, OELs can respond to requests from parties to implement an appropriate decision-making process to solve a specific environmental problem. OELs can also be charged with leading innovative efforts in the area of direct democracy. OELs can be given responsibility for managing a values or citizens' jury process (Brown, Peterson, and Tonn 1995). OELs can also manage innovative efforts to allow environmental neighborhoods, acting through an appointed representative, to decide important environmental matters. What decisions can and should citizens make directly and how should they be made are very important and difficult questions to answer. This paper is not the venue to review this literature or debate the subject. With respect to helping citizens become better citizens and with respect to increasing public participation in environmental decision making, however, it should be noted that there are numerous opportunities for innovation and experimentation.

Proactively, OELs can manage the Environmental Citizen Certificate Program (discussed below). OELs can also manage on-going community visioning processes. Citizens need to be rewarded for their efforts at citizenship, be allowed to exercise their responsibilities as citizens of EPCs and neighborhoods, and be allowed to satisfy their own consciences as driven by their ideologies by having direct impact on decision making about environmental issues. As a precursor to decision making, 
citizens need to work together to envision the future of their environmental community. Numerous U.S. cities are now engaging in visioning processes, spurred by the goal of creating sustainable communities. OELs and similar groups should be given the mandate to create the capability to manage successful visioning processes and to implement and manage such processes.

\section{Collaborative Programs}

In addition to using government spaces and cyberspaces as gathering places to reduce the separation of government and society, agencies can work to include citizens more in everyday operations. In other words, opportunities for citizens to collaborate with agencies and with each other in the provision of government services should be explored. With respect to the environment, citizens, individually or through their neighborhood or other organizations, can help to collect data to monitor the environrnent (e.g, the GLOBE program is an excellent model). Water and air can be sampled and the health of animals and plants assessed at regular intervals. As is happening in many communities around the United States, volunteers help out with environmental restoration activities, tree planting programs, and wildlife preservation activities. Governments can also consider ways of allowing citizens to help parttime in more mundane activities (e.g., data entry), possibly in lieu of paying some portion of their taxes. These kinds of collaborative activities work to increase identification, provide avenues for effort, and help people further their understanding of governance. Sirnilar efforts can focus on engendering collaborations with the private sector.

\section{Environmental Citizen Certificate Program}

For many years, educators have been calling for the United States to implement life-long learning programs. These programs are intended to be inclusive of many important topics; therefore, environmental topics and citizenship capability topics ought to be included. In addition, life-long learning programs need to be just that, integrated over $\mathrm{K}-12$, college and graduate education, community college and technical/vocational school programs, and private-sector training activities. The OELs can work with the plethora of educational institutions within their boundaries to coordinate such efforts. It should also be mentioned that K-12 classes are also good avenues for collaborative government. For example, numerous classes around the country already collect environmental data and collaborate with other classes over the Internet to compare and analyze data. 
A focus of these efforts can be an Environmental Citizen Certificate Program (ECCP). A person could earn an environmental citizen certificate by achieving a predetermined set of goals. The goals could include the following: attending a six-week, one-night-a-week class on environmental principles; attending a seminar on interpreting graphs and statistics; attending a role-playing workshop on effective participation in public meetings, citizen advisory boards, negotiations, etc.; attending discussion groups about books and articles related to democracy, quality of life, and other subjects related to ideology; attending seminars on political, agency, and environmental decision-making processes; spending time in the community with people at great places, in parks, and other public places; joining an environmental neighborhood; completing an oral or written test on their rights as citizens vis-à-vis environmental laws and regulations; attending formal public hearings on environmental issues; volunteering to assist an agency collect environmental data; and helping others understand environmental issues. The certificate could be renewed every two or three years, to foster continued effort and learning. Lifetime environmental citizen awards can be given to exceptional citizens.

One potential criticism of the ECCP is that it is too formal. It would cost money to produce and handout certificates, not to mention managing the certification process. One benefit accrued from these expenses is that people like to have something to show for their effort. The United States is an achievement-oriented society and a smart-looking certificate can be a powerful symbol of accomplishment. In addition, employers are more apt to provide employees support to achieve something tangible such as an environmental citizenship certificate. Finally, the certification program can help to provide structure and guidance to citizens' efforts related to environmental citizenship.

\section{Change Built Environment}

Government can take the lead in working to change the built environment. The goals of change are to decrease wasted time and other resources spent traveling and to create built environments that are more conducive for the building of community and social capital. These goals need to be pursued without sacrificing amenities associated with the "American Dream," home ownership, privacy, security, greenspace, and an enriching environment for children. New efforts need to focus on higher density, pedestrian-friendly designs that lower traffic volumes, speeds, and noises. Zoning plans may need to be revised to allow more mixed land uses, neighborhood business centers, and innovative developments. 
Great good places need to be recreated, but rethought for families, work, education, and citizenship. It is a proper role for government to be involved in changing the built environment through public goods such as roads and other infrastructures and legal means such as zoning. Effective redesign of the built environment can also help increase trust.in government.

To reduce the separation of government from society, one idea would be to redesign "City Hall" to be a good great place. The space could have features of government, such as a legislative chamber open to the public, as well as features of a park, plaza, mall, library, center of education, day care, and business. The entire setting could be cyberspace accessible. Such a setting would bring politicians together with citizens in social and informal ways, as contrasted with current artificial and formal gatherings.

\section{Community Enterprise Systems}

The purpose of a community enterprise system (CES) is to facilitate all the above recommendations and others through the use of computers and telecommunication technology. The goal is to build a system to support citizenship, community involvement, environmental decision making, etc., similar in concept to systems being developed by corporations to support employees, information management, and corporate decision making. A generic CES could have the following features:

- e-mail access for all community members;

- moderated real-time and asynchronous on-line discussions on specific environmental issues;

- special provisions to enhance communication among members of environmental neighborhoods (e.g., dedicated discussion areas);

- environmental bill of rights database system;

- maps of environmental protection communities and other geographic information;

- access to environmental resources;

- access to community teleconferences at places of employment (including neighborhood centers), public places, schools, great places, etc.;

- access to educational resources associated with the ECCP; 
- access to a community visioning system that makes use of 3-D modeling if not virtual reality technology;

- on-line community histories with special emphasis on environment and mentorship;

- point-casting of specific information about community environmental matters to specific citizens according to preferences provided by individual citizens;

- schedules related to collaborative efforts among citizens, employers, and agencies; and

- support for new initiatives in the area of direct democracy (e.g., through remote voting).

An even more advanced system could allow citizens access through web-based systems in their cars, buses, automobile repair shops, doctor offices, grocery stores, kids activities, cybercafes, and lunch places. The CES can be tied with other efforts as well. For example, a community-based talk show radio program aired during rush hour could reference information in CES in real-time, as could traditional face-to-face public meetings and legislative gatherings. The CES can also be tied to devices used to gather community-based environmental information. Citizens can have hand-held devices to input data as part of their volunteer efforts. Finally, the CES can be synthesized with other systems that have indirect impacts on citizenship, constraints, etc. For example, the CES can be tied to an intelligent transportation system designed to improve traffic flows.

The envisioned CES can support the goals of environmental citizenship in numerous ways. E-mail and on-line real-time discussion sessions can support social network building, capability building, and ideology development. Special features to support environmental neighborhoods can also support social network development as well as identity development. Electronic communications can bring government more into society as government staff contribute to the discussions. A well designed CES can overcome time constraints to public participation and be tied to additional capabilities to save time. Anxiety about coming forward can be reduced by using the CES; many people will be more open and expressive in computer-mediated environments than they will be in person. 


\subsection{NON-GOVERNMENTAL ORGANIZATION INITIATIVES AND OTHER THOUGHTS}

Citizen, employer, and government-related initiatives cover a great deal of the "imagination space" associated with improving environmental citizenship in the United States. However, much unexplored room is left in the imagination space, as NGOs, schools, foundations, religious organizations, professional associations, and the media, to name a few, have not been addressed. This subsection focuses on NGOs.

Environmentally-oriented NGOs are quite numerous. Familiar names include the Sierra Club, the Wilderness Society, the Nature Conservancy, Greenpeace, the Worldwatch Institute, and the Environmental Defense Fund. These kinds of national NGOs have large memberships and political visibility. They influence environmental decision making through lawsuits and direct mail campaigns, for example. They are finding themselves more often at the table to negotiate new environmental laws and regulations.

The national organizations are augmented by thousands of grassroots organizations. These NGOs may have very specific and limited foci on community-based issues, such as restoring a wetland, cleaning up a creek, and remediating a Superfund site. Grassroots NGOs may disband after an issue has been resolved, only to come back to life when a new issue emerges.

All types of NGOs offer many environmental citizenship opportunities. For example, NGOs can promote volunteerism, which can provide citizens with situations to hone their capabilities, learn about environmental decision-making processes, build social networks and focus their efforts. Well-financed NGOs can provide educational resources related to environmental issues as well as environmental citizenship in general. NGOs can be a source of identity. To the extent that NGOs are characterized by different ideologies, people can enhance their ideological foundations through interacting with NGOs and find one or two in which they feel comfortable.

NGOs could possibly be entrusted to carry out many of the government-related initiatives presented in Section 6.3. One can imagine an NGO administering the ECCP. A well-regarded NGO could provide leadership required of the OEC, especially the sensitive leadership required for community-wide 
adaptive work. NGOs can be a source of environmental citizenship mentors, and, to continue, a source of support of individual adaptive work.

NGOs can provide a link between consumerism and environmental concerns. For example, the Land and Water Fund of the Rockies is working to educate people about environmentally sensitive products, and is an advocate of green pricing. NGOs are engaged in a plethora of other activities that are related to environmental citizenship and/or could be enhanced to also foster these goals. 


\section{CONCLUDING REMARKS}

This report covers a great deal of ground. To summarize, the main points are these:

- democratic decision making about environmental issues requires broad public participation;

- environmental citizenship places significant demands upon individuals and communities (e.g., to build capability, to expend effort);

- citizen participation in environmental decision making is very low;

- numerous substantial forces act to constrain citizen participation in environmental decision making (e.g., work-related, consumerist);

- governments have implemented various programs to foster public participation in environmental decision making (e.g., information programs);

- these efforts have mixed results and in general do not help people become better environmental citizens; and

- citizens, employers, and governments have numerous options available-such as downshifting, letting employees use employer resources, and environmental protection communities, respectively-to improve environmental citizenship in the United States

Can participation in environmental decision making be increased in all sectors of the society? Verba et al. (1995) recognize that there is a decidedly unequal dimension to participation in American political processes. The more advantaged groups in society, in terms of economic and educational position as well as in terms of race and ethnicity, have louder voices are better situated to be heard, and what they say is articulated better. They conclude, "Despite the absence of references to class in political discourse, when it comes to political participation, class matters profoundly for American politics." These factors of class and advantage are likely to remain potent:

To the extent that patterns of participation-whose voice is heard and whose is muted-are based in fundamental institutions of American society, the overall contours of American political activity are not likely to change rapidly. The society as a whole may become better 
educated or more affluent. However, so long as inequalities in education and income persist - and income inequality in America has become more pronounced of late- so long as jobs continue to distribute opportunities to practice civic skills in a stratified manner, then individuals will continue to command stockpiles of participatory factors of very different sizes and, to participate at very different rates.

It is easy to be cynical about this topic. Earlier in this report, Combs and Nimmo (1996) are cited for saying that people tend to ignore politics when things are going badly in order to focus on improving their own situations. But they caution that there is equally bad news about the good times for the body politic: "When things are going well, people don't need to worry, so they go after private pleasures and achievement, and turn away from politics to leisure."

A fundamental question not answered by this paper is whether people can become better citizens. It is clear that many people will continue to be model citizens and that many people will never become engaged in environmental decision-making processes. The question is whether the vast majority of Americans who do not fit into either of these two categories could benefit from the recommendations listed above. Are the economic pressures too great, the demands on people's time too overwhelming, the lures of entertainment too alluring, and the stresses of becoming involved too daunting? Do the physical designs of our cities and suburbs obstruct active civic life? The answers may be yes. On the other hand, it is clear that progress will not be made in improving citizenship and participation in environmental decision making without some innovative approaches.

A second question not answered by this paper is whether the benefits of these recommendations vis-àvis changes in government would be worth the costs? Will government decision making become too weighted down by the new institutional arrangements and time-consuming public participation? Will agencies lose control of some of their decision-making authority, and if so, is this good or bad? Will issues of conflict of interest increase as agencies become more a part of regional and local social networks, or decrease as stronger and more comprehensive social networks act to diminish the importance of special-interest influences on government? This paper would not have been written if the answers to these questions were thought to be negative. However, these questions ultimately will have to be answered empirically as a result of accumulated trials and experience. 
Do we need people to be better citizens vis-à-vis environmental decision making? Why can we not continue to let people simply elect representatives to city councils and state legislatures, let the representatives pass the laws, and let administrative and technical experts make all the rest of the environmental decisions? The response is this. Every person has a responsibility to society. Protecting the environment is an extremely important responsibility, and everyone's behavior has some impact upon the environment. It is a responsibility that will never go away because environmental issues are a permanent concern of humanity. The problems will only get more severe as the U.S. population increases, to 350 million by the mid 2000s by some accounts, and as the world's population increases to ten billion and beyond. Globally, economic activity will need to increase tenfold just to provide the bare essentials to a global population double its current size, and technology will have to improve twenty-fold merely to keep the earth at its current levels of environmental burden (Hart 1997).

In terms of employment and income disparities in the United States, Jeffrey Garten asks (Garten 1997):

\begin{abstract}
What will be the impact of nearly 2 billion non-Western workers entering the global economy over the next decade and working for $\$ 5$ to $\$ 10$ per hour at a rate of efficiency of $80 \%$ to $90 \%$ that of workers in the West? Where will the purchasing power come from to absorb the massive production increases made possible by low-cost labor, technology and new investments?
\end{abstract}

Because everyone has responsibility for the environment and everyone's behavior has an impact upon the environment, and given the enormity of the existing and especially potential future problems, it stands to reason that responsible citizens need to be active in helping to make decisions about the environment. 


\section{4}




\section{ACKNOWLEDGMENTS}

We wish to thank Danny Moore and Dina Franceschi for providing research assistance to this project. We also wish to thank the following for providing comments on a draft of this report: Inga Treitler, Mary English, Don MacGregor, Caron Chess, Eric Blank, Elinor Ostram, Virginia Dale, Woody Dowling, and Steve Keach. The comments provided were insightful and challenging. This report greatly benefitted from the comments, but alas, it seemed to us that several more years of research would be required to address them all! We wish to thank Sheila Moore for her assistance in preparing this report. Finally, we thank Sherry Estep for editing this report. 


\section{REFERENCES}

Ackerman, B., “Why Dialogue?" Journal of Philosophy, 86 (1), pp. 5-22, 1989.

Almond, G. and S. Verba, The Civic Culture, Sage, Princeton, NJ, 1963.

Armour, A., "The Citizen's Jury Model of Public Participation: A Critical Evaluation," in O. Renn, T. Webler, and P. Wiedemann (Eds.), Fairness and Competence in Citizen Participation, Kluwer Academic Publishers, Dordrecht, 1995.

Barbalet, J., Citizenship: Rights, Struggle, and Class Inequality, Open University Press, Milton Keynes, England, 1988.

Barber, B., "Jihad vs. McWorld," Atlantic Monthly, March 1992.

Barber, B., Strong Democracy: Participatory Politics for a New Age, University of California Press, Berkeley, CA, 1984.

Beamon, K., "Get a Life!” National Business Employment Weekly, April 28-May 4, 1996, pp. 21-22.

Beeman, L., "Too Many Things to Do and Too Little Time to Do Them," The Oak Ridger, Oak Ridge, TN, May 3, 1996.

Bellah, R., R. Madsen, W. Sullivan, A. Swidler, and S. Tipton, Habits of the Heart, Harper \& Row, New York, NY, 1985.

Bernstein, A., "Is America Becoming More of a Class Society," Business Week, February 26, 1996, pp. 86-91.

Berry, W. Home Economics. Farrar, Strauss \& Giroox, NY, 1987. 
Binswanger, L., Being-in-the-World: Selected Papers of Lua'wig Binswanger, Basic Books, New York, NY, 1963. .

Bluestone, B., and S. Rose, "Overworked and Underemployed: Unraveling an Economic Agenda," The American Prospect, (31), March-April, 1997, pp. 58-69.

The Boston Globe, "Newsletter Offers Map for the Road Less Traveled," March 23, 1997.

Brechin, S., and W. Kempton, "Global Environmentalism: A Challenge to the Postmaterialism Thesis," Social Science Quarterly, 75 (2), pp. 245-269, 1994.

Brenner, M., "Nuclear Commission Visiting Uranium Sites," Independent, Gallup, NM, October 11, 1995.

Brown, T., G. Peterson, and B. Tonn, "The Values Jury to Aid Natural Resource Decisions," Land Economics, 71 (2), pp. 250-260, 1995.

Carnes, S., "The Plethora of Publics and Their Participation in Policy Making: How Can They Properly Participate?" National Association of Environmental Professionals 20th Annual Conference Proceedings, NAEP Publications, Washington, DC, pp. 202-213, 1995.

Christensen, J., ". . and the Words from the Meaning on the Nevada Range," High Country News, February 5, 1996, p. 19.

Clark, K., "How to Make Traffic Jams a Thing of the Past," Fortune, March 31, 1997, p. 34.

Clymer, A., "Class Warfare: The Rich Win by Default," The New York Times, August 11, 1996.

Cobb, R., and C. Elder, Participation in American Politics: The Dynamics of Agenda Building, Allyn and Bacon, Boston, MA, 1972. 
Coles, R., The Call to Service: A Witness to Idealism, Houghton Mifflin Company, Boston, MA, 1993.

Combs, J. E., and D. Nimmo, The Comedy of Democracy, Praeger, Westport, CT, 1996.

Covello, V., D. von Winterfeld, and P. Slovic, "Risk Communication: A Review of the Literature," Risk Abstracts, 3, pp. 171-182, 1986.

Crosby, N., "Citizen Juries: One Solution for Difficult Environmental Problems," in O. Renn, T. Webler, and P. Wiedmann (Eds.), Fairness and Competence in Citizen Participation, Kluwer Academic Publishers, Norwell, MA, pp. 157-187, 1995.

Daughters of the American Revolution, DAR Manual for Citizenship, National Society Daughters of the American Revolution, Washington, DC, 1981.

Davidoff, P., "Advocacy Pluralism in Planning," in A. Faludi (Ed.) A Reader in Planning Theory, Pergamon Press, Oxford, pp. 277-296, 1973.

Davis, S.C., Transportation Energy Data Book: Edition 15, Center for Transportation Analysis, Oak Ridge National Laboratory, prepared for Office of Transportation Technologies, U.S. Department of Energy, Oak Ridge, TN, ORNL-6856, 1995.

de Tocqueville, A., Democracy in America, translated by G. Lawrence, Ed. by J.P. Mayer, Doubleday, Anchor Books, New York, NY, 1969.

Dunlap, R., G. Gallup, and A. Gallup, The Health of the Planet Survey: A Preliminary Report on Attitudes on the Environment and Economic Growth Measured by Surveys of Citizens in 22 Nations to Date, A George H. Gallup Memorial Survey, The George Gallup International Institute, Princeton, NJ, 1992.

The Economist, "The Restless Valley," June 29, 1996a, pp. 26-27. 
The Economist, "Learning to Cope," 339 (7960), April 6, 1996b. pp.13-14.

Elgin, D., and A. Mitchell, Voluntary Simplicy, SRI International Business Intelligence Program, Guidelines (1004), 1976.

Ellis, J., "Bad Times in Rancho Santa Fe, Hollywood and Dover," The Boston Globe, March 29, 1997.

Etzioni, A., "Toward a Theory of Societal Guidance," The American Journal of Sociology, 73 (2), pp. 173-187, 1967.

Feenberg, D., and J. Poterba, Income Inequality and the Incomes of Very High Income Taxpayers, National Bureau of Economic Research Working Paper 4229, December 1992, as cited in Wolf, Martin, "The Dilemma of Inequality," Financial Times, July 23, 1996.

Financial Times, "Downsizers Under Fire," unsigned editorial, Financial Times, May 20, 1996.

Fortune, "Hard Labor," February 3, 1997, p. 113.

Friedmann J., Retracking America: A Theory of Transactive Planning, Doubleday, New York, NY, 1973.

Fromm, E., The Sane Society, Rinehart, New York, NY, 1955.

Fukuyama, F., "The End of History," The Washington Post, July 30, 1989.

Fukuyama, F., Trust: Social Virtues and the Creation of Prosperity, Free Press, New York, NY, 1995.

Gamson, W., Talking Politics, Cambridge University Press, New York, NY, 1992. 
Garten, J. E., "Can the World Survive the Triumph of Capitalism?" Harvard Business Review, January-February, 1997, pp. 144-150.

Gingrich, N., "Renewing American Civilization: Toward an Opportunity Society," The Futurist, 29 (4), July-August, 1995, pp. 10-14.

Gore, A., "The Deadly Age of Cynicism," The Aspen Institute Quarterly, 6 (4), pp. 7-21, 1994.

Gregg, R., 1936. "Voluntary Simplicity," Visva-Bharati Quarterly, reprinted in Manas in 1974.

Greider, W., "One World Ready or Not: The Manic Logic of Global Capitalism," Simon and Schuster, New York, NY, 1997.

Gross, M. B., "Political Poison at the Grass Roots," The New York Times, May 4, 1996.

Hale, A., "The Way We Are," letter to the editor of the Boston Globe Magazine, April 6, 1997, p. 8.

Hames, T., "On the Oregon Trail," Financial Times, February 3-4, 1996.

Handy, C., The Age of Paradox, Harvard Business School Press, Cambridge, MA, 1994.

Handy, C., Beyond Certainty: The Changing Worlds of Organizations, Harvard Business School Press, Boston, 1995.

Hart, S. L., "Beyond Greening: Strategies for a Sustainable World," Harvard Business Review, January-February 1997, pp. 66-76.

The Harwood Group, Yearning for Balance: Views of Americans on Consumption, Materialism, and the Environment, prepared for the Merck Family Fund, 6930 Carroll Avenue, Suite 500, Takoma Park, MD 20912, July, 1995. 
Heifetz, R. A., Leadership Without Easy Answers, The Belknap Press of Harvard University Press, Cambridge, MA, 1994.

Herbert, B., "A Job Myth Downsized," The New York Times, March 8, 1996.

Holderness, M. "So Let Them Eat Algae," book review of Joel Cohen's How Many People Can the Earth Support (W. W. Norton), New Scientist, May 18, 1996.

Holmes, S. A., "Children of Working Poor Are Up Sharply, Study Says," The New York Times, June 4, 1996.

Hoover, J. E., Your Task as a Citizen, U.S. Government Document Office, Washington, DC, June 21, 1939.

Howell, R., M. Olsen, and D. Olsen, Designing a Citizen Involvement Program: A Guidebook for Involving Citizens in the Resolution of Environmental Issues, Western Rural Development Center, Oregon State University, Corvallis, OR, 1987.

Jackson, T., "Now It's a Case of Dumbsizing," Financial Times, May 20, 1996.

Jacobs, J., The Death and Life of Great American Cities, Vintage Books, New York, NY, 1961.

Jefferson, T., Letter to Du Pont de Nemours, April 24, 1816.

Jones, Del, “Good Works, Good Business,” USA Today, April 25, 1997.

Jurkowitz, M., "It's 2007. Do You Know Where Your News Is?" The Boston Globe Magazine, March 9, 1997.

Kahneman, D., P. Slovic, and A. Tversky, (Eds.), Judgment under Uncertainty: Heuristics and Biases, Cambridge University Press, New York, NY, 1982. 
Kasperson, R., "Six Propositions on Public Participation and Their Relevance for Risk Communication," Risk Analysis, 6 (3), pp. 275-281, 1986.

Kaufman, J., "Suburban Parents Shun Many Public Schools, Even the Good Ones," The Wall Street Journal, March 8, 1996.

Kay, J. H., "Stuck in Gear: As the Automobile Turns 100, It Runs Our Lives," The Boston Globe, October 6, 1996.

Kemmis, D., The Good City and the Good Life: Renewing the Sense of Community, Houghton Mifflin Co. Boston, MA, 1995.

Kilborn, P.T., "In Their Quest for Efficiency, Factories Scrap 5-Day Week," The New York Times, June 4, 1996.

King, M. L., "1963 Letter from Birmingham City Jail," in The Democracy Reader, D. Ravitch and A. Thernstrom (Eds), Harper Collins, New York, NY, pp. 191-197, 1992.

Kingdon, J., Agendas, Alternatives, and Public Policies, Little \& Brown, Boston, MA, 1984.

Kleiman, C., "More Workdays are Work-nights," Chicago Tribune syndicated columnist, The Knoxville News-Sentinel, March 30, 1996.

Lancaster, H., "Women at Kraft Tell How to Be Big Cheese While Handling Family," Wall Street Journal, April 23, 1996.

Langner, P., "Her strategy for Civility: Start with Security," The Boston Globe, March 22, 1997.

Leonard, Mary, "Count Them In," The Boston Globe, April 20, 1997. 
Lerner, M., The Politics of Meaning: Restoring Hope and Possibility in an Age of Cynicism, Addison-Wesley Publishing Company, Reading, MA, 1996.

Lexington, "The Worker and the Volunteer," The Economist, April 26, 1997, p. 28.

Manning, E., "Santa Fe Ski-Area Growth Enrages Locals," Figh Country News, February 19, 1996, p. 12.

Margretta, J., "Growth Through Global Sustainability: An Interview with Monsanto's CEO, Robert B. Shapiro," Harvard Business Review, January-February 1997, pp. 79-88.

Marshall, T. H., Citizenship and Social Class, Greenwood Press, Westport, CT, 1950.

Maser, C., Resolving Environmental Conflict: Towards Sustainable Community Development, St. Lucie Press, Delray Beach, FL, 1996.

Maslow, A., Motivation and Personality. Harper and Row, New York, NY, 1970.

McDowell, E., "America's Hot Tourist Spot: The Outlet Mall," The New York Times, May 26, 1996.

McKibben, B., The Age of Missing Information, Penguin Books USA, New York, NY, 1992.

McKnight, J., The Careless Society: Community and Its Counterfeits, Basic Books, New York, NY, 1995.

Mead, W., Worth, April 1996.

Medberry, M., "Who Knows Best: Grassroots or Foundations?" High Country News, October 16, 1995, p. 4.

Mortimer, E., "Surfeit of Good Things," Financial Times, February 28, 1996. 
Neuborne, Ellen, "Volunteers May Feel More Like Draftees," USA Today, April 25, $1997 \mathrm{~b}$.

The New York Times, “America's Dwindling Savings Rate," May 17, 1996.

Oldenburg, R., The Great Good Place: Cafes, Coffee Shops, Community Centers, Beauty Parlors, General Stores, Bars, Hangouts and How They Get You Through the Day, Paragon House, New York, NY, 1991.

Pedersen, L., "500 Pages of Merchandise, but Should I Invest?" The New York Times, June 9, 1996.

Peelle, E., "Beyond the Nimby Impasse II: Public Participation in an Age of Distrust," Spectrum 88, Proceedings Nuclear and Hazardous Waste Management, Pasco, WA, pp. 575-582, 1988.

Peelle, E., and B. Farhar, "Public Participation in Agency Decision Making: A Review," Oak Ridge National Laboratory, Oak Ridge, TN, draft, 1995.

Peelle, E., M. Schweitzer, J. Munro, S. Carnes, and A. Wolfe, "Factors Favorable to Public Participation Success," Proceedings of the National Association of Environmental Professionals, Houston, TX, June 2-5, 1996, pp. 601-610.

Phibbs, P., "National Research Council Panel Outlines New Approach to Risk," Nuclear Waste News 16, 24, pp. 235-236, and "Commission Recommends Systemic Approach to Assess, Manage Risks," Nuclear Waste News 16 (25), pp. 247-248, 1996.

Pinkerton, J. P., "Not just Another Country," The New York Times Book Review, review of Seymour Martin Lipset's American Exceptionalism: A Double-Edged Sword, W. W. Norton \& Company, 1996.

Pinkerton, J. P., "The New Environmanticism," Foreign Affairs, May/June 1997, pp. 2-7.

Pitkin, H., and S. Shumer, “On Participation," Democracy, 2, 1982. 
Poarch, Maria T., "Rekindling Our Community Spirit," The Boston Globe, April, 17, 1997.

Point of Light Foundation, Fortune, advertising supplement April 7, 1997.

Pollan, M., "Living at the Office," The New York Times, March 14, 1997.

Pomice, Eva, 1996, “As Moonlighting Spreads, It Loses Its Blue-Collar Hue," The New York Times, May 5, 1996.

Post, R., "Between Democracy and Community: The Legal Constitution of Social Form," in Democratic Community: Nomos XXXV, J. Chapman and I. Shapiro (Eds.), 1993.

Putnam, R., "Bowling Alone: America's Declining Social Capital," Journal of Democracy, January, 1995.

Putnam, R., "The Strange Disappearance of Civic America," The American Prospect, Winter, 24, pp. 34-48, 1996.

Quintanilla, C., "As Jobs Go Begging, Bosses Toil Nights-and Improvise," The Wall Street Journal, March 31, 1997.

Rapaport, R., “The Network Company," Fast Company, April-May, 1996, pp. 116-121.

Raspberry, W., “Americans are Afraid We'll Be Suckers," Washington Post syndicated columnist in The Knoxville News-Sentinel, February 10, 1996.

Ray, P., "The Rise of Integral Culture," Noetic Sciences Review, Spring, pp. 4-15, 1996.

Reitz, A. E., M.D., Medical Staff, Indian Health Service-Crownpoint HealthCare Facility, Crownpoint, New Mexico, personal letter to Ivan Selin, Chairnan, U.S. Nuclear Regulatory Commission, Washington, D.C., February 6, 1995. 
Rogers, C., "A Theory of Therapy, Personality, and Interpersonal Relationships, as Developed in the Client-Centered Framework," in Psychology: A Study of a Science, 3, S. Koch (Ed.), McGraw-Hill, New York, NY, pp. 184-256, 1959.

Roszak, T., Where the Wasteland Ends: Politics and Transcendence in Post-Industrial Society, Doubleday Anchor Books, New York, NY, cited in Shamos, op cit, 1993.

Sandel, M., “America's Search for a New Public Philosophy,” The Atlantic Monthly, 277 (3), March, 1996, pp. 57-74.

Schmidt K., "Green Education Under Fire," Science, 274, pp. 1828-1830, 1996.

Schneider, S., "Creating a Democratic Public Sphere through Political Discussion: A Case Study of Abortion Conversation on the Internet," Presented at the Conference on Computing for the Social Sciences, Minneapolis, MN, May 13-15, 1996.

Schor, J. B., The Overworked American: The Unexpected Decline of Leisure, BasicBooks, New York, NY, 1992.

Schrag, P., "The Populist Road to Hell," The American Prospect, 24, Winter, pp. 24-30, 1996.

Schwartz P., The Art of the Longview, Doubleday, New York, NY, 1991.

Senge, P. M., The Fifth Discipline: The Art and Practice of the Learning Organization, Doubleday Currency, New York, NY, 1990.

Shamos, M. H., The Myth of Scientific Literacy, Rutgers University Press, New Brunswick, NJ, 1995.

Sharp, D., "So Many Lists, So Little Time," USA Weekend, March 15-17, 1996, pp. 4-6.

Sillince, J., A Theory of Planning Gower Publishing, Hampshire, England, 1986. 
Siwolop, S., "Overtime vs. Time Off: A Debate Over a Choice," The New York Times, August 18, 1996. .

Skocpol, T., "Unraveling From Above," The American Prospect, March-April, Number 25, pp. 20-25, 1996.

Smith, L., "Stamina: Who Has It; Why You Need It; How You Get It," Fortune, November 28, 1994, pp. 127-139.

Solberg, D., “One Less Vote,” High Country News, March 4, 1996.

Stanley, M., "The Mystery of the Commons: On the Indispensibility of Civic Rhetoric," Social Research, 50 (4), pp. 851-883, 1983.

Stone, D., "Causal Stories and the Formation of Policy Agendas," Political Science Quarterly (104), pp. $281-300,1989$.

Stuller, J., "Overload: Coping with the Glut of Communications," The Conference Board Magazine, April 1996, pp. 16-22.

Taylor, R., "Outlook Grows Bleaker for the Unskilled," Financial Times, May 31, 1996.

Thomas, J., Public Participation in Public Decisions: New Skills and Strategies for Public Managers, Jossey-Bass Publishers, San Francisco, CA, 1995.

Thurow, L. C., "Finding Gold in 'Golden Years': As Elderly Become Wealthier, Markets Start to Shift," The Boston Globe, January 28, 1997.

Thurow, L. C., "Companies Merge; Families Break Up," The New York Times, September 3, 1995. 
Tilden, M., Church Rock, New Mexico, comments given at a public hearing, U.S. Nuclear Regulatory Commission, in the matter of Hydro Resources, Inc., proposed Uranium In Situ Leach Mines, Crownpoint, New Mexico, Docket No. 40-8968-ML, evening session, February 22, 1995.

Tonn, B., "The Court of Generations: A Proposed Amendment to the US Constitution," Futures, June 1991, pp. 482-498.

Tonn, B., and D. Feldman, "Non-Spatial Government," Futures, 27 (1), pp. 11-36, 1996.

Tonn, B., and A. Schaffhauser, "Global and Utility Industry Scenarios," Futures Research Quarterly, 1996.

Tonn, B. and J. Peretz, "Field Notes on Using Risk in Environmental Decision-making: Lack of Credibility All Around," Inside EPA: Risk Policy Report, Summer, (11) 34-36, 1997.

Tonn, B., M. English, and C. Travis, "Frameworks for Understanding and Improving Environmental Decision Making," Oak Ridge National Laboratory, Oak Ridge, TN, (Draft), 1997.

Treitler, I., Politics as Masquerade: Multiple Ideologies in Antigua, Ph.D. Dissertation, University of Illinois at Urbana-Champaign, Urbana, IL, 1992.

Turner, B., "Culture Crash," USA Weekend, April 26-28, 1996, pp. 4-5.

Turner, B., "Postmodern Culture/Modern Citizens," in The Condition of Citizenship, B. van Steenbergen (Ed.), Sage Publications, London, pp. 153-168, 1994.

U.S. General Accounting Office, Restoring the Everglades: Public Participation in Federal Efforts, GAO/RCED-96-5, Washington, DC, 1995.

Uchitelle, L., “A New Era of Ups and Downs: Volatility of Wages is Growing: As Economy Changes, Pay is Thrown into Flux," The New York Times, August 18, 1996. 
United Nations, "Principles on General Rights and Obligations, "Preparatory Committee for the United Nations Conference on Environment and Development, Working Group III, Fourth Session, (New York: March 2-April 3, 1992) A/CONF.151PC/WG.III/L.8/REV.1/Add.2, February 21, 1992.

Valelly, R., "Couch-Potato Democracy?" The American Prospect, March-April, (25), pp. 25-26, 1996.

van Steenbergen, B., "Scenarios for Europe in the 1990s: The Role of Citizenship and Participation," Futures, November 1990, pp. 961-969.

van Steenbergen, B., "Introduction," in The Condition of Citizenship, B. van Steenbergen, (Ed.), Sage Publications, London, pp. 1-9, 1994a.

van Steenbergen, B., "Towards a Global Ecological Citizen," in The Condition of Citizenship, B. van Steenbergen (Ed.), Sage Publications, London, pp. 141-152, $1994 \mathrm{~b}$.

Verba, S., and N. Nie, Participation in America: Political Democracy and Social Equality, Harper and Row, New York, NY, 1972.

Verba, S., K. L. Schlozman, and H. E. Brady, Voice and Equality: Civic Volunteerism in American Politics, Harvard University Press, Cambridge, MA, 1995.

Verhovek, S. H., "Charcoal Grilling Is Going Up in Smoke," The New York Times, May 26, 1996.

Vogel, U., and M. Moran, "Introduction" in The Frontiers of Citizenship, U. Vogel and M. Moran (Eds.), St. Martin's Press, New York, NY, pp. x-xxi, 1991.

von Uexkull, J., "Opportunity Society Won't Work," letter to the editor, The Futurist, JanuaryFebruary, 1996, p. 2. 
The Wall Street Journal, "Time Off for Volunteer Work Grows in Corporate Favor," November 26, 1996.

Wanniski, J., "One Breadwinner Should Be Enough," The Wall Street Journal, February 26, 1996.

Warner, M., "Working at Home- the Right Way to be a Star in Your Bunny Slippers," Fortune, March 3, 1997, pp. 165-166.

Webler, T., H. Kastenholz, and O. Renn, "Public Participation in Impact Assessment: A Social Learning Perspective," Environmental Impact Assessment Review, 15, pp. 443-463, 1995.

Williams, L., "Local Group Critical of DOE Hearings," The Oak Ridger, Oak Ridge, TN, March 18, 1996.

Wurman, R. S., Information Anxiety, Doubleday, New York, NY, 1989.

Yates, D., Bureaucratic Democracy: The Search for Democracy and Efficiency in American Government, Harvard University Press, Cambridge, MA, 1982. 


\section{INTERNAL DISTRIBUTION}

1. J. Cannon

2. G. E. Courville

3. T. R. Curlee

4. S. G. Hildebrand

5. S. Moore

6 C. I. Moser.

7. C. Petrich
8.

9

10. Central Research Library

11. Document Reference Section

12-13. Laboratory Records

14. Laboratory Records - RC

15. ORNL Patent Office

\section{EXTERNAL DISTRIBUTION}

16. Dr. Lilia A. Abron, President, PEER Consultants, P.C., 1460 Gulf Blvd., $11^{\text {th }}$ Floor, Clearwater, FL 34630 .

17. Dr. Thomas E. Drabek, Professor, Department of Sociology, University of Denver, Denver, CO 80208-0209.

18. Mr. P. Richard Ritteimann, FAIA, Executive Vice President, Burt Hill Kosar Rittelmann Associates, 400 Morgan Center, Butler, PA 16001-5977.

19. Dr: Susan F. Tierney, The Economic Resource Group, Inc., One Mifflin Place, Cambridge, MA 02138.

20. Dr. C. Michael Walton, Paul D. and Betty Robertson Meed Centennial, Professor and Chairman, Department of Civil Engineering, College of Engineering, The University of Texas at Austin, Cockrell Hall, Suite 4.2, Austin, TX 78712.

21. ORNL Site Manager, U.S. Department of Energy, Oak Ridge National Laboratory, P.0. Box 2008, Oak Ridge, Tennessee 37831-6269.

22-23. Office of Scientific and Technical Information, U.S. Department of Energy, P.O. Box 62, Oak Ridge, Tennessee 37831. 